University of New England

DUNE: DigitalUNE

8-2016

\title{
Registered Dietitians: Attitudes And Perceptions Regarding Bachelor's Degree In Nutrition And Dietetics
}

Ashwini R. Wagle

University of New England

Follow this and additional works at: https://dune.une.edu/theses

Part of the Dietetics and Clinical Nutrition Commons, Educational Leadership Commons, and the Higher Education Commons

(C) 2016 Ashwini Wagle

\section{Preferred Citation}

Wagle, Ashwini R., "Registered Dietitians: Attitudes And Perceptions Regarding Bachelor's Degree In Nutrition And Dietetics" (2016). All Theses And Dissertations. 70.

https://dune.une.edu/theses/70

This Dissertation is brought to you for free and open access by the Theses and Dissertations at DUNE: DigitalUNE. It has been accepted for inclusion in All Theses And Dissertations by an authorized administrator of DUNE:

DigitalUNE. For more information, please contact bkenyon@une.edu. 


\title{
REGISTERED DIETITIANS: ATTITUDES AND PERCEPTIONS REGARDING BACHELOR'S DEGREE IN NUTRITION AND DIETETICS
}

\author{
By \\ Ashwini Wagle \\ BS (SNDT University, Mumbai, India) 1990 \\ MS (Indiana University of Pennsylvania) 1992
}

\section{A DISSERTATION}

Presented to the Affiliated Faculty of

The College of Graduate and Professional Studies at the University of New England

In Partial Fulfillment of Requirements

For the degree of Doctor of Education

Portland \& Biddeford, Maine

July, 2016 
Copyright by

Ashwini R. Wagle (C) 2016 
Ashwini Wagle

July 2016

Educational Leadership

REGISTERED DIETITIANS: ATTITUDES AND PERCEPTIONS REGARDING

BACHELOR'S DEGREE IN NUTRITION AND DIETETICS

\begin{abstract}
The profession of dietetics is transitioning to the master's degree (MS) as the entry-level requirement for registered dietitians' (RDs) to practice. The purpose of this quantitative study was to examine the attitudes and perceptions of registered dietitians with bachelor's degrees (BS, RD's) regarding a transition to the MS degree as the requirement for the RD certification. This study also examined these RD's attitudes and perceptions regarding impacting factors such as their years of work experience including salary levels and increments, professional stature including promotions and positions, and scope and type of practice. A cross-sectional survey was utilized to collect data and Statistical Package for Social Sciences (SPSS) Version 22.0 was used to conduct data analysis. The participant pool was comprised of $107 \mathrm{BS}$, RDs and included 99 (92.5\%) females and 8 (7.5\%) males. Fifty-six percent of participants $(\mathrm{n}=60)$ were predominantly between the ages of 30-39 years and $88.0 \%(n=94)$ reported working in California. Participants expressed greater support for a one-year transitional master's degree (tMS) rather than the MS degree, and findings indicated lack of support for the universal degree requirement of the MS degree for practice. Participants felt that the MS degree improved the RD's ability to apply research in clinical practice and improved clinical reasoning skills, however, the degree would not alter the role of the $\mathrm{RD}$, lead to a more defined type and scope of practice, improve the quality of health care for the patients, improve leadership skills or enhance
\end{abstract}


professionalism. RDs who were younger in age and had practiced for a few years were more inclined to be supportive of the transition and were willing to enroll in the MS degree. However, the support decreased with increase in age and years of practice. Participants who believed that the transition was a positive change were found to favor the MS degree and were willing to enroll in the tMS degree, and preferred the "online" mode of instruction. This study provides insight into some attitudes of BS, RDs toward both the educational changes that are taking place and those that may be implemented in the near future.

Keywords: Registered dietitian, Dietetics, Transitional master's program, Type of practice, and Scope of practice 


\title{
University of New England \\ Doctor of Education \\ Educational Leadership
}

This dissertation was presented

by

\begin{abstract}
Ashwini R. Wagle
It was presented on

July 18, 2016

and approved by:
\end{abstract}

Dr. Carol Holmquist, Lead Advisor

University of New England

Dr. Peter Fifield, Secondary Advisor
University of New England

Dr. Lucy McProud, Affiliate Member

San Jose State University 


\section{ACKNOWLEDGEMENTS}

I would like to express my special appreciation and thanks to my advisor Dr. Carol Holmquist, for being a tremendous support for me. I would like to thank you for encouraging my research and for allowing me to grow as a researcher. Your advice and positive feedback on this project have been priceless. I would also like to thank my committee member, Dr. Peter Fifield, for serving as my committee member and for your constant support and encouragement. I want to express my deep gratitude to Dr. Lucy McProud, for her constant support and encouragement as an advisor, mentor, and my committee member. I want to thank you all for letting my journey as a researcher be an enjoyable one, and for your positive comments and suggestions always.

A special thanks to all my family here and around the world. Words cannot express how grateful I am to my husband who has supported me in every endeavor of mine. His input, understanding, and compassion are my strength. I want to thank my parents who have always believed that I could do whatever I set my mind to and have given me wings to fly. A special thanks to my mother-in-law who is always happier at my success than I am, and lastly my fatherin-law who always said "there is no doubt you won't do it, you will get your doctorate". Although, my heart is filled with sadness that my father-in-law passed away before he saw me complete, I know he is filled with joy wherever he is. I would also like to thank my two sons who have are my pillars of strength. They have smiled and taken everything handed to them. My family's prayer for me was what has sustained me this far. I would also like to thank all of my friends in the United States and around the world for supporting me in writing, for feeding me and my family in times of stress, and encouraging me to strive towards my goal. 


\section{TABLE OF CONTENTS}

CHAPTER 1:

Statement of the Problem.

2

Purpose of Study...................................................... 3

Research Questions...................................................... 4

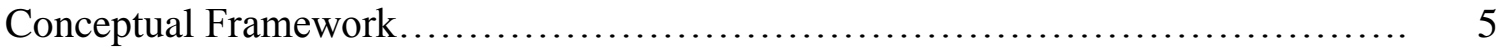

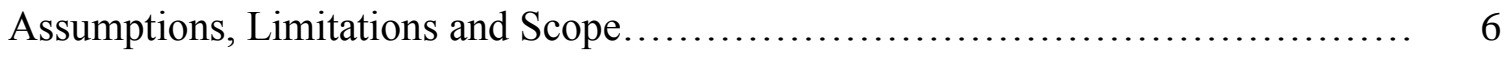

Rationale and Significance.............................................. 7

Definitions of Key Terms............................................. 9

Conclusion........................................................... 10

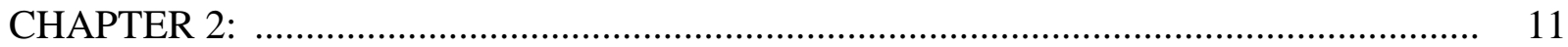

Method.................................................................. 13

Current Research on Transition to Graduate Degrees in Health Care Professions ........ 14

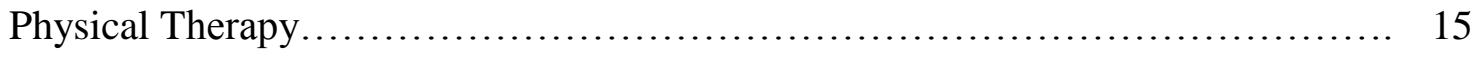

Occupational Therapy................................................ 20

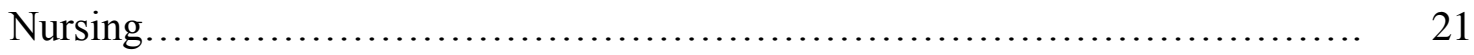

Current Research in Curriculum Planning.................................... 23

Outcomes-Based Learning Approach in Curricular Revisions................... 24

Student-Centered Learning Approach in Curricular Revisions.................. 26

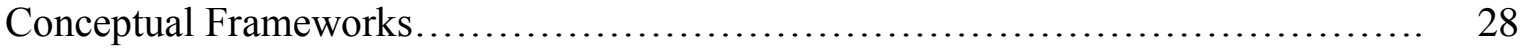

Professional Education................................................ 30

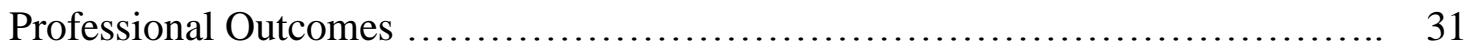

Conclusion............................................................ 34 


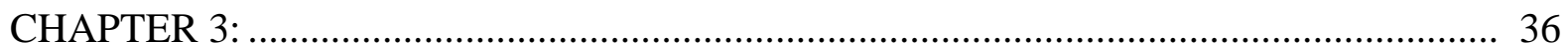

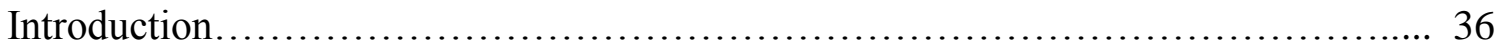

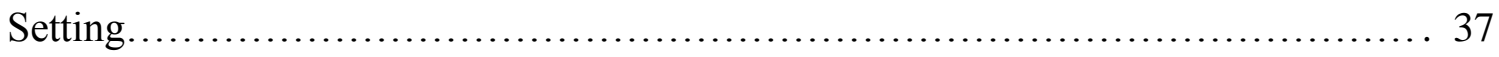

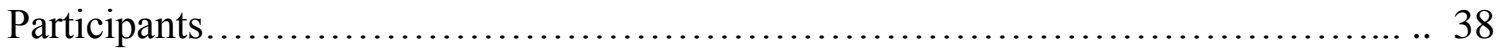

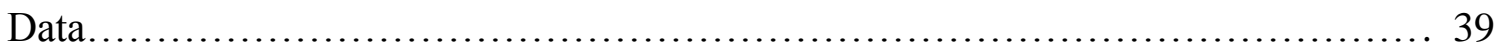

Data Analysis........................................................... 41

Participant Rights.................................................... 42

Potential Limitations.................................................... 42

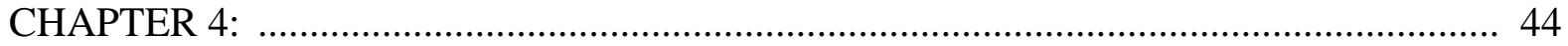

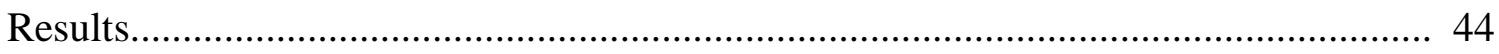

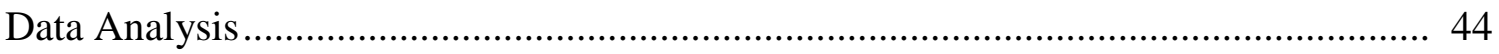

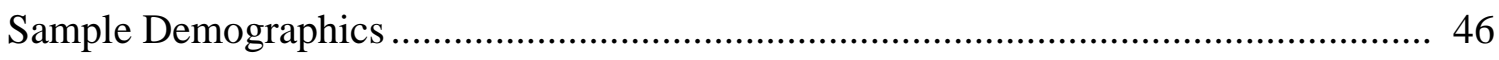

Support for Transition to the Master's Degree: Relationships and Association ........... 49

Attitudes toward Transition from Bachelor's to Master's Degree ............................. 52

Attitudes toward Transition from Bachelor's to Transitional Master's Degree ............ 53

Demographic Characteristics vs Attitudes Regarding the Transition to Master's ........ 55

Demographic Characteristics vs Attitudes Regarding the Transition to tMaster's ........ 58

Perceptions Regarding Importance and Ranking of Skill Sets ............................... 66

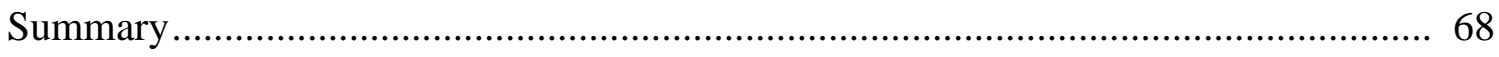

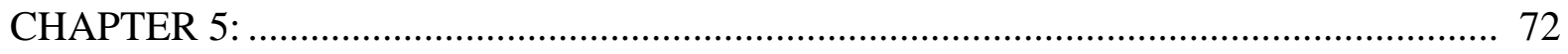

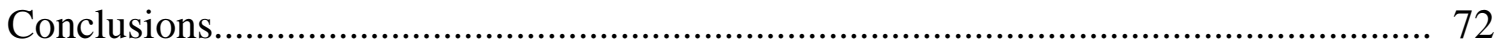

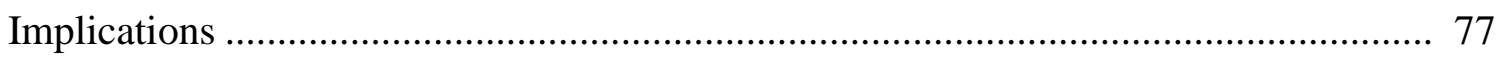

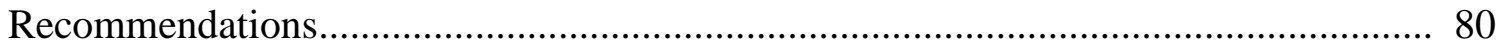


Summary.

REFERENCES 84

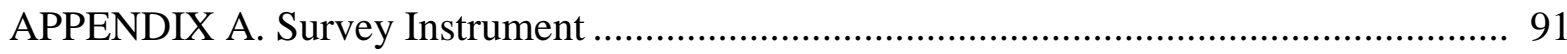

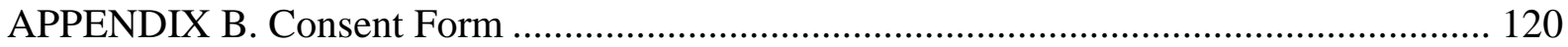

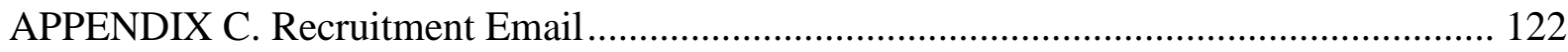

APPENDIX D. Letter of Participation-San Jose State University …................................... 123

APPENDIX E. Letter of Participation from California Academy of Nutrition and

Dietetics

APPENDIX F. Institutional Review Board- San Jose State University ............................... 126

APPENDIX G. Institutional Review Board- University of New England ............................ 127 


\section{LIST OF TABLES}

1. Participant demographic information

2. Associations and relationships regarding transition to the master's degree and support for the transitional master's degree

3. Correlations between years of practice and attitudes towards transition to the master's and transitional master's degrees

4. Correlations between attitudes towards the transition to the master's degree and the willingness to apply for the transitional master's degree

5. Correlations between attitudes towards universal degree requirement of the master's degree and the transition to the master's degree

6. Correlations between employers and support for the transition to the master's degree

7. Years of practice as a registered dietitian and support for implementation of the transitional master's degree.

8. Comparison between percentage of time working in clinical setting and support for the transitional master's degree

9. Perceptions regarding importance and ranking of skill sets based on bachelor's and master's degree 


\section{LIST OF FIGURES}

1. Conceptual framework representing the major factors affecting professional education

2. Age groups comparison and attitudes towards transition to the master's degree as a positive change

3. Comparison of years of practice and support for the transition to the master's degree as a positive change

4. Age group comparison to willingness to apply for the transitional master's degree

5. Age groups and support for a universal degree requirement of the master's degree

6. Comparison of age groups and support for implementation of the transitional master's degree

7. Years of practice and willingness to enroll in the one-year transitional master's degree

8. Years of practice and support for universal degree requirement for the master's degree

9. Years of practice and support for the implementation of the one-year transitional master's degree 


\section{CHAPTER ONE}

\section{INTRODUCTION}

In the last couple of decades, the change in the health care system in the country and the advances in knowledge and research in all health care fields has led to a revolution in health care professions to increase their academic requirements and standards. Most allied health care professions have shifted their focus to practice-oriented and clinical specialization (Clement, 2005). In 1989, the American Physical Therapy Association (APTA) Taskforce recommended that the Doctorate in Physical Therapy (DPT) be considered as an entry-level degree for physical therapists and this recommendation was endorsed by the APTA House of Delegates in 2000 as part of the Vision Statement for Physical Therapy 2020 (APTA, 2000). The APTA decision was soon followed by the American Occupational Therapy Association (AOTA) in 1998 endorsing the minimum entry-level degree in Occupational Therapy (OT) to be post-baccalaureate with all OT programs changing to master's (MOT) or doctorate (OTD) by 2007 (Griffiths \& Padilla, 2006). Degree evolution has become a common practice with the changing health care system and professions such as physical therapy, pharmacy, chiropractic, optometry, osteopathy, audiology, and advance practice nursing have transitioned to a clinical doctorate as the entrylevel education for practice (Phelps \& Gerbasi, 2009).

Following a path taken by several health care related professions, the Academy of Nutrition and Dietetics (AND) and its governing bodies, the Accreditation Council for Education in Nutrition and Dietetics (ACEND), as well as the Commission on Dietetics Registration (CDR) have declared that the dietetic internship (DI) and the eligibility for applying for the Registered Dietitian (RD) exam will be restricted to graduate students only (CDR, 2015). The arbitrary decision states that all students entering the nutrition and dietetics field will require a minimum 
of a master's degree by 2024 and all accredited Didactic Programs in Dietetics (DPD programs) will be required to have the curricular reforms in place for all freshmen entering Fall semester of 2017 (ACEND, 2015).

The researcher currently serves as the Director for the Didactic Program in Dietetics at San Jose State University (SJSU) and is responsible for maintaining all accreditation requirements for the DPD program. With the decision handed down by CDR and the Future Education Model proposed by ACEND, the current undergraduate dietetics program at SJSU will be revised so that students graduating with the bachelor's degree will be eligible for the new proposed Nutrition and Dietetics Technician Registered (NDTR) credential. Additionally, a new DPD curriculum for the graduate program will be developed so that students graduating with the master's degree will be eligible for the DI and the RD certification upon passage of the Registration exam (CDR, 2015).

The transition to master's degree as the entry -level degree for the profession will result in curricular reforms and program reorganization in educational institutions, but will also bring about changes in the professional scope of practice and organizational structure in the work environment for RDs practicing with bachelor's and master's degrees. It will be important to understand the effect of the transition on the future of practicing RDs with bachelor's degrees as the governing bodies of ACEND and CDR have not yet mentioned whether the transitional master's degree will be required for this population to bring them in compliance with the new mandate and make them educationally equivalent to the new graduate degree holders.

\section{Statement of the Problem}

As seen in other allied health care professions, the transition to the entry-level master's degree profession will possibly impact the professional stature of the RDs with bachelor's 
degrees, their promotions and hierarchal movement in their organizations, scope of practice, employer status related to hiring and retention, salary increments, and may also add the expectation of acquiring a transitional master's degree for RDs. The data received from this study will help understand the direct impact of the transition on the professional and personal values of the practicing RD's with bachelor's degrees and their work environment.

As the entire dietetics education system at San Jose State University (SJSU) is reorganized, the program changes will affect the students it serves, and challenges and obstacles will be faced by all of the stakeholders such as the faculty, the students, the preceptors, and the employers during the transformation process. Hence, it will be important to look at the "larger systems of society" and examine the repercussions of the changes that will occur such as the attitudes and perceptions of registered dietitians with undergraduate degrees working in the field as the newer credentialed RDs with graduate degrees enter the market.

The decision determined by the Accreditation Council for Education in Nutrition and Dietetics (ACEND) and the Commission on Dietetics Registration (CDR) does not specify that the master's degree needs to be in nutrition or dietetics and states that the degree could be in any area as long as the required dietetics curriculum is completed by the graduate student. There is lack of literature to examine the research gap related to the implications of the impending change of acquiring the master's degree as the entry-level degree for the registered dietitian (RD) credential.

\section{Purpose of Study}

The current trend of movement towards higher degree requirements for entry into the health care professions has been debated among the educational and professional community. It has evoked a myriad of sentiments among educators and professionals, as some members have 
been excited, while others are skeptical. Proponents of the change believe that the higher degree requirements will acknowledge the current rigorous academic education and training that is already provided to the graduates, while opponents question whether the changes will address the issues and challenges that face the educational institutions and the health care system in the United States (Mathur, 2011). The ACEND decision is recent and nationwide, and all dietetics programs across the country will be implementing the curricular changes by Fall semester of 2017 (CDR, 2015).

The purpose of this quantitative study was to examine the attitudes and perceptions of a self-selected sample of registered dietitians with bachelor's degrees regarding a transition to an entry-level master's degree as the requirement for certification as a Registered Dietitian (RD). This study also examined these RD's attitudes and perceptions regarding impacting factors such as their years of work experience including salary levels and increments, professional stature including promotions and positions, and scope and type of practice.

\section{Research Questions}

The research questions identified for the purpose of the study examined the attitudes and perceptions of registered dietitians with bachelor's degrees in nutrition and dietetics. The main questions identified were:

- $\quad$ Do the RDs with bachelor's degrees indicate that they would be willing to complete a one year transitional master's degree and would they prefer the method of instruction of the curriculum be online, face-to-face, or mixed-mode classes?

- How do RDs with bachelor's degrees perceive that the transition to the master's degree will affect the RD's scope of practice and type of practice? 
- How do RDs with bachelor's degrees perceive that the transition to the master's degree will impact the RDs regarding factors such as hiring and retention, years of work experience and salary levels and increments, and professional stature such as promotions and positions?

\section{Conceptual Framework}

Stark et al. (1986) developed a conceptual framework based on the grounded theory study of eleven professions to understand the similarities and differences between the professional programs. The study states that professional programs vary in "educational goals, expected outcomes, teaching methods, student time commitment, relations with practitioners, and even educational level (baccalaureate or post-baccalaureate) and it is a challenge to understand them" (Stark et al. 1986, p. 231). The framework focused on two areas: professional education and professional outcomes. The professional preparation environment included the education received in the programs and the various influences within the preparation environment which affected the professional outcomes expected. Professional programs have often been criticized for not preparing students optimally for practice. It has also been seen that programs have their own needs and requirements and tend to work with silo mentality, unaware of common objectives and challenges that may exist in other programs. Stark et al. (1986) proposed the conceptual framework to facilitate an understanding between professional preparation programs regarding their similarities and challenges and to assist educators, researchers, and administrators in assessing professional outcomes and collaboration.

Threlkeld et al. (1999) examined the considerations of the Doctorate in Physical therapy (DPT) program and proposed the conceptual framework based on the work of Stark et al. (1986). They focused on the application of two core dimensions of the framework: (1) professional 
education and (2) professional outcomes, which resulted from the professional education and asserted that professional education was influenced by external forces, intra-organizational forces, and internal forces. The external forces included societal need and other factors such as professional community, licensing agencies etc., intra-organizational forces focused on institutional forces, and internal forces including issues specific to the program and its mission. These three factors or forces shaped the professional education of physical therapists for professional practice. Furthermore, the efficacy of professional education is demonstrated by the performance of graduates, as measured by professional outcomes. In this model, professional outcomes were divided into the categories of professional competence and professional attitudes and the achievements of the graduates were expected to define and redefine the external, intraorganizational, and internal forces.

The Threlkeld et al. (1999) model was highly applicable to the study with the RDs and their perception and attitudes towards the change in educational requirements of the profession of dietetics. The concept of using the two core dimensions of professional education and professional outcomes was easily adapted to the study with the RDs as the challenges of the external forces, intra-organizational forces, and internal forces were similar to the DPTs. It was interesting to understand the professional outcomes of the RDs with the multiple degrees based on professional competence, and professional attitudes of the RDs.

\section{Assumptions, Limitations and Scope}

The current trend of transitioning towards higher degree requirements for entry into the health care professions has been debated by educators and professionals. The reasons for this transition are common among all health care professions and are influenced by the need to function as an autonomous practice, expand the depth and breadth of knowledge to meet the 
demands of the population, improve application of research to practice and enhance clinical reasoning and skills (Griffiths \& Padilla, 2006). Although most allied health care fields have moved to higher degree requirements for entry level professions in the last decade, there is a lack of research on the impact of the changes implemented.

The accreditation decision to transition to master's level entry is recent for the dietetics profession and is based on similar assumptions as other allied health care professions and follows their path of increasing academic requirements for entry level professionals. As the Director of the Didactic Program in Dietetics at San Jose State University, the primary researcher will be responsible for all curricular reforms taking place at the undergraduate and graduate level in the dietetics program.

There is a lack of literature available to study the impact of the transition on the bachelor's RDs and curricular reforms in dietetics programs at the undergraduate or graduate level and hence most information used will need to be derived from other allied health care programs. The researcher has attempted to describe other health care professional programs to study the research gap and summarized the findings in the literature review. In addition, studies lack an exploration of employer attitudes and perceptions towards the hiring of registered dietitians. As the dietetics program moves to a minimum of a master's level, a comparison of the professionals holding undergraduate and graduate degrees is needed.

\section{Rationale and Significance}

The Future Education Model proposed by the accreditation agency and the registration agency of the Academy of Nutrition and Dietetics to move the Registered Dietitian licensure and certification to minimum of a master's degree is mandatory with curricular reforms to take effect Fall 2017 and completed by January 1,2024. All dietetics students entering the dietetic 
internships in year 2024 will be required to complete a graduate level dietetics program (ACEND, 2015).

As the impending changes will be effective in the near future, most educational institutions offering the dietetics programs including San Jose State University find themselves implementing curricular reforms without much guidance from the responsible agencies as the mandate is nationwide. The review of literature was derived from other allied health care professions that have implemented the higher degree requirement for entry level professionals in the last decade.

Literature from studies conducted on curricular reforms in allied health care fields such as Physical therapy, Occupational Therapy, and Nursing have focused on the outcomes-based learning approach which is a student centered approach to learning and focuses on the student knowledge and the skills they gain during the course of the study or program. It focuses on what the students know and what they can do. The student-centered learning approach is a term used synonymously and in conjunction with outcomes-based learning and focuses on what the students are expected to know and do at the end of their learning experience. The teachercentered approach also known as the traditional approach focuses on the teacher's work and student achievement is important. It is dependent on the abilities, skills and efforts of the students and teachers are driven to meet student needs.

The research doctorate is the highest academic degree conferred such as the doctor of philosophy $(\mathrm{PhD})$. Students who earn the $\mathrm{PhD}$ degree are required to complete coursework, complete a comprehensive examination, and a dissertation. The expectation with a $\mathrm{PhD}$ is continued involvement in research, dissemination of information, and publication of the research. Some practice-oriented doctoral degrees such as the Doctorate in Nursing Science (DNS) have 
been considered similar in rigor to the $\mathrm{PhD}$ and may have the same expectations (Brudvig \& Colbeck, 2007). The clinical doctorate degree is a practice-oriented degree which is considered to be necessary for entry into a profession. Although there is a lesser amount of research involved with clinical doctorates, individuals are required to update themselves with continued education and training for specialization and maintenance of licensure (Clement, 2005). Practitioners with a clinical doctorate are expected to apply their foundational knowledge and skills to unique clinical scenarios and challenges (Plack \& Wong, 2002).

There is a lack of research available in the area of curricular reforms in the field of nutrition and dietetics, and also on the impact of moving to a higher degree requirement as the entry level for the profession. The lack of literature in nutrition and dietetics makes it imperative that the research gap be studied to understand the repercussions and implications of the changes on educational institutions and all of the stakeholders.

\section{Definitions of Key Terms}

Several terms have been used and defined for the purpose of understanding in the literature review:

Curriculum revision will be generally defined as changes to the curriculum based on course content (new and revised), course learning outcomes (CLO's) and student learning outcomes (SLO's).

Learning Outcomes can be defined as a flexible way to look at student learning as a more lifelong, non-traditional learning, which may include different forms of non-formal educational experiences also.

Course learning outcomes (CLO's) and student learning outcomes (SLO's) are defined as "the development or growth as a result of studying a particular course or program" (Ewell, 2008). 
Professionalism is the degree to which the members of a profession exhibit the unique attributes of a profession or engage in activities that characterize professionalization.

Transitional Master's Degree is a one-year program for registered dietitians with bachelor's degree focusing on research methodology and application of research to the clinical setting. An entry-to-practice master's degree (MS) focuses on the essential competencies required to enter clinical practice as a registered dietitian $(\mathrm{RD})$.

\section{Conclusion}

The study was necessary to understand the implications of increasing the entry-level degree requirement of the profession of dietetics and the Registered Dietitian (RD) certification to the master's degree. It was important to understand the impact of the changes on not just the educational institutions that undergo the monumental task of implementing curricular reforms, but also the stakeholders, especially the professionals. As the transition takes place, the work environment will consist of RDs practicing with bachelor's and master's degrees and it was important to know whether the RDs with bachelor degrees will feel the need to pursue the transitional master's degree to be on par with the new RDs with master's degrees and understand the attitudes and perception of the RDs regarding their educational levels, their clinical skills, employment status, job satisfaction, salaries, and public image. 


\section{CHAPTER TWO}

\section{REVIEW OF LITERATURE}

The purpose of this chapter is to examine and present a review of literature pertaining to the objectives of the study. Bloomberg and Volpe (2012) emphasize the importance of critically analyzing and synthesizing the information from the literature so that the critical elements of the research such as purpose, problem, research questions, participants, methodology, results, conclusions, implications, and future research can be identified. They developed five questions to help the researcher organize the literature and synthesize it: "1) What are the origins and definitions of the topic? 2) What are the key theories, concepts, and ideas? 3) What are the major debates, arguments, and issues surrounding the topic? 4) What are the key questions and problems that have been addressed to date? 5) Are there any important issues that have been insufficiently addressed or not addressed at all?” (p. 82).

The following review of literature answers the five questions and utilizes them to synthesize information regarding the proposed research questions:

- Do the RDs with bachelor's degrees indicate that they would be willing to complete a one year transitional master's degree and would they prefer the method of instruction of the curriculum be online, face-to-face, or mixed-mode classes?

- How do RDs with bachelor's degrees perceive that the transition to the master's degree will affect the RDs' scope of practice and type of practice?

- How do RDs with bachelor's degrees perceive that the transition to the master's degree will impact the RDs regarding factors such as hiring and retention, years of work experience and salary levels and increments, and professional stature such as promotions and positions? 
This review of literature examines the impact of the transition regarding higher degrees in health care fields based on factors such as years of work experience and salary levels and increments, professional stature such as promotions and positions, and scope and type of practice. As the accreditation mandate is recent and nationwide, all dietetics programs across the country will be implementing the curricular changes by Fall semester 2017 and little research identifying the research gap has been conducted yet. What are the potential repercussions of the impending change for the profession, for the customers, and the educational institutions? What are the primary factors that are driving the profession to move to an entry level master's degree? Will the transition to the entry level master's degree improve patient care? Will the employment patterns, work place issues, and salaries improve with the transition? Much of the information used to study the research gap was derived from other allied health care fields such as physical therapy (PT), occupational therapy (OT), and nursing.

There are several studies published on the topic of student-centered learning approaches in curriculum development and revisions in all levels of education, however articles discussing curriculum revisions in the field of nutrition and dietetics are almost non-existent and over a decade old, and focus on shorter programs or courses. This literature review investigates: 1) introduction to allied health care programs, 2) the objectives of the literature review and the research question, 3) the definitions of an outcomes-based learning approach and studentcentered learning approach in higher learning institutions, clinical doctorate, and research doctorate, 4) the current research on outcomes- based and student-centered learning approach in curriculum revisions at higher learning institutions, 5) the impact of the transition of allied health care fields to graduate level entry professions, and 6) the need for more research focusing on curriculum revisions in the area of nutrition and dietetics, as the accreditation mandate is 
implemented nationwide. This literature review also looks at the research question, different theoretical/conceptual frameworks used in the health care professions, and implications for future research in nutrition/dietetics.

The research question identified for the purpose of the literature review examines the attitudes and perceptions of professionals with undergraduate degrees as compared to postbaccalaureate degrees in allied health care professions due to the lack of literature in the field of nutrition and dietetics. The purpose of this quantitative study was to examine the attitudes and perceptions of a self-selected sample of registered dietitians with a bachelor's degree regarding a transition to an entry-level master's degree as the requirement for certification as a Registered Dietitian (RD). This study also examined these RDs' attitudes and perceptions regarding impacting factors such as their years of work experience including salary levels and increments, professional stature including promotions and positions, and scope and type of practice.

This literature review focused on the needs of all stakeholders such as the students, faculty, preceptors, employers, and the community in the process of curriculum revisions to the undergraduate and graduate level program so that students meet the requirements for the Nutrition and Dietetics Technician Registered (NDTR) credential at the bachelor's level and the dietetic internship and RD certification at the master's level.

\section{Method}

Data were collected from online databases such as Academic Search Premier and Education Research Complete and included scholarly peer-reviewed articles, and books. Educational websites were also used and a search of key words and terms was conducted. Other sources used for the literature review were Google Scholar, web searches, selecting articles from 
reference sections of relevant articles and serendipitous review of relevant journals from the "suggestions" box on online databases.

Articles were chosen based on relevance to the research question and studies focusing on the impact of transition to the entry level professional doctoral level for the field of physical therapy (PT), master's level for occupational therapy (OT), and nursing were included to broaden the scope of search and methodology. Relevant literature that was applicable to the topic was kept and articles that were too broad were discarded.

Other criteria chosen were curricular revisions in higher learning institutions, focus on outcomes-based learning approach, student-centered learning rather than teacher-centered learning. Recent literature comprised of scholarly, peer reviewed articles in the area of outcomes-based learning, and student-centered learning published within the last 10 years was researched. However, studies done on curriculum revisions in the area of dietetics and other allied fields, such as physical therapy, that have already moved to a minimum of a graduate degree were included and ranged back to the last 15 years due to lack of literature in the area.

\section{Current Research on Transition to Graduate Degrees in Health Care Professions}

In the last twenty years, there has been an explosion in knowledge in health care in the United States, which has led to a conscientious shift in health care professions to expand their academic standards. Degree evolution has become a common practice with the changing health care system and professions such as physical therapy, pharmacy, chiropractic, optometry, osteopathy, audiology, and advance practice nursing have transitioned to a clinical doctorate as the entry-level education for practice (Phelps \& Gerbasi, 2009). Occupational therapy now requires a professional master's degree as the entry-level qualification and the field of dietetics recently following suit with the mandate to move the registered dietitian credential to the 
master's level entry for the profession. The reasons for this transition are common among all health care professions and are influenced by the need to function as an autonomous practice, expand the depth and breadth of knowledge to meet the demands of the population, improve application of research to practice and enhance clinical reasoning and skills (Griffiths \& Padilla, 2006).

The current trend of movement towards higher degree requirements for entry into the health care professions has been debated among the educational and professional community. It has evoked a myriad of sentiments among educators and professionals, as some members have been excited, while others are skeptical. As the accreditation mandate to transition to master's level entry is recent for the dietetics profession, there is a lack of literature available to study the impact of the transition. The review of literature provides a discussion of the shift in academic standards for the health care professions of physical therapy, occupational therapy and nursing and the impact of the transition to graduate level entry professions within their academic and the professional community. It also discusses the political, social, and economic factors that have influenced the transition of the professions. As the new entry level educational standards are adopted by the professions, the different viewpoints surrounding the debate have also been included.

\section{Physical Therapy}

In year 2000, the American Physical Therapy Association's (APTA's) House of Delegates adopted a vision statement for the profession of physical therapy. The vision statement indicated that by 2020 , physical therapy would be provided by physical therapists with a clinical doctorate degree as the entry-level degree to practice in the profession (APTA, 2000). In 2001, APTA released the Strategic Plan for Transitioning to the proposed education model and many 
programs offered a transitional Doctor of Physical Therapy (t-DPT) degree for practicing therapists with the Masters in Physical Therapy (MPT) degree (King, Freburger, \& Slifkin, 2010). The strategic plan "identified 6 elements that are necessary to transition the physical therapy profession to a doctoral profession: the Doctor of Physical Therapy (DPT) degree, evidence-based practice, autonomous practice, direct access, practitioner of choice, and professionalism" (Johanson, 2005, p.67). By 2010, the transition was nearly complete with 95\% of accredited physical therapist education programs offering an entry-level DPT degree (APTA, 2010).

The clinical doctorate in physical therapy and other allied health care professions has prompted debate on its impact, especially on the availability and quality of health care. The degree's proponents claim it is necessary because of the growing complexity of health care and that the quality and efficiency of care will improve with additional education and training (Touger-Decker, 2005; Montoya \& Kimball, 2007; Leibach, 2008). Woods (2001) explains that increased curricular rigor, improved training and research contributions through the DPT programs would prepare the therapists for autonomous practice and bring public recognition for the profession as well as build image. The transition to the DPT programs has been deeply influenced by the educational community in physical therapy as they try to meet the demands of the changing health care and practice. The new graduates are required to be equipped in clinical practice skills where they can identify, examine, evaluate, diagnose and then provide treatment and at the same time need skills in client and patient management. The DPT program was expected to provide all of the tools to the graduates to function as entry-level practitioners and be accepted as competent professionals. 
Opponents argue that the added costs to students are unnecessary and will discourage individuals from entering these professions (Brown et al., 2015). There is also a concern that additional degree requirements may affect the diversity of practitioners in the profession. This may ultimately lead to decreases in practitioner supply in fields already facing shortages (Beck \& Doig, 2002; Graham et al., 2008). Plack and Wong (2002) examined the controversial nature of the DPT program and noted that due to the recent transition to a post-baccalaureate entry-level degree, there were several physical therapists practicing with bachelor's and master's degrees along with the doctorate degree. The availability of the transitional DPT (tDPT) programs to the mix has led to degree confusion for the public and the profession. There was also a concern regarding the rigor of the curriculum as the programs transitioned to the clinical doctorate degree, and researchers questioned whether the change would result in degree inflation (Clement, 2005).

Proponents of the DPT program argued that as the physical therapy programs countrywide transitioned to the clinical doctorate, there would be consistency and the confusion would be eliminated, especially as the post-professional and tDPT programs were made available for all practitioners (Hasson, 2003). The APTA (2010) report states that by January, 2010 more than 11,000 physical therapists had received the tDPT degree. Similarly, supporters of the transition to the DPT programs also argue that the rigor of the DPT programs was much higher, and according to the APTA (2010) fact sheet, the number of units for the DPT programs throughout the country averaged more than the mandated number of 72 units.

Despite these concerns, there is little published research on how the DPT is affecting the physical therapy workforce or the provision of services (Ellis, 2007). Even less attention has been paid to the consequences of the transition for subpopulations that may be particularly 
affected, such as rural communities. Rural areas have long faced problems with recruitment and retention of health-care providers, including physical therapists (Fraher et al., 2007). However, King, Freburger, \& Slifkin (2010) in their study examined the early impact of the DPT program on the supply and quality of physical therapy in rural areas. They conducted semi-structured telephone interviews with three key groups: physical therapy program directors and educators, directors of physical therapy at acute-care hospitals in rural areas, and presidents of state physical therapy associations and concluded from the data collected that the DPT had no significant effect on rural health care. The results from the study indicated that there was no difference in quality of physical therapy in rural areas, however similar to other research there was a shortage of supply of physical therapists in rural communities, although the shortage could not be attributed to the transition to DPT.

The APTA has a history of supporting increased professionalization of physical therapists by advocating for all of the educational reforms and activities, hence there is some amount of literature available on the impact of transition to the DPT in the profession. Studies done prior to the implementation of the doctoral profession mandate reported that there were significant differences between students enrolled in MPT and DPT degree programs in factors deemed important during students' selection of a physical therapist education program. Students enrolled in DPT degree programs were more likely than MPT degree program enrollees to report that the degree conferred, availability of the DPT degree, and the curriculum were more important when they selected their program (Johanson, 2004).

A study conducted in Canada examined the attitudes of physical therapists towards the master's and clinical doctorate degrees as the Canadian Physiotherapy Association (CPA) endorsed the requirement of master's degrees for all physical therapists by 2010 (Mistry et al., 
2014). This study collected data from a cross-sectional survey completed by 1397 Canadian physical therapists and the results indicated that the transition from the bachelor's degree to the master's would help integrate research into clinical practice, however it would not impact health care, or improve reasoning, and clinical skills of the therapists. The same study results showed significant differences in the transition to the clinical doctorate with the perception that the doctorate would improve application of research into clinical practice, acceptance of the profession and its impact on health care, thus enhancing the quality of health care (Mistry et al., 2014).

Studies have assessed the perceptions of employers in expectations from professionals with MPT and DPT and if the differences in education level affected their hiring decisions (Bank et al., 1998; Hummer et al., 1994). Bank et al. (1998) surveyed over 350 employers and concluded from the findings that employers did prefer to hire MPTs over therapists with a bachelor's degree or DPT for several reasons. Employers believed that MPTs applied research to clinical practice more frequently and were better prepared in areas of patient education, supervisory and management roles, and professional development. The results also indicated that MPTs earned higher salaries than professionals with lesser degrees. Hummer et al. (1994) concluded that the perceptions of clinical capabilities were significantly different from MPTs as compared to DPTs. Their survey design study concluded that DPTs were expected to have enhanced clinical skills and practice, although the results of the study indicated that DPTs were less likely to continue education for advanced training for professional development. Detweiler et al. (1999) reported similar findings, indicating that DPTs earned higher salaries compared to MPTs and believed that the DPT was essential for career advancement. 
Threlkeld, Jensen, and Royeen (1999) examined the major considerations for the DPT and concluded that DPT was favored to meet societal needs, such as professional attitudes, competence, program influences, career enhancement, improved clinical skills and evidencebased practice for patient care and education. Several studies also reported that the cost of the education to students, length of the program, potential for decreased diversity amongst professionals, lack of faculty to teach, lack of resources, and lack of demand and need in the community were major deterrents for the transition to the professional doctoral degree (Hummer et al.,1994; Detweiler et al., 1999; Beck and Doig, 2002; Domholdt et al., 2006; Graham et al., 2008).

\section{Occupational Therapy}

The American Occupational Therapy Association (AOTA) in 1998 endorsed the minimum entry-level degree in Occupational Therapy (OT) to be post-baccalaureate with all OT programs changing to master's (MOT) or doctorate (OTD) by 2007 (AOTA, 2001). Although the clinical doctorate (OTD) is offered by several educational institutions in the country, the occupational therapy profession is currently a master's level (MOT) profession. The American Occupational Therapy Association (AOTA) is currently considering a recommendation that all occupational therapy programs in the country will transition to the clinical doctorate as an entrylevel profession by 2025, and the OTD would be a practice-oriented degree.

Griffiths and Padilla (2006) conducted a survey to identify the factors that would influence occupational therapy programs in the country to transition to the clinical doctorate degree. The survey results from 111 occupational therapy programs in the country indicated that the supporting factors for the OTD program were "(a) existence of a physical therapy doctorate program along with OTD, (b) enhanced preparation of graduates, and (c) improved student 
recruitment" (p. 545). Factors that impeded the decision to establish the OTD program were "(a) limited resources, (b) philosophical objections, and (c) lack of demand" (p. 546). The results also suggested that there was overall support for the clinical doctorate program as a postprofessional degree for improved clinical skills and practice, however national consensus for establishing the entry-level clinical doctorate program was lacking.

Brown, Crabtree, Mu \& Wells (2015) conducted a review of literature on the implications of transitioning to the OTD as an entry-level degree on all stakeholders such as students, educators, clients, the profession as a whole, and the service providers. The review sought to understand the compelling factors and the influences that would propel the field to a doctoral level profession. The authors evaluated several studies that focused on occupational therapists, occupational therapy program directors, educators, occupational therapy associations etc. to understand the complexities of the transition to OTD including international repercussions. The review identified supporting factors for the OTD to be career enhancement, improved salaries, acceptance of the profession, improved public image, improved clinical skills and practice, and improved ability to apply research to practice. Some of the factors identified that impeded the implementation of the OTD program were cost, lack of resources and additional time, degree inflation, shortage of professionals, the need for OTD when the MOT degree provided adequate education and clinical skills for practice (Brown et al., 2015).

\section{Nursing}

Historically, the American Association of Colleges of Nursing (AACN) has advocated for improved education, technology, innovation, and practice in the field of nursing. The topic of a clinical doctorate has been advocated by the group since 1978 and in 2002, the AACN Task Force on the Practice Doctorate in Nursing decided to reexamine the need for clinical doctorate 
in nursing (Lenz, 2005). The AACN finally adopted the Doctor of Nursing Practice (DNP) in preparation for advanced practice nursing in 2004, due to an increase in complexities of the health care system, and the need for leadership in nursing (AACN, 2006).

Lenz (2005) wrote a position paper summarizing the results of the two years of work completed by the AACN Taskforce and the report contained information on existing practiceoriented doctorate programs in nursing, their resources, including input from all stakeholders. The report identified the trend of other health care fields and the transition to entry-level clinical doctorates such as the PharmD in pharmacy, DPT in physical therapy, and AuD in audiology. Nursing was identified as one of the few remaining health care fields where the doctorate was not considered as the highest credential for practice.

The nursing profession also struggles with the same set of challenges as other health care fields regarding resources, shortage of faculty, increased demand for quality in practice, acuity of patients, complexities of the health care system, and research and educational institutions have tried to cope with the demand (Brown-Benedict, 2008). Many colleges have increased the number of credits, courses, and undergone curricular reforms to counter the societal needs. The nursing profession has seen an extreme shortage of doctoral faculty in nursing to teach nursing practice as the demand for evidence-based practice and research increases and seems to be moving to the inevitable point of the doctorate degree as the need for nurse practitioners increases. Berlin (2002) predicted that the problem of shortage of faculty was going to worsen as more faculty reached retirement age, and the result would be a lack of well-trained bedside nurses to provide care.

The body of literature available in the professions of physical therapy, occupational therapy, and nursing as discussed in this review indicates that an increase in the entry level 
educational requirements has become necessary for improving the knowledge base and skills of the professional. There is a push to apply research to evidence-based practice and to improve clinical skills as the professions strive for autonomous status. The research base provided by the new educational requirements meets the demands of the complex medical community, insurance agencies, and a highly sophisticated public. It is important that the professions gather ample outcome data to help form a clear plan to transition to higher educational standards. Assessment of societal and professional needs along with the needs of all stakeholders will be imperative in making informed decisions regarding the future path of the professions.

\section{Current Research in Curriculum Planning}

The changes in technology, student needs, type of students, and progression in academic standards by governing agencies require faculty and academic staff to continuously evaluate and revise the curricula. Academic programs have tackled the challenges using different approaches for curriculum revisions and their main focus has been to enhance student learning. Lattuca and Stark (2009) explain that usually individual faculty decide and control curriculum planning as they decide on the content that is being taught. Data from past literature has shown that assessment results, such as grades from previous courses and student course evaluations, are rarely used by faculty to improve courses (Ewell, 2008). Faculty members often lack formal training in curriculum development or teaching and few take advantage of professional development programs offered or consider the professional development opportunities as helpful to improve their teaching skills or pedagogical knowledge (Stark et al., 1990). Most faculty are overburdened in terms of teaching load and lack the experience to work on curriculum revisions, hence educational developers and strategic planners have often been used to assist the academic staff (Lattuca et al., 2006). 
This literature review examines a new wave in the philosophy of education and a paradigm shift in academic standards and discusses approaches that fit within the umbrella of student-centered learning, and outcomes-based learning.

\section{Outcomes-Based Learning Approach in Curricular Revisions}

In the last few decades, a paradigm shift in the philosophy of education and practice has occurred and student learning has become a focus of all public institutions with outcomes dependent on the graduates and their skills upon graduation. With the increasing pressure on educational institutions, many universities and colleges have shifted their curriculum and assessment standards to more outcome-based learning and have revised their goals and objectives. This shift has allowed for improvement in student learning, and assessing students' capabilities at the end of their learning experience. They have resulted in significant changes in the skills of the graduates, as multiple learning options to fit students' learning styles were offered and student success was evaluated through measured outcomes.

Ewell (2008) notes that the image of a high-quality education has shifted from the traditional view of what teachers provide in the classroom environment to a practical concern for what learners actually learn, achieve, and become. The whole premise of outcomes-based learning approaches is that students take ownership of their learning and because they pursue their own goals and learning, they create a sense of ownership amongst all which eventually enhances student learning outcomes.

The examination of the curriculum revision process is one that is highly researched, and often new education models are developed to create a sense of ownership amongst all stakeholders (Elizondo-Montemayor, Hernández-Escobar, Ayala-Aguirre, and Aguilar, 2008); Desbrow, Leveritt, Palmer, and Hughes, 2014). The Elizondo-Montemayor et al. (2008) study 
created a curriculum committee with seven subcommittees involving students, medical residents, teachers and directors in the planning process to build a sense of ownership and reduce the resistance to change. The committees worked together during three phases: (1) curriculum revision; (2) preparation of an integrated timetable and the course syllabi; (3) definition of outcomes. The analysis from the planning phase gave rise to what is known as the SPICES model of curriculum planning: (1) a student-centered approach; (2) problem-based learning as a teaching/learning strategy; (3) an integrated curriculum structure and teaching; (4) a community orientation; (5) elective study modules; (6) a systematic approach to curriculum planning (Elizondo-Montemayor et al., 2008, p. 84). The results indicated that the new curriculum developed used a student-centered, outcomes-based learning approach, was problem based, and community oriented.

Similar to the Elizondo-Montemayor et al. (2008) study, Desbrow, Leveritt, Palmer, and Hughes (2014) conducted a study aimed at examining the use of learning and teaching interventions for developing research and evaluation competencies, with the intention of providing students with an experience of conducting a structured significant research project. Semi-structured interviews were used to explore student motivations for doing the research project, the student's experience of the full-time semester long research project, and the actual and perceived outcomes of this experience. The findings showed that the students reflected on the high sense of achievement associated with the research project and the competitive advantage it had provided on seeking employment.

Both studies found that there was a sense of ownership and commitment to change from all participants as they were part of designing the strategies to bring about the change. The findings also indicated that an emphasis on professionalism and ethics was high amongst the 
participants in an outcomes-based learning approach due to the level of participation from the students.

\section{Student-Centered Learning Approach in Curricular Revisions}

Student-centered learning requires students to be responsible for their learning, set their own goals for learning, and determine resources and activities that will help them meet those goals. In this approach, the teachers actually take on the role of facilitators of learning and create an environment of learning for the student in a way that the student can enhance their learning and abilities through experience and participation in active learning.

The topic of curriculum revisions and the use of different approaches to achieve enhanced student learning has extensive literature. Lambert, Terenzini, and Lattuca (2007) examined the effects of program characteristics and faculty activities on students' experiences and improvement in student learning. The objective was to learn the impact on student learning and to develop students' analytical and group skills in the process. Findings indicated that program structures, characteristics, policies, and faculty values have significant effects on student learning by encouraging or discouraging certain kinds of student experiences, which, in turn, influence student learning. The results also found that the greater use of active learning and less use of traditional methodologies, participation in professional development activities, and collaborative work enhanced student experiences and improved student learning.

Horel, Ziegenfuss, and Perry (2013) in their study examine the revision of the atmospheric science program at University of Utah while attempting to maintain a balance between the financial constraints and student, faculty and departmental needs. Different strategies were used and included discussions and day long retreats for the faculty, undergraduate and graduate student representatives to brain storm the strengths and weaknesses of the program. 
Students were surveyed and focus groups were created amongst faculty, and students to discuss areas of change. Curriculum revision was approached to improve the quality of education and program goals were broadened to give students more freedom to pursue their area of interest.

Similar to the atmospheric science study mentioned above, Naughton and Friesner (2012) examined the assessment of program level outcomes and curricular outcomes for the doctor of pharmacy degree. New accreditation standards have created a need for more assessment and accountability. There is some debate about whether incremental progress examinations could produce useful information on curriculum effectiveness, as well as providing formative assessment feedback. Naughton and Friesner (2012) looked at "whether a correlation exists between third-year PharmD students' perceived pharmacy knowledge and actual pharmacy knowledge as assessed by the Pharmacy Curricular Outcomes Assessment (PCOA)” (p. 1). Their findings indicated that students rated their competencies higher than average and performed higher than average on the PCOA, but there was no correlation between what students thought they knew and what they actually knew.

Lieberman et al. (2010) looked at broad-based curricular reform in medical education and its impact on a diverse student population. Academic programs are known to change teaching strategies, implement problem-based learning, and small focus groups to improve student learning and outcomes, however literature discussing the success of these curricular reforms is limited. This study examined student performance in the United States Medical Licensing Examination (USMLE) and graduation rates before and after broad based curriculum reforms were implemented and concluded that the improvement in student performance and their success was directly related to the curricular reforms implemented. The Naughton and Friesner (2012) and Lieberman et al. (2010) studies are relevant to the topic of research, as the dietetics field uses 
the Registered Dietitian (RD) exam as a measure of program effectiveness and student learning. The accreditation standards require a minimum of an $80 \%$ pass rate for the RD exam as a learning outcome for dietetics programs (eatrightacend.org, 2015).

One central theme to all student-centered learning approach studies discussed previously was that the initial planning was decided by what needed to be learned by the student and the desired level of learning a student had to achieve through the experience. The approach is results-oriented and curriculum success is measured by their level of understanding and competence, and dependent on what the students actually know and are able to do. As the students set their own goals towards learning, participation in the learning process and activities is more meaningful and satisfying.

\section{Conceptual Frameworks}

The literature on outcomes-based and student-centered learning suggests that learning outcomes together with the theory of constructive alignment are found to be the essential components in the outcomes-based approach. The three main variables - outcomes, teaching and learning, and assessment need to be connected to achieve consistency and coherence in the design process, resulting in instruction and assessment that are developed to address the learning outcomes. The adoption of the learning outcomes approach has the potential to help support a more systematic approach to the design of programs and courses (Tam, 2014).

The factors found in most curriculum reform studies include an exploration of the curriculum changes, teaching strategies, administrative policies and procedures, and faculty culture and their effect on student learning experiences and learning outcomes. The conceptual frameworks for most studies were based on the student outcome model presented by Terenzini and Reason (2005), which included the sociological and social psychologically-based theories of 
college effects. These studies incorporated student pre-college characteristics, organizational environment, student experiences and student outcomes, and examined the connection between faculty culture, and student learning. These frameworks address a gap in the literature by describing the complex and interconnected range of variables and settings which influence student learning. Despite the different approaches to curriculum revisions, the body of literature does have some consistency in the process at the core.

Lattuca and Stark (2009) "developed a model that supports the idea of a two-phase filtering process at the initiation of curriculum design. The phases in this early filtering process were: (1) to explore staff considerations/beliefs; and (2) to explore student needs and the factors influencing their learning" (p. 421). In another article, Stark (2000) concludes that the "three most common steps for most models were: 1) the learning goals/aims/outcome; 2) the design of teaching and learning goals; and 3) the design of assessment methods" (p. 63). The body of literature suggests that students' collaborative experiences in the classroom contribute to the development of students' group skills. The change in teaching strategies and more of a participatory role for students have resulted in enhancement of student learning.

Stark et al. (1986) emphasize that programs vary immensely in how they prepare students and have been often criticized for not providing the students with the educational breadth to work as professionals. Professional programs vary in "educational goals, expected outcomes, teaching methods, student time commitment, relations with practitioners, and even educational level (baccalaureate or post-baccalaureate) and it is a challenge to understand them" (Stark et al. 1986, p. 231). They developed a conceptual framework based on the grounded theory study of eleven professions to understand the similarities and differences between the professional programs. The framework was expected to help educators and researchers understand student 
needs and the college outcomes, university administrators understand the systematic information about the various programs and make decisions. The conceptual framework would also allow venues for professionals and educators to collaborate with colleagues from other fields on curricular pathways.

The conceptual framework was divided into two core areas of professional education and professional outcomes. The professional preparation environment included the education received in the programs and the various influences within the preparation environment which affected the professional outcomes expected.

\section{Professional Education}

\section{External influences from the society and the professional community.}

External influences are those "factors from outside the immediate program which influence the professional preparation environment" (Stark et al.,1986, p. 253). They categorize two main external influences: society and the professional community which include criteria such as societal needs in determining the demand for registered dietitians' services as well as the social status of dietitians as a profession; Workforce issues given the limited pool of dietetics programs offering the master's degree; Salary issues; Public image of the profession of registered dietitians (RD) and of the master's degree; Governmental policies and funding patterns on education programs for registered dietitians; Professional licensing of the profession of registered dietitians and its impact on the educational format. Dietitians are granted access to practice licensure on a state-by state basis, and California does not allow RD licensure. The state licensure laws influence the scope of practice for RDs within a state. 


\section{Intra-organizational influences.}

Stark et al. (1986) describe intra-organizational influences as those "influence(s) of the university, school, college, department, or division on the specific program "(p. 253). The intraorganizational variables include the institutional mission, the inter-relational support between programs, the financial support, and the governance. The interaction of all of the influences can contribute to the professional culture and shape the values and behaviors of professionals.

\section{Internal influences.}

Stark et al. (1986) describe "four internal influences: mission and staffing, structure of the professional program, curricular tensions, and continuing professional education” (p. 241). These variables influence the differences in educational environments and how they prepare the professionals.

\section{Professional Outcomes}

Stark et al. (1986) proposed that professional outcomes were categorized in two areas: "professional competence and professional attitudes" (p. 244). Professional competence was considered to be the direct result of the educational preparedness of the students and the primary objective of the programs. The competence was expected to influence the attitudes of the professionals and create an identity for the professions, along with building professional ethics, and motivation for continued learning in the field.

Threlkeld et al. (1999) examined the considerations of the Doctorate in Physical Therapy (DPT) program and proposed the conceptual framework based on the work of Stark et al. (1986). They focused on the application of two core dimensions of the framework: (1) professional education and (2) professional outcomes, which resulted from the professional education and asserted that professional education was influenced by external forces, intra-organizational 
forces, and internal forces. The external forces included societal need and other factors such as professional community, licensing agencies etc., and intra-organizational forces focused on institutional forces, and internal forces that included issues specific to the program and its mission. These three factors forced the shape of the professional education of physical therapists for professional practice. Furthermore, the efficacy of professional education is demonstrated by the performance of graduates, as measured by professional outcomes. In this model, professional outcomes were divided into the categories of professional competence and professional attitudes and the achievements of the graduates were expected to define and redefine the external, intraorganizational, and internal forces.

The Threlkeld et al. (1999) model as seen in Figure.1 was applied to the study of registered dietitians and the profession of dietetics. The conceptual framework helped address many questions including:

- Does the master's degree in dietetics serve the greater good of society within the marketplace?

- Will the master's degree influence the current and anticipated number and type of employment prospects available to the registered dietitians?

- Will the pressures of the marketplace influence the applicant pool to master's programs in dietetics, the market niches that the master's program graduates will fill, or the salaries they earn?

- How is the master's degree viewed at national, state, and local levels?

- What are the cultural and socio-economic considerations in the media portrayal of the master's degree? 
- In the public eye, how does the master's degree relate to other allied health care fields that have moved to a graduate level entry profession?

- What is the relationship of the master's degree to federal, state, and local funding policies and regulations that influence the practice of registered dietitians?

- What federal, state, and local funding sources are available for dietetics education, and will those sources be influenced by the master's degree?

- Would the master's degree have an effect on the registered dietitian licensure or the scope of practice?

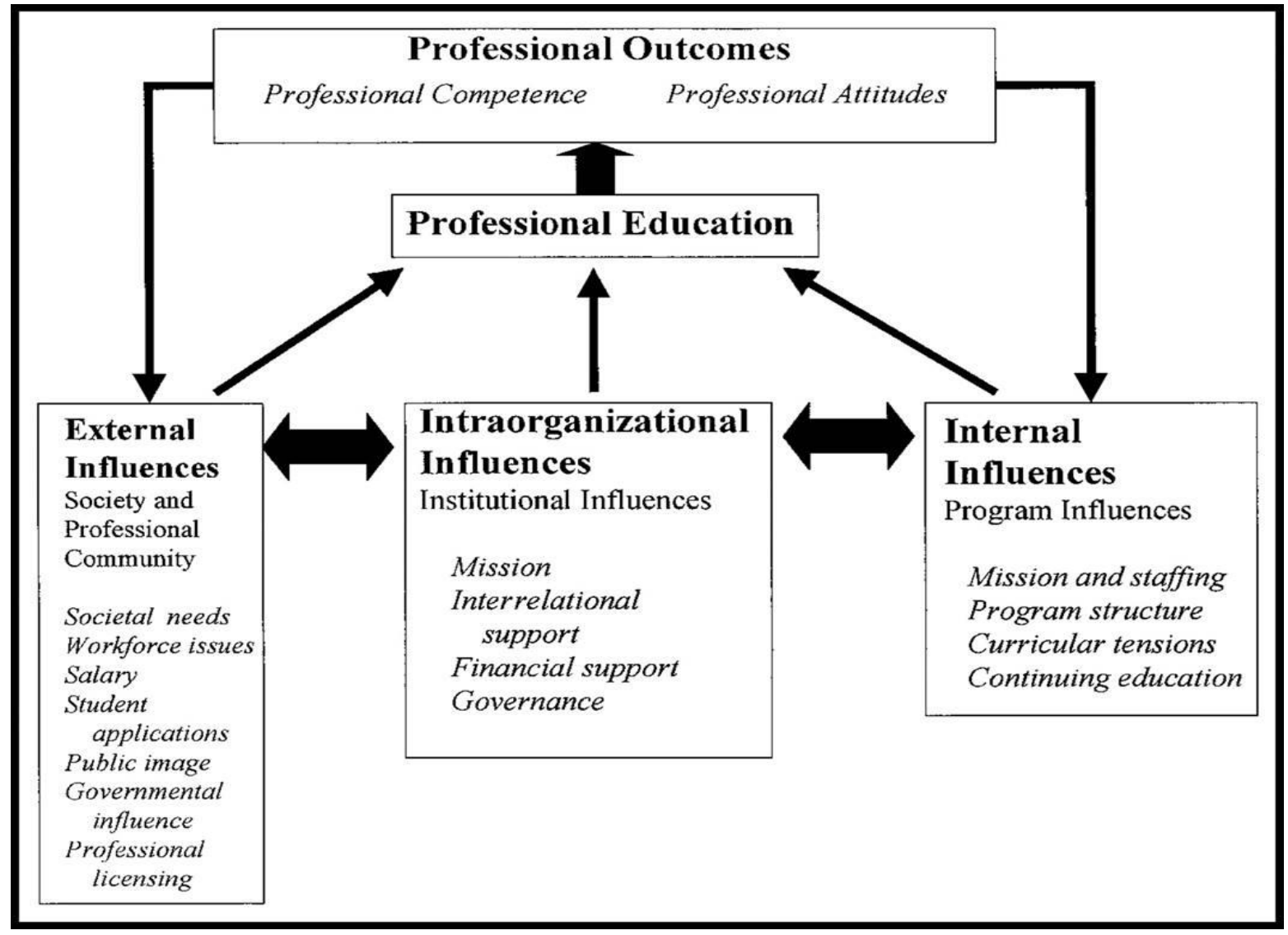

Figure 1. Conceptual framework representing the major factors affecting professional education Copyright. Threlkeld et al. (1999). Physical Therapy, 79, 567-581 


\section{Conclusion}

The health care professions are entering an exciting era of growth and development. Health care systems are undergoing change with the delivery of care, and patient demographics are changing with a diverse population and a rising number of elderly (Plack \& Wong, 2002). Most health care programs have transitioned to higher academic requirements for entry level professionals and the field of dietetics is moving to a master's level for the registered dietitian licensure/certification. Due to the lack of literature in the field of nutrition and dietetics, this review of literature has focused on data available from the professions of Physical Therapy, Occupational Therapy, and Nursing as they transitioned to graduate level entry requirements over five years ago. Whether the transition to graduate level entry requirements has been the topic of debate and discussion, it can be concluded that the time is right to investigate the educational needs of the professions to meet the demands of the society and professions.

Curriculum reform is definitely not a simple process and from the body of literature available, it can be concluded that there is no one framework or methodology to plan an ideal curriculum. However, it is an admirable attempt on the part of all educators, academic staff, students and the community to continuously evaluate and think about improvement in instruction and curriculum. Evaluation provides a direction and a dynamic for the faculty to modify the curriculum.

The focus on the outcomes of educational experiences has resulted in a shift away from the teacher-centered model that emphasizes what is presented, towards the learning-based model focusing on what students know and can actually do. Learning outcomes are defined according to the context in which they are used and at the individual student level helps students understand what is expected of them at the end of an educational experience. Learning outcomes have been 
beneficial at several levels in the academic setting from improvement in course or programs, to the institutional goals and accreditation requirements. At the courses or program level, learning outcomes are useful to guide curriculum, learning and assessment to aim at the achievement of those competencies or abilities by students enrolled in a particular course or program. Outcomes at the institutional level are often linked to institutional performance in terms of the efficiency and effectiveness towards achieving the institutional-level outcomes or goals.

Elizondo-Montemayor (2008) aptly summarizes the strengths of the outcomes-based learning model as follows: “(1) relevance; (2) acceptability; (3) clarity; (4) provision of a framework; (5) accountability; (6) self-directed learning; (7) flexibility; (8) guides for assessment; (9) participation in curriculum planning; (10) integration of learning experiences, teaching methods and assessment; and (11) it is a tool for curriculum evaluation" (p. 91).

Similar to the Elizondo-Montemayor (2008), Ewell (2008) also stated the benefits of the outcomes-based learning model to be "clarity, flexibility, comparison and portability" (p. 163). Curriculum development can be a long and tedious process, but if it is conducted in a proper manner, it can build collaborative and meaningful relationships between professional scholars. Faculty are hugely affected by curricular reforms and it is important that they take an active participatory role in the change process. The shift in focus from teacher-centered to studentcentered, outcome-based learning curriculum has provided several opportunities for all stakeholders. Curriculum revisions force faculty to rethink their course objectives and examine their teaching strategies to support the learning outcomes. An outcomes-based curriculum helps students to think of their academic program as a base to build knowledge and skills that will help them in their careers and future endeavors. 


\section{CHAPTER THREE}

\section{METHODOLOGY}

The main objective of this quantitative study was to examine the attitudes and perceptions of a self-selected sample of registered dietitians with a bachelor's degree regarding a transition to an entry-level master's degree as the requirement for certification as a Registered Dietitian (RD). The research questions developed for the study also examined these RDs' attitudes and perceptions regarding impacting factors such as their years of work experience including salary levels and salary increments, professional stature including promotions and positions, and scope and type of practice as a registered dietitian with the transition to the master's degree as an entry-level requirement for the profession.

A process for this analysis was posed based on a conceptual framework developed by Threlkeld et al. (1999). External influences from society and the profession, institutional and programmatic influences, and articulation of critical areas of professional competence and professional attitudes are discussed as major categories in relation to the master's degree in dietetics. By building upon the conceptual foundation, the researcher delineated categories of issues to be considered and present a series of questions that are believed to facilitate the process regarding implementation of a master's level dietetics program within a given site or setting. By providing the framework for consideration and evaluation of the dietetics programs, it is hoped to facilitate, focus, and advance the discussion and deliberative reflection concerning the transition to the master's degree.

A cross-sectional survey was administered to determine the attitudes and perceptions of registered dietitians with a bachelor's degree in dietetics regarding the transition to the master's degree and their willingness to pursue a transitional master's degree. An online questionnaire 
was created using Qualtrics and was sent to eligible participants with a link to the survey by email. A series of questions generated from the application of the Threlkeld et al. (1999) model was put forth for continued discussion and deliberation concerning the master's degree. Through the model, the researcher discusses dietetics education programs in a broad context in an effort to describe the choices, actions, educational policies, and practices that should be discussed among administration, faculty, students, the profession, and public agencies. The adoption of the Threlkeld et al. (1999) model provides a contextual framework within which participants brought their beliefs and values into a discussion that leads to action, a process described as "deliberative reflection". The deliberative reflective process required consideration of the trends and forces shaping professional practice and education through problem identification and problem solving. By building upon a conceptual foundation proposed by Threlkeld et al. (1999), the researcher delineated categories of issues to be considered and presented a series of questions that facilitate the deliberative process regarding implementation of the master's degree within a given educational setting.

\section{Setting}

Following a path taken by several health care related professions, the Academy of Nutrition and Dietetics (AND) and its governing bodies, the Accreditation Council for Education in Nutrition and Dietetics (ACEND), as well as the Commission on Dietetics Registration (CDR) have declared that the dietetic internship (DI) and the eligibility for applying for the RD exam will be available to graduate students only (cdrnet.org, 2015). A decision was passed down which states that all students entering the nutrition field will have a minimum of a master's degree by 2024 and therefore all dietetic programs in the country are required to have the curricular reforms in place for all freshmen starting Fall semester 2017 (eatrightacend.org, 2015). 
With the mandate handed down by CDR and the Future Education Model proposed, the current undergraduate level dietetics program at San Jose State University (SJSU) will be revised so that students graduating with bachelor's degrees will be eligible for the Nutrition and Dietetics Technician Registered (NDTR) credential. Additionally, a new curriculum for the graduate degree will be developed so that students graduating with the master's degree will be eligible for the DI and the RD certification (cdrnet.org, 2015).

As the Director of the Dietetics (DPD) program at San Jose State University, the researcher is responsible for maintaining accreditation requirements, implementing curricular reforms, and has access to past and present dietetics students along with professional organizations at the local, state, and national level. The researcher is required to advise students in their curricular goals and career goals, and the impending changes in the profession have created a lot of questions and caused anxiety in the minds of several students. Students are feeling the need to change their academic goals to include a master's degree to be a dietitian. The results from this study will answer questions to benefit the dietetics students, and registered dietitians with bachelor's degrees and master's degrees.

\section{Participants}

The participant pool was comprised of registered dietitians with bachelor's degrees and was accessed from the Nutrition and Food Science (NUFS) Alumni Group, the San Jose Peninsula District (SJPD) of the California Academy of Nutrition and Dietetics (CAND), CAND membership, and Academy of Nutrition and Dietetics (AND) membership. However, the pool was limited to members of the groups mentioned and may not be representative of the United States registered dietitian population. 
Information about the study was sent to the NUFS Alumni group; the members of the SJPD, CAND membership, and AND membership. The most accessible groups to survey were the NUFS Alumni group of 60 members with BS, RDs and the SJPD membership of approximately $80 \mathrm{BS}$, RDs. The survey was also distributed to CAND membership through the monthly newsletter. The RD members of all professional organizations mentioned were identified and an initial email invitation to complete the questionnaire was sent to only those registered dietitian members. Eligible participants were required to have the certified and/or licensed registered dietitian (RDs) status, have earned a bachelor's degree, and have internet access.

The study did not include dietetic students, certified dietetic technicians registered (DTRs), and DTR students as these individuals had not yet completed the educational requirements for the dietetics program and could not practice or work as registered dietitians.

\section{Data}

This quantitative study used a modified Dillman tailored study design which utilizes mixed mode surveys with the use of internet, telephone and mail (Dillman, 2009). After the study was approved by the Institutional Review Board at the University of New England, the questionnaire Qualtrics link was first emailed to the eligible NUFS Alumni group, SJPD, and distributed to CAND members via the monthly newsletter; the link was sent to members three more times at 2-week intervals starting May 2016. Qualtrics provides a protective privacy policy regarding e-mail addresses and personal information to the study participants. However, for this study, no results were collected or shared that linked individual participant identities (such as participant name or email address) to the content of the data they supplied. Participant data was saved under the internet protocol (IP) as they are assigned to computers and not the person. The 
initial email included a brief outline and explanation of the study, as well as the link to the questionnaire; subsequent emails were sent to thank those who had already completed the survey and to remind those who had not completed the survey and they were provided a link to the questionnaire. Completed questionnaires were accepted until June 2016.

The primary researcher developed the questionnaire based on similar research and consultation with committee members. The conceptual framework of Threlkeld et al. (1999) helped guide the development of subcategories and the questions within each subcategory. The questionnaire developed had four sections, sections B and C have been adapted from the Mistry et al. (2014) study and section D was adapted from the Rationale Document published by the Accreditation Council for Education in Nutrition and Dietetics (ACEND, 2015). Section A elicited demographic information; Section B examined attitudes toward the transition from a bachelor's to a master's degree in dietetics at the entry-level qualification; Section C examined attitudes toward the bachelor's and transitional master's degrees; Section D examined the perceptions of the bachelor's RDs regarding importance of skill sets for practice and scope of practice based on degree levels. Subcategories in each section explored the impact of these educational changes on the registered dietitian themselves, the health care system, and the dietetics profession. For sections B-C, participants rated their level of agreement with each item using a 5-point Likert-type scale (1 strongly disagree; 5 strongly agree). For section D, participants ranked the importance of skill sets using ranks 1-6 with 1 being most important skill set and 2 being second most important skill set and 6 being the least important skill set. The participants also rated their perception of skill sets based on degree level (BS and MS) using a 5point Likert-type scale (1 somewhat essential; 4 very essential; and 5 unable to answer). 
The questionnaire was pilot-tested with five registered dietitians to ensure that items were clear and readable, the content was appropriate, and to estimate the time required to complete the questionnaire. Minor wording modifications were made to the questionnaire based on feedback received from pilot-testing. The questionnaire provided a definition of the following terms: attitude: a representation of a person's manner, disposition, or feeling of like or dislike for something; transitional master's degree: a one-year program for registered dietitians with bachelor's degrees focusing on research methodology and application of research to the clinical setting.

\section{Data Analysis}

Descriptive statistics was used to describe the sample and to examine participants' attitudes regarding the transition from bachelor's to master's qualifications in dietetics. Responses were collapsed into one of three categories: favored $(\mathrm{F})$, neutral $(\mathrm{N})$, or did not favor (DNF) (i.e., all responses of 1 and 2 will be collapsed into the DNF category, and all responses of 4 and 5 will be collapsed into the F category); those who indicated a neutral attitude were not considered when describing trends in the data. Chi-square statistics was used to compare those in favor of a master's degree to those in favor of the one-year transitional master's degree, which were not mutually exclusive categories. Paired sample T-test was used to compare the attitudes of transition to the traditional master's degree and the one-year transitional master's degree. One-way ANOVAs and post-hoc Tukey analyses were used to examine the effect of: (1) age groups, 2) years of practice, (3) percentage of time working in a clinical setting and (4) employment status and the participants' attitudes toward the transition from bachelor's to master's degrees and their level of support for the master's degrees in dietetics. The effect of employer status on attitudes toward the master's degrees was studied using Pearson's correlation 
along with examining relationships between support for the transition to the master's degree and willingness to enroll in the master's degree. Spearman's correlation was used to assess relationships between perceptions regarding importance and ranking of skill sets based on bachelor's degree and master's degree.

\section{Participant Rights}

Participants were provided informed consent before completing and submitting the questionnaire. No personal identifiers were included in the submitted questionnaires. This study was considered to be minimal risk for participants and 'Minimal Risk' means the probability and magnitude of harm or discomfort anticipated in the research are not greater in and of themselves than those ordinarily encountered in daily living or during the performance of routine physical or psychological examinations or tests (UNE, 2016). The participant had the right to leave the study at any point of time if they so wished and were not coerced into completing the survey.

The Institutional Review Board (IRB) is a committee responsible for reviewing research proposals submitted by UNE students that involve the use of human subjects. IRB members make sure that the proposed research is in compliance with university policy and federal regulations established to ensure the safety of research participants and the ethical and responsible conduct of investigators. This study proposal was submitted to San Jose State University IRB and University of New England IRB upon approval of the dissertation committee members and was approved by both IRB before data collection was started.

\section{Potential Limitations}

The accreditation decision to transition to the master's degree at entry-level for the dietetics profession has been enforced arbitrarily and hence, there might be some amount of bias and resentment regarding the public agencies and their decisions in the registered dietitian 
population. Contrary to other allied health care professions where the member opinion was solicited and the transition voted upon, the accreditation agency and the registration agency for dietetics passed the decision as a mandate. Also, due to the accessibility of the groups most participants were comprised of BS, RDs from California. 


\section{CHAPTER FOUR}

\section{RESULTS}

The purpose of this quantitative study was to examine the attitudes and perceptions of a self-selected sample of registered dietitians with bachelor's degrees regarding a transition to an entry-level master's degree as the requirement for certification as a Registered Dietitian (RD). The research questions also examined these RD's attitudes and perceptions regarding impacting factors such as their years of work experience including salary levels and increments, professional stature including promotions and positions, and scope and type of practice.

\section{Data Analysis}

Study participants $(n=107)$ completed a cross-sectional questionnaire reflecting their attitudes and perceptions regarding the transition to the master's degree and their willingness to pursue a transitional master's degree. After the study was approved by the Institutional Review Board at the University of New England, the questionnaire Qualtrics link was first emailed to the eligible Nutrition and Food Science (NUFS) Alumni group, and distributed to the San Jose Peninsula District (SJPD) of the California Academy of Nutrition and Dietetics (CAND), CAND membership, and Academy of Nutrition and Dietetics (AND) membership via the monthly newsletter; the link was sent to members three more times at 2-week intervals starting May 2016. The initial email included a brief outline and explanation of the study, as well as the link to the questionnaire; subsequent emails were sent to thank those who had already completed the survey and remind those who had not completed it. Upon completion of data collection, the data from Qualtrics was exported in .spv format to Statistical Package for Social Sciences (SPSS) Version 22.0. Data file in SPSS was reviewed and saved. Incomplete surveys $(n=4)$ were discarded and a participant pool of 107 completed questionnaires was used for the study. 
Descriptive statistics was used to describe the sample and to examine participants' attitudes regarding the transition from bachelor's to master's qualifications in dietetics. Responses to the questions pertaining to the attitudes regarding the transition to the master's degree (questions 30-37) were collapsed into one of three categories: favored (F), neutral (N), or did not favor (DNF) (i.e., all responses of 1 and 2 were collapsed into the DNF category, and all responses of 4 and 5 were collapsed into the $\mathrm{F}$ category). Chi-square statistics was used to compare those in favor of a master's degree to those in favor of the one-year transitional master's degree, which were not mutually exclusive categories. Paired sample T-test was used to compare the attitudes of transition to the traditional master's degree and the one-year transitional master's degree.

One-way ANOVAs and post-hoc Tukey analyses were used to examine the effect of: (1) age groups, 2) years of practice, (3) percentage of time working in a clinical setting and (4) employment status on the participants' attitudes toward the transition from bachelor's to master's degrees and their level of support for the master's degrees in dietetics. The effect of employer status on attitudes toward the master's degrees was studied using Pearson's correlation along with examining relationships between support for the transition to the master's degree and willingness to enroll in the master's degree. Spearman's correlation was used to assess relationships between perceptions regarding importance and ranking of skill sets based on bachelor's degree and master's degree.

The research findings reported in this chapter are based on the development, collection, and statistical analysis of the data collected from the completed questionnaires. This chapter is divided into the following sections: 1) sample demographics; 2) support for transition to the master's degree: relationships and associations; 3) attitudes toward transition from bachelor's to 
master's degrees; 4) attitudes toward transition from bachelor's to transitional master's degrees; 5) demographic characteristics versus attitudes toward the transition from bachelor's to master's degrees; 6) demographic characteristics versus attitudes toward the transition from bachelor's to transitional master's degrees; and 7) perception regarding importance of rank of skill sets based on bachelor's degree and master's degree.

\section{Sample Demographics}

The participant pool completing the questionnaire was comprised of 107 registered dietitians with bachelor's degree (BS, RDs) and included 99 (92.5\%) females and 8 (7.5\%) males. Fifty-six percent of participants $(n=60)$ were predominantly between the ages of 30-39 years. Eighty percent of the participants $(n=86)$ had completed the Didactic Program in Dietetics (DPD) or its equivalent in California and $88.0 \%(n=94)$ reported working in California.

Participants' demographic characteristics are summarized in Table 1. Data collected indicated that $82 \%$ of the participant pool $(n=88)$ had practiced as registered dietitians' for $0-10$ years and $67.3 \%$ of the BS, RDs ( $n=72)$ were working full-time, $16.8 \%$ BS, RDs $(n=18)$ were working part-time, 9.4\% BS, RDs ( $\mathrm{n}=10)$ were working per-diem, and 6.5\% BS, RDs $(n=7))$ were either working on-call, as temporary registered dietitians, or in search of jobs. The majority (64.4\%) of the BS, RDs' ( $n=69)$ worked in the health care setting comprised of acute-care hospitals, subacute care facilities, or physician network and 49\% $(n=53)$ participants identified their role as working in a direct patient care setting as in-patient RDs' and 30.8\% $(n=33)$ identified their role as out-patient RDs. 
Table 1.

Participant demographic information

\begin{tabular}{|c|c|}
\hline Characteristics & $\mathrm{n}=107(\%)$ \\
\hline \multicolumn{2}{|l|}{ Gender } \\
\hline Females & $99(92.5)$ \\
\hline Males & $8(7.5)$ \\
\hline \multicolumn{2}{|l|}{ Age } \\
\hline $70-79$ years & $3(2.8)$ \\
\hline $60-69$ years & $3(2.8)$ \\
\hline $50-59$ years & 7 (6.6) \\
\hline $40-49$ years & $19(17.8)$ \\
\hline 30-39 years & $60(56.0)$ \\
\hline $20-29$ years & $15(14.0)$ \\
\hline \multicolumn{2}{|l|}{ State where Didactic Program in Dietetics (DPD) was completed: } \\
\hline California & $86(80.3)$ \\
\hline Pennsylvania & $6(5.6)$ \\
\hline Michigan & $3(2.8)$ \\
\hline Massachusetts & $2(1.9)$ \\
\hline Ohio & $2(1.9)$ \\
\hline Other States & $8(7.5)$ \\
\hline \multicolumn{2}{|l|}{ State currently working: } \\
\hline California & $94(88.0)$ \\
\hline Pennsylvania & $6(5.6)$ \\
\hline Michigan & $2(1.9)$ \\
\hline Hawaii & $1(0.9)$ \\
\hline Massachusetts & $1(0.9)$ \\
\hline New Mexico & $1(0.9)$ \\
\hline Virginia & $1(0.9)$ \\
\hline Washington & $1(0.9)$ \\
\hline \multicolumn{2}{|l|}{ Years practicing as a Registered Dietitian: } \\
\hline $0-5$ years & $74(69.2)$ \\
\hline $6-10$ years & $14(13.1)$ \\
\hline $11-15$ years & $6(5.6)$ \\
\hline $16-20$ years & $6(5.6)$ \\
\hline Greater than 20 years & $7 \quad(6.5)$ \\
\hline \multicolumn{2}{|l|}{ Time currently practicing in a clinical setting: } \\
\hline $1-25 \%$ & $8 \quad(7.5)$ \\
\hline $26-50 \%$ & $8 \quad(7.5)$ \\
\hline $51-75 \%$ & $4 \quad(3.8)$ \\
\hline $76-100 \%$ & $64(59.8)$ \\
\hline Non-clinical & $23(21.4)$ \\
\hline \multicolumn{2}{|l|}{ Primary place of employment: } \\
\hline Health care & $69(64.4)$ \\
\hline Behavioral care clinics & $4(3.8)$ \\
\hline Educational setting & $2(1.9)$ \\
\hline Community non-profit & $1(0.9)$ \\
\hline Government & $6(5.6)$ \\
\hline Wellness programs & $2(1.9)$ \\
\hline Corporate/industry settings & $3(2.8)$ \\
\hline Self-employed consultant RD or private practice & $8(7.5)$ \\
\hline Not currently working & $3(2.8)$ \\
\hline Other & $9(8.4)$ \\
\hline
\end{tabular}


Fifty percent $(n=54)$ of the participants worked in settings that were affiliated with academic institutions and dietetic internships, and 63.5\% $(\mathrm{n}=68) \mathrm{BS}$, RDs had supervised a minimum of 1-2 dietetic interns in the last two years. Approximately $88 \%$ (n=94) BS, RDs had participated in and completed continuing professional education units (CPEU's) in the last two years. Out of the 107 participants, $14 \%$ BS, RDs $(n=15)$ were employers of registered dietitians, of whom 8 indicated that they had hired BS, RDs, 6 indicated that they had hired MS, RDs and 1 participant indicated that they had hired a $\mathrm{PhD}, \mathrm{RD}$. Thirteen percent $(\mathrm{n}=14)$ of the participant pool indicated that their workplace required a graduate degree for job promotions for registered dietitians, and 52\% $(n=56)$ participants stated that their workplace required a graduate degree such as Master of Arts, Master of Science, Master of Business Administration, and or a Doctorate degree for management level registered dietitian positions. Twenty-six percent $(\mathrm{n}=28)$ of participants indicated that there was a salary cap or salary limit for BS, RDs at their workplace and approximately $63 \%(n=67)$ of participants indicated that there was a system in place for promotions and level increases for BS, RDs at their work setting.

Participants were asked whether they would be willing to apply for and enroll in a oneyear transitional master's degree in nutrition and dietetics and $64.5 \%(n=69)$ of participants indicated that they would be willing to enroll in the program. Approximately half of those participants $(\mathrm{n}=33)$ indicated they would prefer the "online" mode of instruction, another half $(n=34)$ indicated they would prefer a "mixed" mode of instruction including online and face-toface interaction, and only $3 \%(n=2)$ participants indicated that they preferred in-class face-toface interaction only. Only $35.5 \%(n=38)$ of the participant pool of $107 \mathrm{BS}$, RDs indicated that there should be a universal entry-level master's degree requirement for the profession of dietetics and to practice as a registered dietitian. 


\section{Support for Transition to the Master's Degree: Relationships and Associations}

Chi-square statistics was used to compare those in favor of a traditional master's degree to those in favor of the one-year transitional master's degree, which were not mutually exclusive categories. Results as seen in Table 2 indicated that overall, a significant association and relationship existed between participants who were willing to apply and enroll in the one yeartransitional master's degree $(\mathrm{p}<.003)$, between those who thought that a universal degree requirement of a master's degree was needed to practice as a registered dietitian $(\mathrm{p}<.003)$, between those believing that the transition to the master's degree was a positive change $(\mathrm{p}<.048)$, and those who supported the implementation of the one-year transitional master's degree $(\mathrm{p}<.000)$. Participants who believed that the transition to the master's degree was a positive change favored the one-year transitional master's degree. However, Paired sample T-tests indicated statistically significant differences were found in the participant beliefs between the transition to the traditional master's degree and the one-year transitional master's degree in the area of "enhanced professionalism" $(\mathrm{p}<.04)$ and "improved quality of care for the patients" $(\mathrm{p}<.02)$.

Table. 2

Associations and relationships regarding transition to the master's degree and support for the transitional master's degree

\begin{tabular}{|c|c|c|c|c|}
\hline & $\begin{array}{c}\text { If educational } \\
\text { institutions offer a } \\
\text { one year } \\
\text { transitional-master's } \\
\text { program in nutrition } \\
\text { and diete... } \\
\end{array}$ & $\begin{array}{c}\text { Do you think that } \\
\text { there should be a } \\
\text { universal entry-level } \\
\text { degree requirement } \\
\text { (Master's degree } \\
\text { req... }\end{array}$ & $\begin{array}{l}\text { Overall, the transition } \\
\text { from Bachelor's to } \\
\text { Master's is a positive } \\
\text { change for the } \\
\text { profession of di... }\end{array}$ & $\begin{array}{l}\text { Overall, you support the } \\
\text { implementation of a } \\
\text { transitional master's } \\
\text { degree post entry-to- } \\
\text { practi... }\end{array}$ \\
\hline Chi-Square & $8.981^{\mathrm{a}}$ & $8.981^{\mathrm{a}}$ & $9.589^{b}$ & $31.645^{b}$ \\
\hline & 1 & 1 & 4 & 4 \\
\hline Sig.(p value) & .003 & .003 & .048 & .000 \\
\hline
\end{tabular}

Significance level set at $\mathrm{p}<.05$ 
A Pearson's correlation was run to determine the relationship between years of practice as a registered dietitian and willingness to apply and enroll in a one-year transitional master's degree and a very strong, positive correlation was found between the two variables $(r=.234$, $\mathrm{n}=107, \mathrm{p}<.015)$ as seen in Table 3 . Data also indicated a very strong, positive correlation between BS, RDs' with 0-10 years of practice supporting the implementation of the one-year transitional master's degree $(\mathrm{r}=.218, \mathrm{n}=88, \mathrm{p}<.024)$.

Table 3.

Correlations between years of practice and attitudes towards transition to the master's and transitional master's degrees

\begin{tabular}{|c|c|c|c|c|c|c|}
\hline & & $\begin{array}{c}\text { How long } \\
\text { have you been } \\
\text { practicing as a } \\
\text { Registered } \\
\text { Dietitian? }\end{array}$ & $\begin{array}{l}\text { If educational } \\
\text { institutions } \\
\text { offer a one } \\
\text { year } \\
\text { transitional- } \\
\text { master's } \\
\text { program in } \\
\text { nutrition and } \\
\text { diete... }\end{array}$ & $\begin{array}{c}\text { Do you } \\
\text { think that } \\
\text { there should } \\
\text { be a } \\
\text { universal } \\
\text { entry-level } \\
\text { degree } \\
\text { requirement } \\
\text { (Master's } \\
\text { degree req... }\end{array}$ & $\begin{array}{l}\text { Overall, the } \\
\text { transition } \\
\text { from } \\
\text { Bachelor's } \\
\text { to Master's } \\
\text { is a positive } \\
\text { change for } \\
\text { the } \\
\text { profession } \\
\text { of di... }\end{array}$ & $\begin{array}{l}\text { Overall, you } \\
\text { support the } \\
\text { implementat } \\
\text { ion of a } \\
\text { transitional } \\
\text { master's } \\
\text { degree post } \\
\text { entry-to- } \\
\text { practi... }\end{array}$ \\
\hline \multirow{3}{*}{$\begin{array}{l}\text { How long have you } \\
\text { been practicing as a } \\
\text { Registered Dietitian? }\end{array}$} & $\begin{array}{l}\text { Pearson } \\
\text { Correlation }\end{array}$ & 1 & $.234^{*}$ & -.072 & -.007 & $.218^{*}$ \\
\hline & Sig. (2-tailed) & & .015 & .463 & .943 & .024 \\
\hline & $\mathrm{N}$ & 107 & 107 & 107 & 107 & 107 \\
\hline \multirow{3}{*}{$\begin{array}{l}\text { If educational } \\
\text { institutions offer a one } \\
\text { year transitional- } \\
\text { master's program in } \\
\text { nutrition and diete... }\end{array}$} & $\begin{array}{l}\text { Pearson } \\
\text { Correlation }\end{array}$ & $.234^{*}$ & 1 & .183 & .139 & $.229^{*}$ \\
\hline & Sig. (2-tailed) & .015 & & .059 & .154 & .018 \\
\hline & $\mathrm{N}$ & 107 & 107 & 107 & 107 & 107 \\
\hline \multirow{3}{*}{$\begin{array}{l}\text { Do you think that } \\
\text { there should be a } \\
\text { universal entry-level } \\
\text { degree requirement } \\
\text { (Master's degree req... }\end{array}$} & $\begin{array}{l}\text { Pearson } \\
\text { Correlation }\end{array}$ & -.072 & .183 & 1 & $.400^{* *}$ & $.317^{* *}$ \\
\hline & Sig. (2-tailed) & .463 & .059 & & .000 & .001 \\
\hline & $\mathrm{N}$ & 107 & 107 & 107 & 107 & 107 \\
\hline \multirow{3}{*}{$\begin{array}{l}\text { Overall, the transition } \\
\text { from Bachelor's to } \\
\text { Master's is a positive } \\
\text { change for the } \\
\text { profession of di... }\end{array}$} & $\begin{array}{l}\text { Pearson } \\
\text { Correlation }\end{array}$ & -.007 & .139 & $.400^{* *}$ & 1 & $.600^{* *}$ \\
\hline & Sig. (2-tailed) & .943 & .154 & .000 & & .000 \\
\hline & $\mathrm{N}$ & 107 & 107 & 107 & 111 & 111 \\
\hline \multirow{3}{*}{$\begin{array}{l}\text { Overall, you support } \\
\text { the implementation of } \\
\text { a transitional master's } \\
\text { degree post entry-to- } \\
\text { practi... }\end{array}$} & $\begin{array}{l}\text { Pearson } \\
\text { Correlation }\end{array}$ & $.218^{*}$ & $.229^{*}$ & $.317^{* *}$ & $.600^{* *}$ & 1 \\
\hline & Sig. (2-tailed) & .024 & .018 & .001 & .000 & \\
\hline & $\mathrm{N}$ & 107 & 107 & 107 & 111 & 111 \\
\hline
\end{tabular}

*. Correlation is significant at the 0.05 level (2-tailed) and **. Correlation is significant at the 0.01 level (2-tailed). 
Results as summarized in Table 4 also indicated strong, positive relationships between "considering the transition to master's degree as a positive change for the profession of dietetics" and "willingness to apply and enroll in a one-year transitional master's degree" $(\mathrm{r}=.293, \mathrm{n}=107$, $\mathrm{p}<.002$ ), and “overall support for the one-year transitional master's degree as the entry-level degree requirement" and "willingness to apply and enroll in a one-year transitional master's degree" $(\mathrm{r}=.401, \mathrm{n}=107, \mathrm{p}<.001)$.

\section{Table 4.}

Correlations between attitudes towards the transition to the master's degree and the willingness to apply for the transitional master's degree

\begin{tabular}{|c|c|c|c|c|}
\hline & & $\begin{array}{l}\text { If educational } \\
\text { institutions } \\
\text { offer a one year } \\
\text { transitional- } \\
\text { master's } \\
\text { program in } \\
\text { nutrition and } \\
\text { diete... }\end{array}$ & $\begin{array}{l}\text { Overall, the } \\
\text { transition from } \\
\text { Bachelor's to } \\
\text { Master's is a } \\
\text { positive change } \\
\text { for the } \\
\text { profession of } \\
\text { di... }\end{array}$ & $\begin{array}{l}\text { Overall, you } \\
\text { support the } \\
\text { implementation } \\
\text { of a transitional } \\
\text { master's degree } \\
\text { post entry-to- } \\
\text { practi... }\end{array}$ \\
\hline $\begin{array}{l}\text { If educational institutions } \\
\text { offer a one year } \\
\text { transitional-master's } \\
\text { program in nutrition and } \\
\text { diete... }\end{array}$ & $\begin{array}{l}\text { Pearson Correlation } \\
\text { Sig. (2-tailed) } \\
\mathrm{N}\end{array}$ & 107 & $\begin{array}{r}.293^{* *} \\
.002 \\
107\end{array}$ & $\begin{array}{r}.401^{* *} \\
.000 \\
107\end{array}$ \\
\hline $\begin{array}{l}\text { Overall, the transition from } \\
\text { Bachelor's to Master's is a } \\
\text { positive change for the } \\
\text { profession of di... }\end{array}$ & $\begin{array}{l}\text { Pearson Correlation } \\
\text { Sig. (2-tailed) } \\
\text { N }\end{array}$ & $\begin{array}{r}.293^{* *} \\
.002 \\
107\end{array}$ & 107 & $\begin{array}{r}.599^{* *} \\
.000 \\
107\end{array}$ \\
\hline $\begin{array}{l}\text { Overall, you support the } \\
\text { implementation of a } \\
\text { transitional master's degree } \\
\text { post entry-to-practi... }\end{array}$ & $\begin{array}{l}\text { Pearson Correlation } \\
\text { Sig. (2-tailed) } \\
\mathrm{N}\end{array}$ & $\begin{array}{r}.401^{* *} \\
.000 \\
107\end{array}$ & $\begin{array}{r}.599^{* *} \\
.000 \\
107\end{array}$ & 107 \\
\hline
\end{tabular}

**. Correlation is significant at the 0.01 level (2-tailed).

Similarly, a summary of findings of Pearson's correlation which indicated strong, positive relationships between “support for a universal degree requirement of master's level for registered dietitians" and "overall support for the one-year transitional master's degree as the entry-level degree requirement" $(\mathrm{r}=.383, \mathrm{n}=107, \mathrm{p}<.00)$, between "support for a universal degree requirement of master's level for registered dietitians" and "considering the transition to master's 
degree as a positive change for the profession of dietetics" $(\mathrm{r}=.539, \mathrm{n}=107, \mathrm{p}<.00)$, and between "considering the transition to master's degree as a positive change for the profession of dietetics" and "overall support for the one-year transitional master's degree as the entry-level degree requirement" $(\mathrm{r}=.599, \mathrm{n}=107, \mathrm{p}<.01)$ is provided in Table 5 .

Table 5.

Correlations between attitudes towards universal degree requirement of the master's degree and the transition to the master's degree

\begin{tabular}{|c|c|c|c|c|}
\hline & & $\begin{array}{l}\text { Do you think } \\
\text { that there } \\
\text { should be a } \\
\text { universal entry- } \\
\text { level degree } \\
\text { requirement } \\
\text { (Master's } \\
\text { degree req... }\end{array}$ & $\begin{array}{l}\text { Overall, the } \\
\text { transition from } \\
\text { Bachelor's to } \\
\text { Master's is a } \\
\text { positive change } \\
\text { for the } \\
\text { profession of } \\
\text { di... }\end{array}$ & $\begin{array}{l}\text { Overall, you } \\
\text { support the } \\
\text { implementation } \\
\text { of a transitional } \\
\text { master's degree } \\
\text { post entry-to- } \\
\text { practi... }\end{array}$ \\
\hline $\begin{array}{l}\text { Do you think that there } \\
\text { should be a universal entry- } \\
\text { level degree requirement } \\
\text { (Master's degree req... }\end{array}$ & $\begin{array}{l}\text { Pearson Correlation } \\
\text { Sig. (2-tailed) } \\
\text { N }\end{array}$ & 1 & $\begin{array}{r}.539^{* *} \\
.000 \\
107\end{array}$ & $\begin{array}{r}.383^{* *} \\
.000 \\
107\end{array}$ \\
\hline $\begin{array}{l}\text { Overall, the transition from } \\
\text { Bachelor's to Master's is a } \\
\text { positive change for the } \\
\text { profession of di... }\end{array}$ & $\begin{array}{l}\text { Pearson Correlation } \\
\text { Sig. (2-tailed) } \\
\text { N }\end{array}$ & $\begin{array}{r}.539^{* *} \\
.000 \\
107\end{array}$ & 107 & $\begin{array}{r}.599^{* *} \\
.000 \\
107\end{array}$ \\
\hline $\begin{array}{l}\text { Overall, you support the } \\
\text { implementation of a } \\
\text { transitional master's degree } \\
\text { post entry-to-practi... }\end{array}$ & $\begin{array}{l}\text { Pearson Correlation } \\
\text { Sig. (2-tailed) } \\
\mathrm{N}\end{array}$ & $\begin{array}{r}.383^{* *} \\
.000 \\
107\end{array}$ & $\begin{array}{r}.599^{* *} \\
.000 \\
107\end{array}$ & 107 \\
\hline
\end{tabular}

**. Correlation is significant at the 0.01 level (2-tailed).

\section{Attitudes toward Transition from Bachelor's to Master's Degree}

Overall, participants believed that the transition from bachelor's to master's degrees as entry-level for the profession of dietetics was a positive change with $48.5 \%(\mathrm{n}=52)$ favoring $(\mathrm{F})$ the transition, $23.5 \%(n=25)$ staying neutral with neither agreeing or disagreeing $(\mathrm{N}), 28 \%$ $(\mathrm{n}=30)$ disagreeing or not favoring $(\mathrm{DNF})$ the transition.

Participants believed that the transition from the bachelor's degree to the master's degree had a positive impact on clinical reasoning $(53 \% \mathrm{~F}, 26 \% \mathrm{~N}, 26 \% \mathrm{DNF})$, improved application and utilization of research to clinical practice $(67 \% \mathrm{~F}, 17 \% \mathrm{~N}, 16 \% \mathrm{DNF})$, and enhanced 
professional opportunities such as promotions, hiring salaries, and salary raises $(56 \% \mathrm{~F}, 22 \% \mathrm{~N}$, $22 \%$ DNF). The participants did believe that the transition to the master's degree led to greater recognition of the profession in the health care system $(52 \% \mathrm{~F}, 20 \% \mathrm{~N}, 28 \% \mathrm{DNF})$.

The transition to master's degree indicated no improvement in leadership skills (41\% F, $28 \% \mathrm{~N}, 31 \% \mathrm{DNF})$, and enhancement in professionalism $(38 \% \mathrm{~F}, 32 \% \mathrm{~N}, 30 \% \mathrm{DNF})$. The participant pool of registered dietitians with bachelor's degrees were divided in their attitudes and did not perceive that the transition to a master's degree affected the health care system leading to a more defined scope of practice $(33.5 \% \mathrm{~F}, 33 \% \mathrm{~N}, 33.5 \% \mathrm{DNF})$, or would improve quality of care for patients $(32 \% \mathrm{~F}, 36 \% \mathrm{~N}, 32 \% \mathrm{DNF})$. The results also indicated that the transition was believed to lead to increased costs to the health care system $(36 \% \mathrm{~F}, 50 \% \mathrm{~N}, 14 \%$ DNF) and would not alter the role of the registered dietitian, such as increase the consultant role or reduce the hands-on care etc. ( $26 \% \mathrm{~F}, 42 \% \mathrm{~N}, 32 \% \mathrm{DNF})$.

Participants agreed, however, that the transition to the master's degree would lead to greater earning potential for the registered dietitians $(46 \% \mathrm{~F}, 31 \% \mathrm{~N}, 23 \% \mathrm{DNF})$, create a hierarchy within the profession $(63 \% \mathrm{~F}, 22 \% \mathrm{~N}, 15 \% \mathrm{DNF})$, and have a positive impact on public perception of the dietetics profession $(53 \% \mathrm{~F}, 21 \% \mathrm{~N}, 26 \% \mathrm{DNF})$.

\section{Attitudes toward Transition from Bachelor's to Transitional Master's Degree}

Overall, participants supported the implementation of the one-year transitional master's degrees as entry-level for the profession of dietetics with $55 \%(\mathrm{n}=59)$ favoring $(\mathrm{F})$ the transition, $20 \%(n=21)$ staying neutral with neither agreeing or disagreeing $(N), 25 \%(n=27)$ disagreeing or not favoring (DNF) the transition.

Participants believed that the implementation of the one -year transitional master's degree had a positive impact and enhanced clinical reasoning (55\% F, 21\% N, 27\% DNF), 
improved application and utilization of research to clinical practice $(71 \% \mathrm{~F}, 14 \% \mathrm{~N}, 15 \% \mathrm{DNF})$, and enhanced professional opportunities such as promotions, hiring salaries, and salary raises $(52 \% \mathrm{~F}, 22 \% \mathrm{~N}, 26 \% \mathrm{DNF})$.

Students obtaining a transitional master's degree did not demonstrate an improvement in leadership skills (37\% F, 29\% N, 34\% DNF), or enhancement in professionalism (33\% F, 33\% N, 34\% DNF). The participant pool of registered dietitians with bachelor's degrees were divided in their attitudes and did not perceive that the transition to a transitional master's degree affected the health care system leading to a more defined scope of practice (34\% F, 37\% N, 29\% DNF), or improved quality of care for patients $(42 \% \mathrm{~F}, 30 \% \mathrm{~N}, 28 \% \mathrm{DNF})$, and believed that it may lead to increased costs to the health care system $(35 \% \mathrm{~F}, 49 \% \mathrm{~N}, 16 \% \mathrm{DNF})$. They did not believe that the transition would alter the role of the registered dietitian, such as increase the consultant role or reduce the hands-on care etc. $(30 \% \mathrm{~F}, 40 \% \mathrm{~N}, 30 \% \mathrm{DNF})$.

The participants however, did believe that the implementation of the transitional master's degree led to greater recognition of the profession in the health care system $(51 \% \mathrm{~F}, 25 \% \mathrm{~N}, 24 \%$ DNF). Participants agreed that the transitional master's degree would lead to greater earning potential for the registered dietitians $(53 \% \mathrm{~F}, 23 \% \mathrm{~N}, 24 \% \mathrm{DNF})$, create a hierarchy within the profession $(65 \% \mathrm{~F}, 21 \% \mathrm{~N}, 14 \% \mathrm{DNF})$, and have a positive impact on public perception of the dietetics profession $(55 \% \mathrm{~F}, 23 \% \mathrm{~N}, 21 \% \mathrm{DNF})$. Participants also believed that requiring the transitional master's degree would help the dietetics profession compete against other health care professions in the private sector $(53 \% \mathrm{~F}, 24 \% \mathrm{~N}, 33 \% \mathrm{DNF})$ and lead to greater recognition of the profession internationally (46\% F, 30\% N, 26\% DNF). 
Demographic Characteristics Versus Attitudes toward the Transition from Bachelor's to

\section{Master's Degree}

Fifty-six percent of participants $(n=60)$ were found to be between the ages of 30-39 years and participants from this group believed that the transition from bachelor's to master's degrees as entry-level for the profession of dietetics was a positive change with $45 \%(\mathrm{n}=27)$ favoring $(\mathrm{F})$ the transition, $25 \%(n=15)$ staying neutral with neither agreeing or disagreeing $(\mathrm{N})$ the transition, and 30\% $(n=18)$ disagreeing or not favoring (DNF) the transition. Participants older than 39 years of age $(n=32)$ were less supportive of the transition to the master's degree and $60 \%(n=19)$ did not feel that there was a need for a universal degree required to practice as a registered dietitian (See Figure 2).

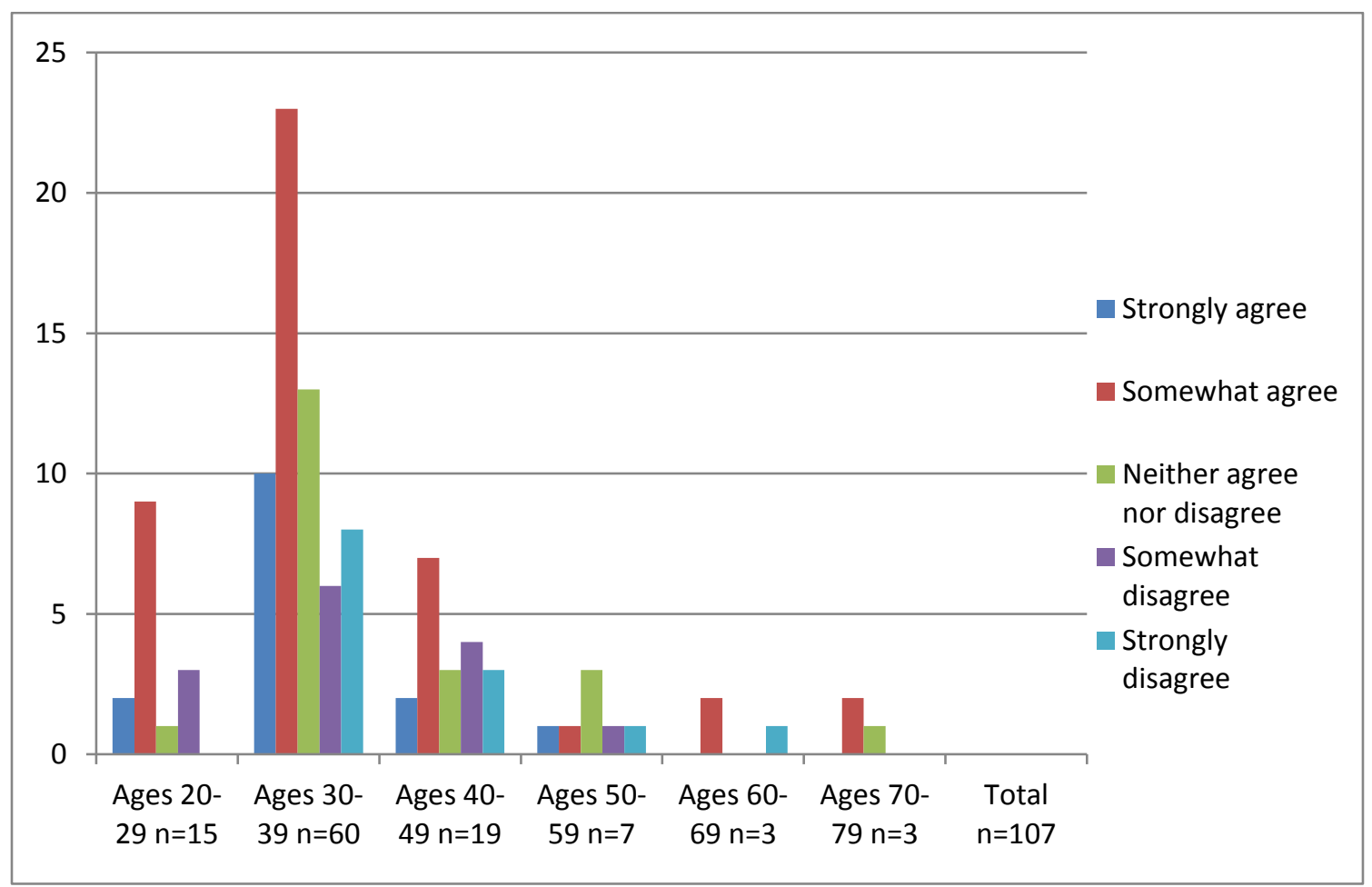

Figure 2. Age group comparison and attitudes towards transition to the master's degree as a positive change 
Overall, participants working in California $(n=94)$ believed that the transition from bachelor's to master's degrees as entry-level for the profession of dietetics was a positive change $(49 \% \mathrm{~F}, 23 \% \mathrm{~N}$, and $28 \% \mathrm{DNF})$. Data indicated that $82 \%$ of the participant pool $(\mathrm{n}=88)$ had practiced as registered dietitians for 0-10 years and participants from this group believed that the transition to the master's degree was a positive change for the dietetics profession $(\mathrm{p}<.024)$, and disagreed that there was a need for a universal degree requirement to practice as a registered dietitian $(\mathrm{p}<.009)$. Participants with > 10 years of practice were more negative in their views towards the transition to the master's degree and the results were not significant. BS, RDs with 0-10 years of experience believed that the transition from bachelor's to master's degrees as entry-level for the profession of dietetics was a positive change $(50 \% \mathrm{~F}, 23 \% \mathrm{~N}, 27 \% \mathrm{DNF})$ as seen in Figure 3.

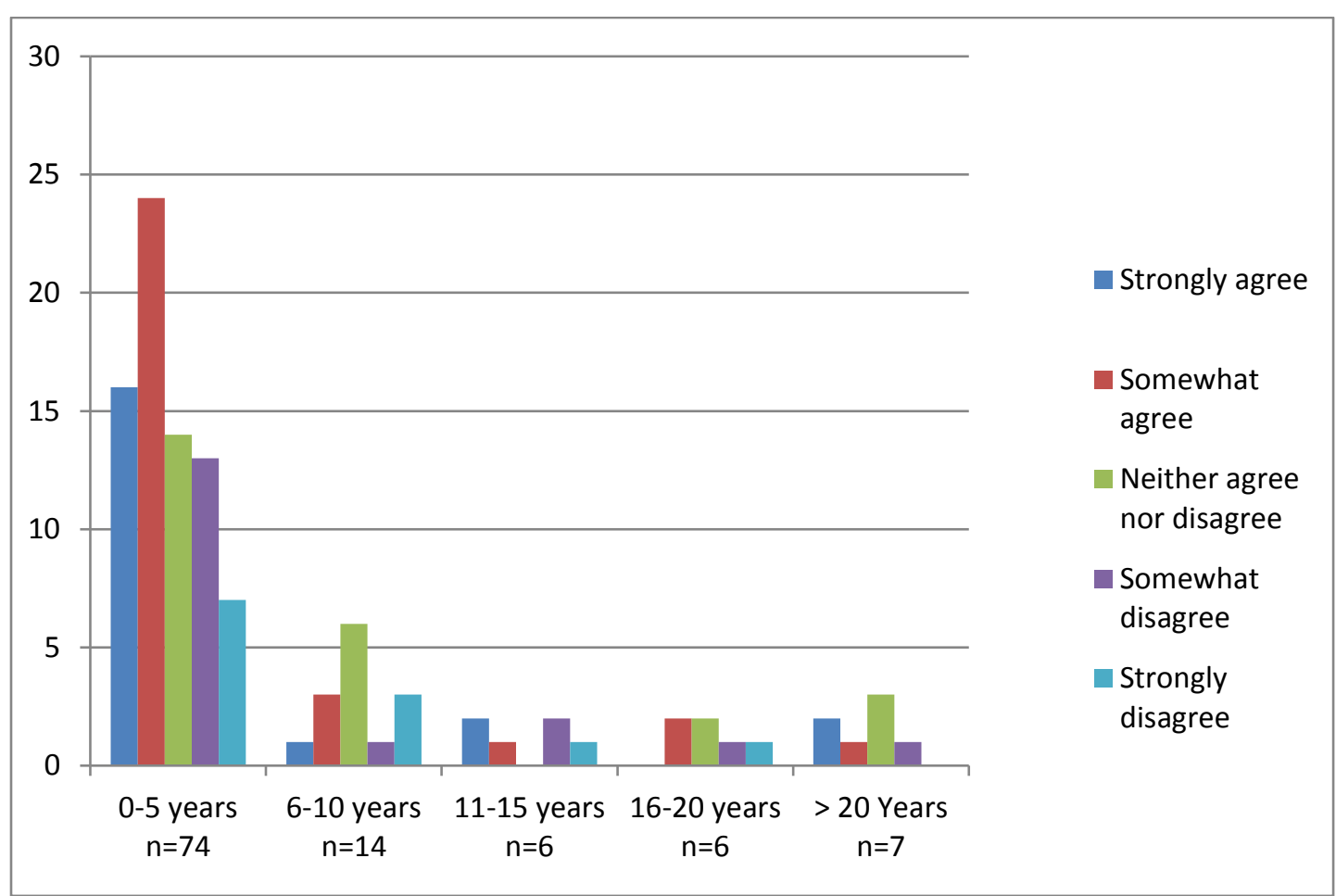

Figure 3. Comparison of years of practice and support for the transition to the master's degree as a positive change 
Sixty-five percent $(n=69)$ of the participant pool $(n=107)$ worked in health care settings such as hospitals, skilled nursing facilities, rehabilitation centers, and physicians' network. Participants from this group believed that the transition from bachelor's to master's degrees as entry-level for the profession of dietetics was a positive change (52\% F, 19\% N, and 29\% DNF).

All participants employed as registered dietitians (full-time, part-time, per diem, on-call, and temporary) were found to believe that the transition to master's degree would lead to enhancement in clinical reasoning skills $(\mathrm{p}<.05)$. Employer status did not affect the overall participants' attitudes and beliefs regarding the transition to the master's degree $(\mathrm{p}>.335)$, however participants' employer status (i.e., those who were employers vs. those who were not) had a strong relationship, and a positive effect on the support for the implementation of universal degree requirement of the master's degree for entry-level registered dietitians $(r=.402, n=107$, $\mathrm{p}<.01)$ and transition to master's degree as an entry-level requirement for registered dietitians $(\mathrm{r}=.578, \mathrm{n}=107, \mathrm{p}<.00)($ See Table 6). 
Table 6.

Correlations between employers and support for the transition to the master's degree

\begin{tabular}{|c|c|c|c|c|c|c|}
\hline & & $\begin{array}{c}\text { Are you an } \\
\text { employer of } \\
\text { Registered } \\
\text { Dietitians? } \\
\end{array}$ & $\begin{array}{c}\text { If } \\
\text { educational } \\
\text { institutions } \\
\text { offer a one } \\
\text { year } \\
\text { transitional- } \\
\text { master's } \\
\text { program in } \\
\text { nutrition and } \\
\text { diete... } \\
\end{array}$ & $\begin{array}{l}\text { Overall, the } \\
\text { transition } \\
\text { from } \\
\text { Bachelor's } \\
\text { to Master's } \\
\text { is a positive } \\
\text { change for } \\
\text { the } \\
\text { profession } \\
\text { of di... }\end{array}$ & $\begin{array}{c}\text { Do you } \\
\text { think that } \\
\text { there should } \\
\text { be a } \\
\text { universal } \\
\text { entry-level } \\
\text { degree } \\
\text { requirement } \\
\text { (Master's } \\
\text { degree req... }\end{array}$ & $\begin{array}{l}\text { Overall, you } \\
\text { support the } \\
\text { implementat } \\
\text { ion of a } \\
\text { transitional } \\
\text { master's } \\
\text { degree post } \\
\text { entry-to- } \\
\text { practi... }\end{array}$ \\
\hline \multirow{3}{*}{$\begin{array}{l}\text { Are you an employer } \\
\text { of Registered } \\
\text { Dietitians? }\end{array}$} & $\begin{array}{l}\text { Pearson } \\
\text { Correlation }\end{array}$ & 1 & & & .094 & \\
\hline & Sig. (2-tailed) & & .699 & .610 & .335 & .395 \\
\hline & $\mathrm{N}$ & 107 & 107 & 107 & 107 & 107 \\
\hline \multirow{3}{*}{$\begin{array}{l}\text { If educational } \\
\text { institutions offer a one } \\
\text { year transitional- } \\
\text { master's program in } \\
\text { nutrition and diete... }\end{array}$} & $\begin{array}{l}\text { Pearson } \\
\text { Correlation }\end{array}$ & -.038 & 1 & $.293^{* *}$ & .183 & $.401^{* *}$ \\
\hline & Sig. (2-tailed) & 699 & & .002 & .059 & .000 \\
\hline & $\mathrm{N}$ & 107 & 107 & 107 & 107 & 107 \\
\hline \multirow{3}{*}{$\begin{array}{l}\text { Overall, the transition } \\
\text { from Bachelor's to } \\
\text { Master's is a positive } \\
\text { change for the } \\
\text { profession of di... }\end{array}$} & $\begin{array}{l}\text { Pearson } \\
\text { Correlation }\end{array}$ & -.050 & $.293^{* *}$ & 1 & $.539^{* *}$ & $.599^{* *}$ \\
\hline & Sig. (2-tailed) & .610 & .002 & & .000 & .000 \\
\hline & $\mathrm{N}$ & 107 & 107 & 107 & 107 & 107 \\
\hline \multirow{3}{*}{$\begin{array}{l}\text { Do you think that } \\
\text { there should be a } \\
\text { universal entry-level } \\
\text { degree requirement } \\
\text { (Master's degree req... }\end{array}$} & $\begin{array}{l}\text { Pearson } \\
\text { Correlation }\end{array}$ & .094 & .183 & & 1 & $.383^{* *}$ \\
\hline & Sig. (2-tailed) & .335 & .059 & .000 & & .000 \\
\hline & $\mathrm{N}$ & 107 & 107 & 107 & 107 & 107 \\
\hline \multirow{3}{*}{$\begin{array}{l}\text { Overall, you support } \\
\text { the implementation of } \\
\text { a transitional master's } \\
\text { degree post entry-to- } \\
\text { practi... }\end{array}$} & $\begin{array}{l}\text { Pearson } \\
\text { Correlation }\end{array}$ & -.083 & $.401^{* *}$ & $.599^{* *}$ & $.383^{* *}$ & 1 \\
\hline & Sig. (2-tailed) & .395 & .000 & .000 & .000 & \\
\hline & $\mathrm{N}$ & 107 & 107 & 107 & 107 & 107 \\
\hline
\end{tabular}

**. Correlation is significant at the 0.01 level (2-tailed).

\section{Demographic Characteristics Versus Attitudes toward the Transition from Bachelor's to}

\section{Transitional Master's Degree}

Fifty-six percent of participants $(n=60)$ were predominantly between the ages of 30-39

years and data indicated that $72 \%(\mathrm{n}=43)$ of the participants from this age group were willing to apply and enroll in the one-year transitional master's degree, however only $30 \%(n=18)$ of this group of participants supported the idea of having a universal degree requirement of the master's 
degree for the profession of dietetics. Participants between the ages of 30-39 years supported the implementation of the one-year transitional master's degrees $(55 \% \mathrm{~F}, 22 \% \mathrm{~N}, 23 \% \mathrm{DNF})$ as seen Figures 4 and 5. Participants older than 39 years of age $(n=32)$ were less supportive of the transition to the master's degree and $56 \%(n=18)$ of this group however reported that they would be willing to apply and enroll in the one-year transitional master's degree and supported the implementation of the program as summarized in Figure 6.

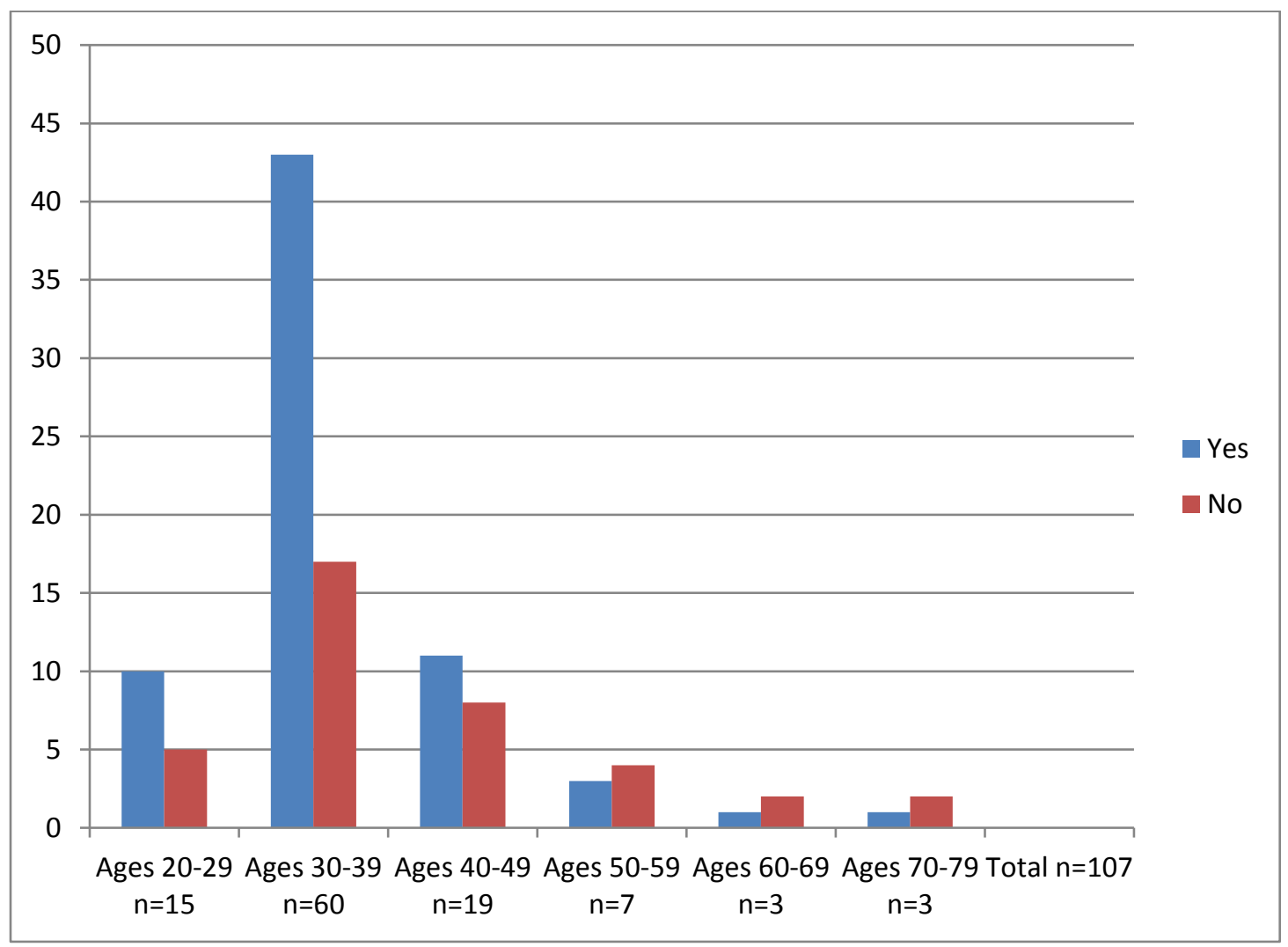

Figure 4. Age group comparison to willingness to apply for the transitional master's degree 


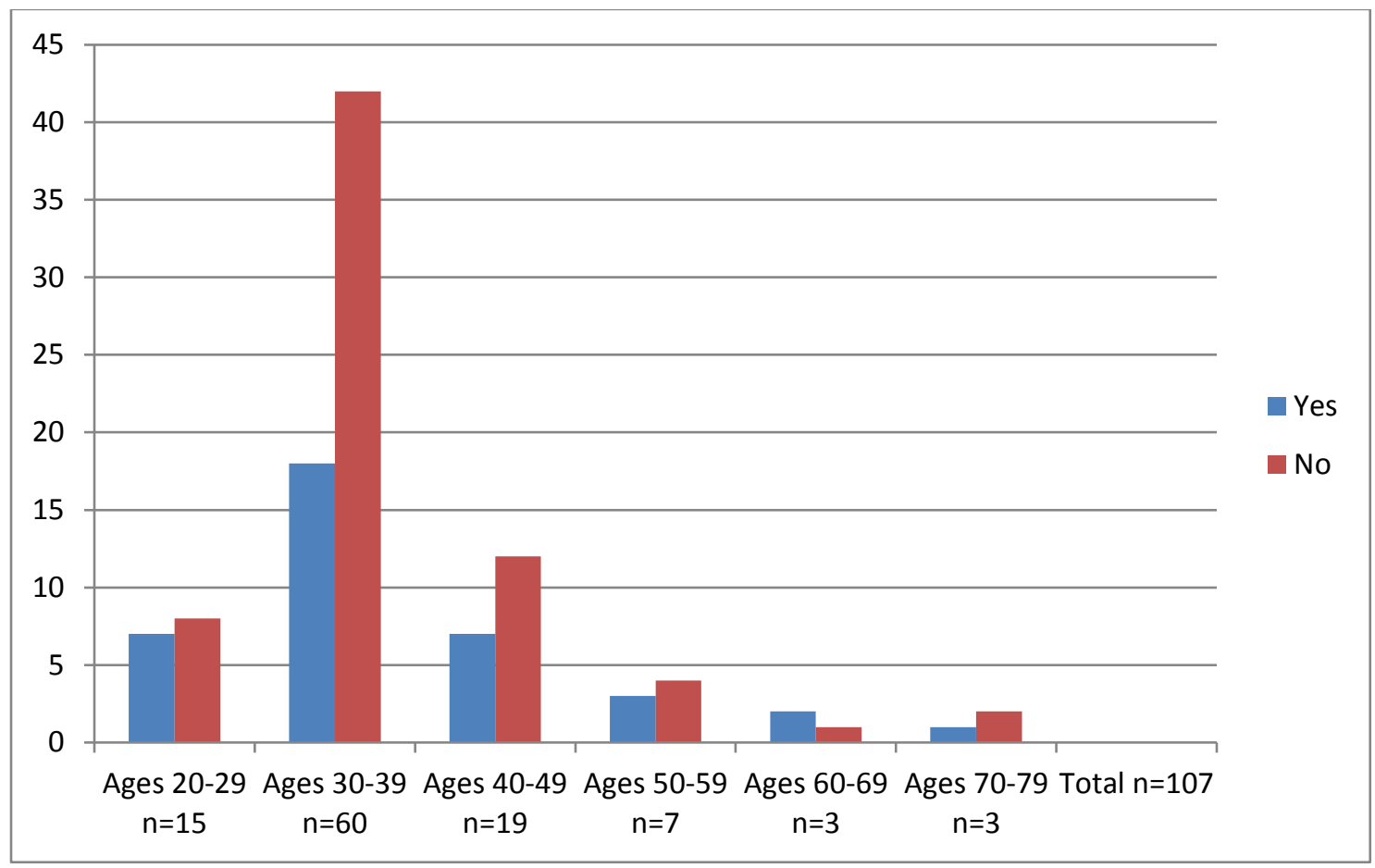

Figure 5. Age groups and support for a universal degree requirement of the master's degree

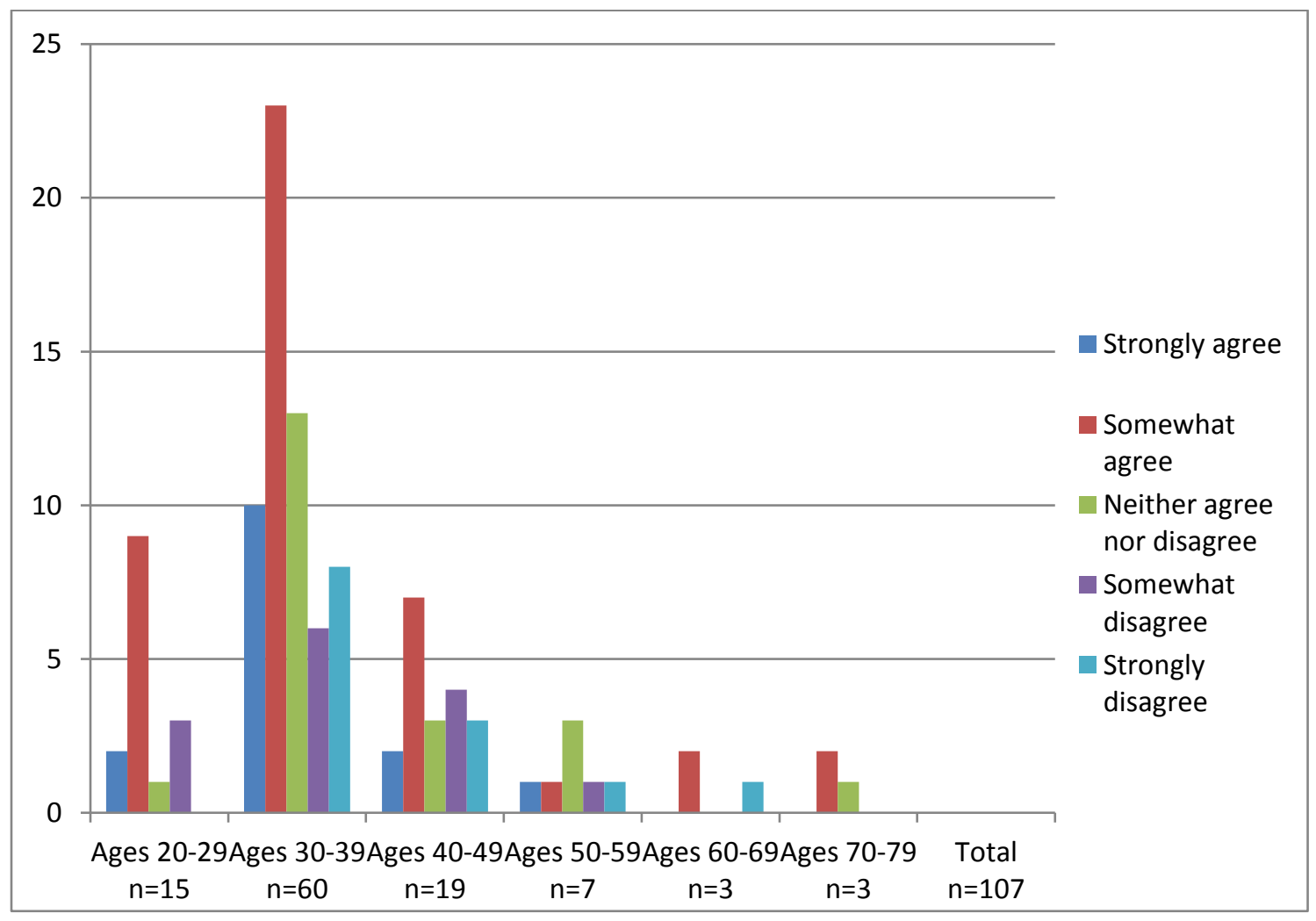

Figure 6. Comparison of age groups and support for implementation of the transitional master's degree 
Data indicated that $82 \%$ of the participant pool $(n=88)$ had practiced as registered dietitians for 0 -10 years and participants' from this group were more willing to apply and enroll in the one-year transitional master's degree $(\mathrm{p}<.000)$, and they supported the implementation of the one-year transitional master's degree $(\mathrm{p}<.002)$. Sixty-nine percent $(n=61)$ of the participants with 0-10 years of practice were willing to apply and enroll in the one-year transitional master's degree and $59 \%(n=52)$ believed that an universal degree was not required to practice as a registered dietitian. BS, RDs with 0-10 years of experience supported the implementation of the one-year master's degree $(57 \% \mathrm{~F}, 19 \% \mathrm{~N}$, and $24 \% \mathrm{DNF})$. The attitudes of the participants towards the universal degree requirement of the master's degree, and the one-year transitional master's degree are summarize in Figures 7, 8, and 9.

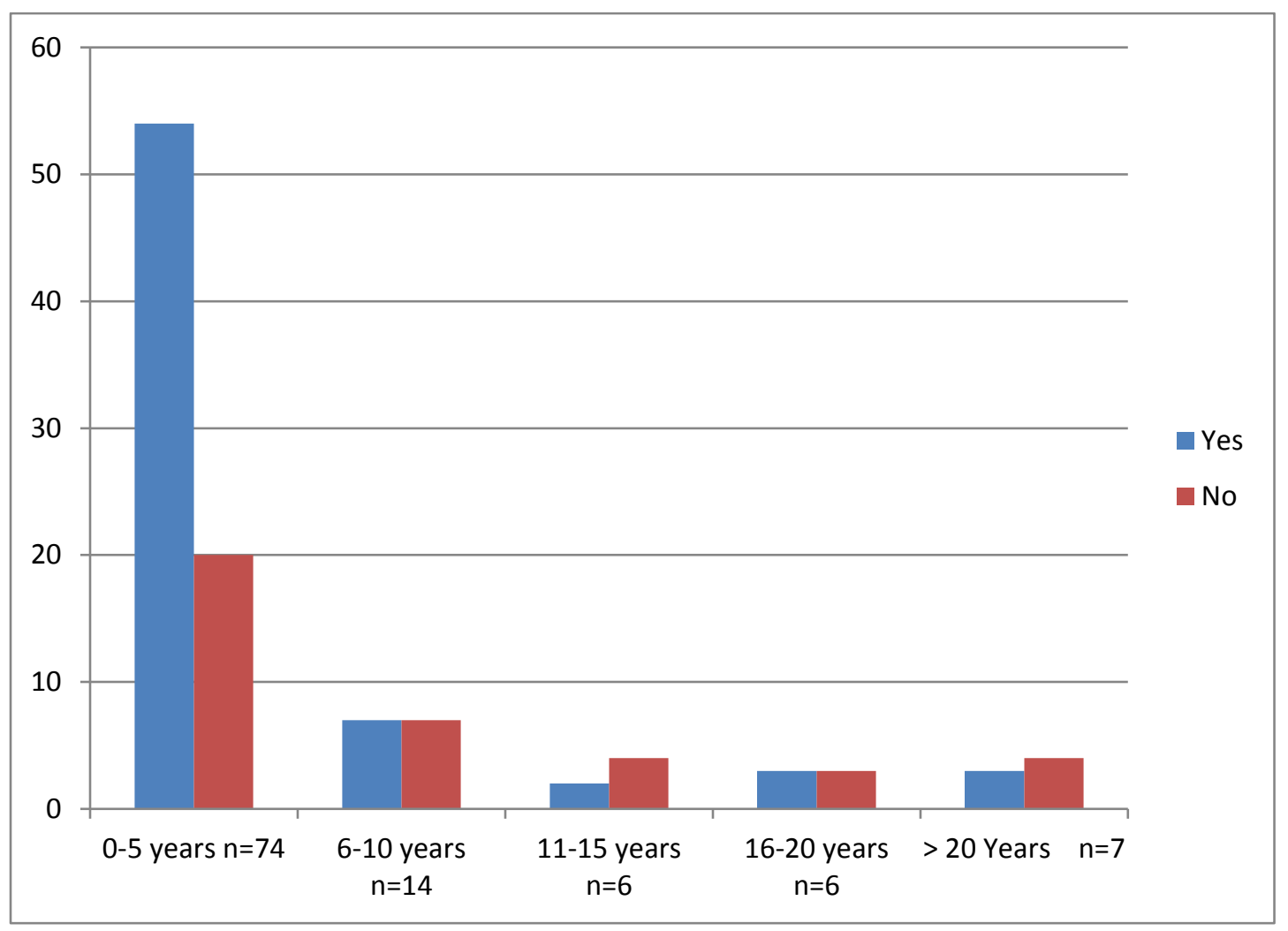

Figure 7. Years of practice and willingness to enroll in the one-year transitional master's degree 


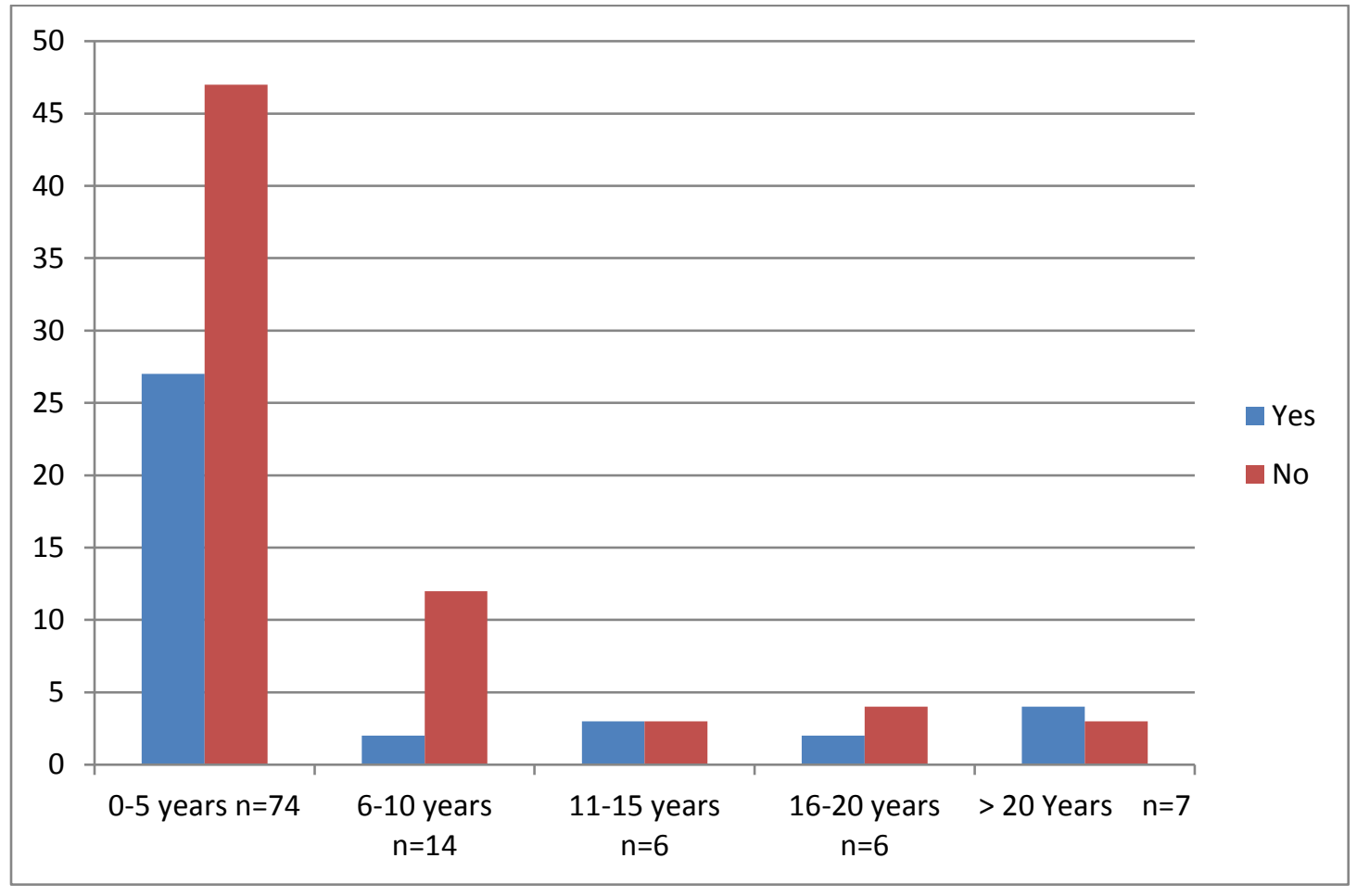

Figure 8. Years of practice and support for universal degree requirement for the master's degree

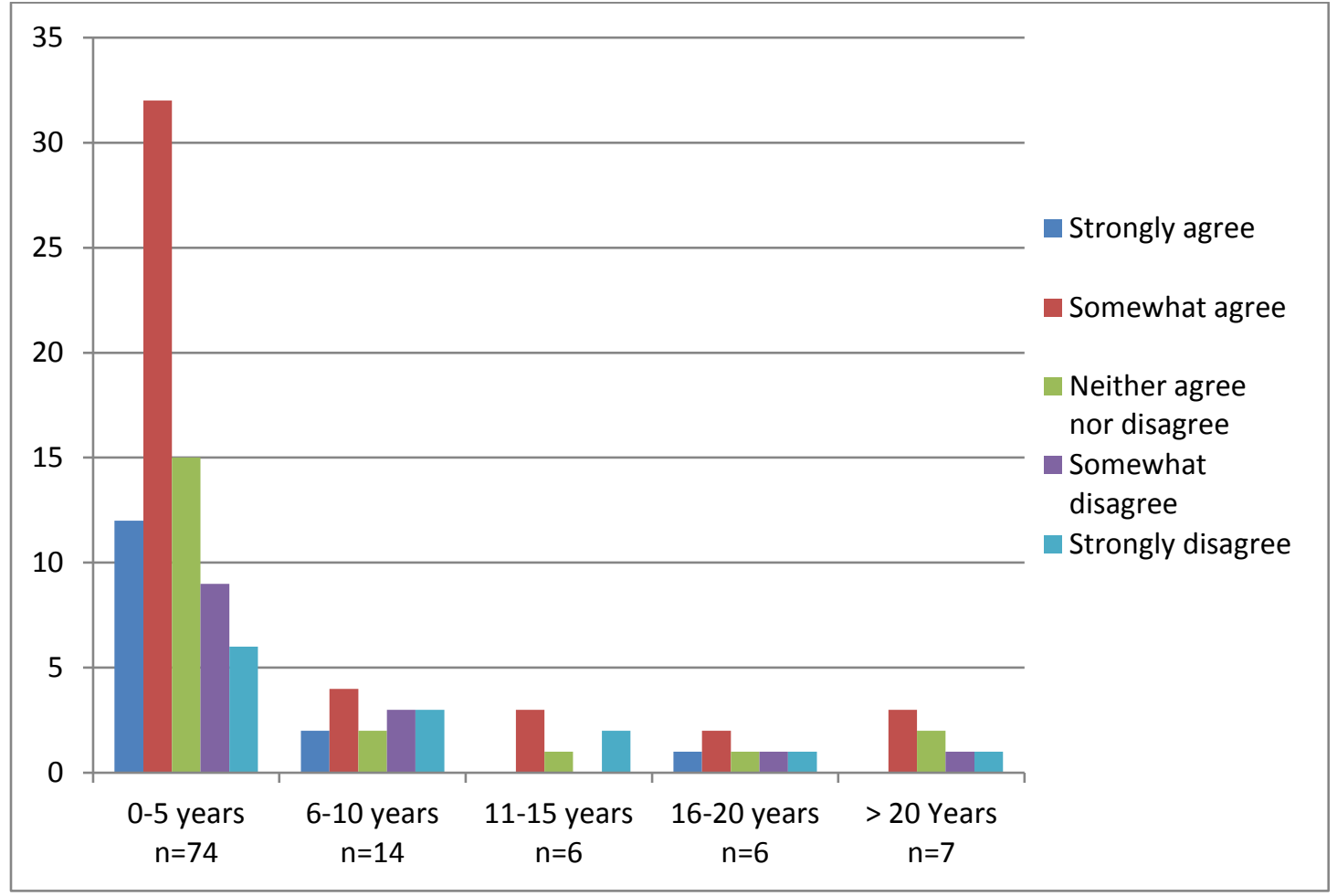

Figure 9. Years of practice and support for the implementation of the one-year transitional master's degree 
As years of practice increased, participants were less supportive of the transition from bachelor's degrees to the one -year transitional master's degree: those with $0-5$ or 6-10 years of practice were more supportive, while those with 11-15, 16-20, and > 20 years of practice were more neutral and significant differences $(\mathrm{p}<0.016)$ were found between all cohorts. Table 7 below summarizes findings for this category.

One-way ANOVA and post-hoc Tukey analyses determined that the support for implementation of the one-year transitional master's degree had a significant effect $(\mathrm{p}<.03)$ on participants with 0-5 and 16-20 years of practice who believed that the transitional master's degree would lead to greater recognition for the dietetics profession in the health care system. Significant differences $(\mathrm{p}<0.05)$ were found between all cohorts in their attitudes to the transition.

Sixty-five percent $(n=69)$ of the participant pool $(n=107)$ worked in health care settings such as hospitals, skilled nursing facilities, rehabilitation centers, and physicians' network. Sixty-eight percent $(n=47)$ of participants of this group were willing to apply and enroll into a one-year transitional master's degree, and 59\% $(n=41)$ did not believe that a universal degree was required to practice as a registered dietitian. The majority of the participants of this group supported the implementation of the one-year master's degree (58\% F, 19\% N, and 23\% DNF). 
Table 7.

Years of practice as a registered dietitian and support for implementation of the transitional master's degree.

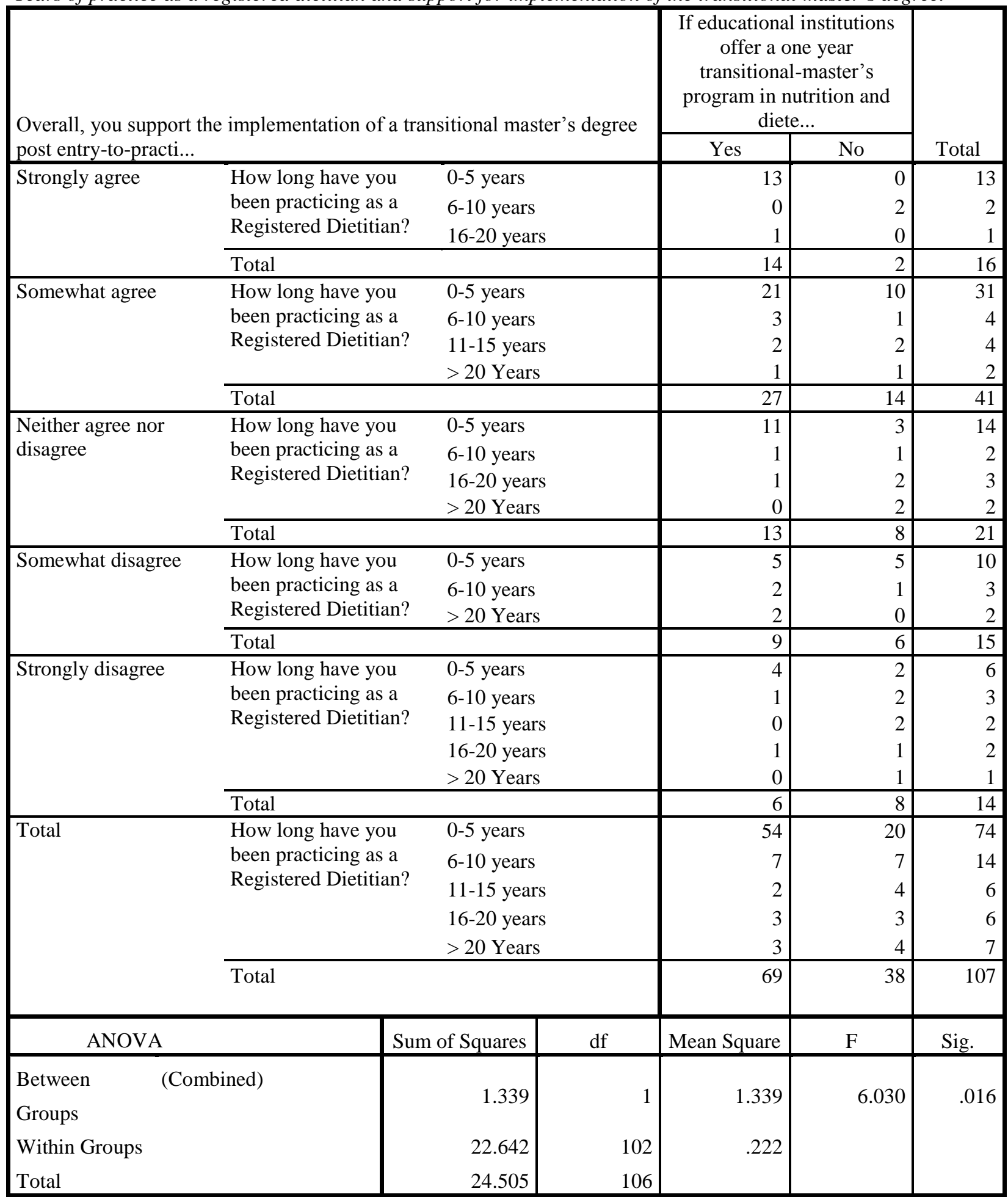


Results indicated that participants working in the clinical setting were found to be most willing to apply and enroll in the one-year transitional master's degree with statistically significant differences found for those working 51-75\% $(\mathrm{p}<.018)$ and $76-100 \%(\mathrm{p}<0.022)$ of the time, and significant differences were also found between all time slots $(\mathrm{p}<0.003)$. Results are summarized in Table 8. Results also indicated that participants' employer status (i.e., those who were employers vs. those who were not) had a positive effect on their level of support for the implementation of the one-year transitional master's degree $(r=.599, n=107, p<.00)$ and willingness to apply and enroll in the transitional master's degree $(\mathrm{r}=.293, \mathrm{n}=107, \mathrm{p}<.002)$. Results are summarized in Table 6.

The majority of the participants $88.0 \%(n=94)$ reported working in California. Sixtythree percent $(n=59)$ of the BS, RDs' working in California were willing to apply and enroll in the one-year transitional master's degree, however only $36 \%(n=34)$ believed that a universal requirement of the master's degree for entry-level registered dietitians' was needed. These results were similar to the overall participant pool of $107 \mathrm{BS}$, RDs from varied states of the United States. Participants working in California $(n=94)$ supported the implementation of the one-year transitional master's degrees (55\% F, 20\% N, 25\% DNF). 
Table 8 .

Comparison between percentage of time working in clinical setting and support for the transitional master's degree

\begin{tabular}{|c|c|c|c|c|c|c|}
\hline \multirow{2}{*}{$\begin{array}{l}\text { (I) What percent of } \\
\text { time are you currently } \\
\text { practicing in a clinical } \\
\text { setting? }\end{array}$} & \multirow{2}{*}{$\begin{array}{l}\text { (J) What percent of } \\
\text { time are you currently } \\
\text { practicing in a clinical } \\
\text { setting? }\end{array}$} & \multirow{2}{*}{$\begin{array}{c}\text { Mean } \\
\text { Difference } \\
(\mathrm{I}-\mathrm{J})\end{array}$} & \multirow[b]{2}{*}{$\begin{array}{l}\text { Std. } \\
\text { Error }\end{array}$} & \multirow[b]{2}{*}{ Sig. } & \multicolumn{2}{|c|}{$95 \%$ Confidence Interval } \\
\hline & & & & & $\begin{array}{l}\text { Lower } \\
\text { Bound } \\
\end{array}$ & $\begin{array}{l}\text { Upper } \\
\text { Bound } \\
\end{array}$ \\
\hline \multirow[t]{4}{*}{ None } & $1-25 \%$ & .315 & .186 & .442 & -.20 & .83 \\
\hline & $26-50 \%$ & .440 & .186 & .133 & -.08 & .96 \\
\hline & $51-75 \%$ & -.435 & .246 & .397 & -1.12 & .25 \\
\hline & $76-100 \%$ & .284 & .110 & .082 & -.02 & .59 \\
\hline \multirow[t]{4}{*}{$1-25 \%$} & None & -.315 & .186 & .442 & -.83 & .20 \\
\hline & $26-50 \%$ & .125 & .227 & .982 & -.50 & .75 \\
\hline & $51-75 \%$ & -.750 & .278 & .061 & -1.52 & .02 \\
\hline & $76-100 \%$ & -.031 & .170 & 1.000 & -.50 & .44 \\
\hline \multirow[t]{4}{*}{$26-50 \%$} & None & -.440 & .186 & .133 & -.96 & .08 \\
\hline & $1-25 \%$ & -.125 & .227 & .982 & -.75 & .50 \\
\hline & $51-75 \%$ & $-.875^{*}$ & 278 & .018 & -1.65 & -.10 \\
\hline & $76-100 \%$ & -.156 & .170 & .889 & -.63 & .32 \\
\hline \multirow[t]{4}{*}{$51-75 \%$} & None & .435 & .246 & .397 & -.25 & 1.12 \\
\hline & $1-25 \%$ & .750 & .278 & .061 & -.02 & 1.52 \\
\hline & $26-50 \%$ & $.875^{*}$ & .278 & .018 & .10 & 1.65 \\
\hline & $76-100 \%$ & $.719^{*}$ & .234 & .022 & .07 & 1.37 \\
\hline \multirow[t]{4}{*}{$76-100 \%$} & None & -.284 & .110 & .082 & -.59 & .02 \\
\hline & $1-25 \%$ & .031 & .170 & 1.000 & -.44 & .50 \\
\hline & $26-50 \%$ & .156 & .170 & .889 & -.32 & .63 \\
\hline & $51-75 \%$ & $-.719^{*}$ & .234 & .022 & -1.37 & -.07 \\
\hline ANOVA & Sum of Squares & \multicolumn{2}{|l|}{$\mathrm{df}$} & $\begin{array}{l}\text { Mean } \\
\text { Square }\end{array}$ & $\mathrm{F}$ & Sig. \\
\hline Between Groups & 3.540 & & 4 & .885 & 4.306 & .003 \\
\hline Within Groups & 20.965 & & 102 & .206 & & \\
\hline Total & 24.505 & & 106 & & & \\
\hline
\end{tabular}

*. The mean difference is significant at the 0.05 level.

\section{Perceptions Regarding Importance and Ranking of Skill Sets Based on Bachelor's Degree}

\section{and Master's Degree}

Results indicated that participants chose "Client Care Skills" as the most important skill with $68.2 \%(n=73)$ of participants ranking it first at the bachelor's degree level and $52 \%(n=56)$ of participants ranking it first at the master's degree level. "Food and Foodservice Skills" were ranked as the least important skills by $37 \%(\mathrm{n}=39)$ of participants at the bachelor's degree level and $54 \%(\mathrm{n}=58)$ of participants at the master's degree level. 
A Spearman's correlation was run to determine the relationship between perceptions regarding importance and ranking of skill sets based on bachelor's degree and master's degree and Table 9 provides details of the analysis. There was a strong, positive monotonic correlation between each of the six skill sets studied at the bachelor's and master's degree level:

Professional Research and Programmatic Skills ( $r s=.646, \mathrm{n}=107, \mathrm{p}<.00)$; Professional Teamwork and Communication Skills ( $r s=.730, \mathrm{n}=107, \mathrm{p}<.00)$; Client Care Skills ( $\mathrm{rs}=.612, \mathrm{n}=107, \mathrm{p}<.00)$; Population and Community Health Skills (rs=.686, n=107, $\mathrm{p}<.00$ ); Management and Organizational Skills ( $r s=.341, \mathrm{n}=107, \mathrm{p}<.00)$; and Food and Foodservice Skills ( $r s=.725, \mathrm{n}=107$, $\mathrm{p}<.00)$. 
Table 9.

Perceptions regarding importance and ranking of skill sets based on bachelor's and master's degree

\begin{tabular}{|c|c|c|c|}
\hline Skill Sets & $\begin{array}{ll}\text { Spearman's } & \text { rho } \\
\text { Correlation } & \\
\text { Coefficient } & \end{array}$ & Sig. (2 tailed & $\mathrm{N}$ \\
\hline $\begin{array}{l}\text { Professional Research and Programmatic } \\
\text { Skills including reading and evaluating } \\
\text { academic and scientific research, } \\
\text { designing, conducting, and applying } \\
\text { translational and basic science research, } \\
\text { and designing, implementing, and } \\
\text { evaluating workplace programs and } \\
\text { studies. }\end{array}$ & $.646^{* *}$ & .000 & 107 \\
\hline $\begin{array}{l}\text { Professional Teamwork and } \\
\text { Communication Skills including working } \\
\text { in collaborative teams and effective } \\
\text { communication (written and oral). }\end{array}$ & $.730 * *$ & .000 & 107 \\
\hline $\begin{array}{l}\text { Client Care Skills including assessing } \\
\text { nutritional status to diagnose problems; } \\
\text { physical assessments; developing, } \\
\text { monitoring and evaluating nutritional } \\
\text { interventions; and counseling clients with } \\
\text { behavior modification therapy. }\end{array}$ & $.612 * *$ & .000 & 107 \\
\hline $\begin{array}{l}\text { Population and Community Health Skills } \\
\text { including planning, directing, and } \\
\text { assessing community nutrition } \\
\text { assessments; designing and implementing } \\
\text { community nutrition interventions; } \\
\text { effectively communicating across cultural } \\
\text { boundaries; and mobilizing community } \\
\text { partnerships }\end{array}$ & $.686 * *$ & .000 & 107 \\
\hline $\begin{array}{l}\text { Management and Organizational Skills } \\
\text { including leading staff development, } \\
\text { project management, managing financial } \\
\text { and human resources, and developing } \\
\text { business plans. }\end{array}$ & $.341 * *$ & .000 & 107 \\
\hline $\begin{array}{l}\text { Food and Foodservice Skills including } \\
\text { food and culinary preparation; monitoring } \\
\text { and evaluating food production, service, } \\
\text { distribution, safety, and sanitation systems; } \\
\text { and designing menus for food systems }\end{array}$ & $.725 * *$ & .000 & 107 \\
\hline
\end{tabular}

** Correlation is significant at the 0.01 level (2-tailed).

Confidence Interval level set at $95 \%$

\section{Summary}

This study may be the first of its kind to examine the attitudes of a sample of registered

dietitians with bachelor's degrees toward the implementation of a professional master's degree as

an entry-level requirement for the profession. The following research questions informed this 
study: 1) Do the RDs with bachelor's degrees indicate that they would be willing to complete a one year transitional master's degree and would they prefer that the method of instruction of the curriculum be online, face-to-face, or mixed-mode classes? 2) How do RDs with bachelor's degrees perceive that the transition to the master's degree will affect the RDs scope of practice and type of practice? 3) How do RDs with bachelor's degrees perceive that the transition to the master's degree will impact the RDs regarding factors such as hiring and retention, years of work experience and salary levels and increments, and professional stature such as promotions and positions?

The results and findings indicate support for some aspects of the transition to an entrylevel master's degree. Participants expressed greater support for a one-year transitional master's degree rather than the traditional master's degree. Participants who believed that the transition to the master's degree was a positive change 49\% (n=52) favored the one-year transitional master's degree. Research findings indicated that $64.5 \%(n=69)$ of participants were willing to enroll in the transitional master's degree and approximately half of those participants stated that they preferred the "online" mode of instruction, and another half stated they preferred a "mixed" mode of instruction including online and face-to-face interaction. Data also indicated lack of support for the universal degree requirement of the master's degree for practice in the dietetics profession. The majority of the participant pool of BS, RDs' $64.5 \%(n=69)$ did not believe that a universal requirement of a master's degree for practice as a registered dietitian was needed. These results were consistent with $64 \%(n=34)$ of participants working in California stating that the universal degree requirement of master's degree was not needed for practice. Registered dietitians (RDs) who were between 30-39 years of age and had practiced for a few years (0-10 years) were seen to be more inclined and supportive of the transition and were willing to enroll 
in the master's degree however, the support decreased with increased years of practice.

Similarly, participants working in a clinical setting especially health care area were seen to be more willing to pursue a master's degree compared to the non-clinical setting.

Results report that even though participants believed that the transition to the master's degree level would improve "clinical reasoning skills", they did not believe that the transition would "enhance professionalism" and "improve quality of care for the patients" $(p<.02)$. Participants believed that the transition from the bachelor's degree to the master's degree had a positive impact on clinical reasoning, improved application and utilization of research to clinical practice, and enhanced professional opportunities such as promotions, hiring salaries, and salary raises. Participants believed that the transition to the master's degree would lead to greater recognition of the profession in the health care system and greater earning potential for the registered dietitians. The transition to the master's degree and one-year transitional master's degree did not indicate an improvement by students in leadership skills, or enhancement in professionalism. The participant pool of BS, RDs were divided in their attitudes and did not perceive that the transitional master's degree would affect the health care system leading to a more defined scope of practice. Participants chose "Client Care Skills" as the most important skill with participants ranking it first at both, the bachelor's degree level and master's degree level. "Food and Foodservice Skills" were ranked as the least important skills by participants at the bachelor's degree and master's degree level.

In addition to participants' attitudes and perception of the transition to the master's degree, results also showed that the master's degree is important in the workplace environment for several participants. Thirteen percent $(n=14)$ of the participants required a graduate degree for job promotions for registered dietitians at their workplace, and 52\% $(n=56)$ of participants 
stated that their workplace required a graduate degree such as Master of Arts, Master of Science, Master of Business Administration, and or a Doctorate degree for management level registered dietitian positions. Twenty-six percent $(n=28)$ of participants indicated that there was a salary cap or salary limit for BS, RDs at their workplace and approximately $63 \%(n=67)$ of participants indicated that there was a system in place for promotions and salary levels for BS, RDs at their work setting. 


\section{CHAPTER FIVE}

\section{CONCLUSIONS}

The current trend of movement towards higher degree requirements for entry into the health care professions has been debated among the educational and professional community. Although there are some who argue that a master's degree would acknowledge the academic training and clinical skills already possessed by the registered dietitians with bachelor's degrees, others question whether the issues facing the dietetics profession today and in the future can be solved by entry-level master's degrees. Proponents of the change believe that the higher degree requirements will acknowledge the current rigorous academic education and training that is already provided to the graduates, while opponents question whether the changes will address the issues and challenges that face the educational institutions and the health care system in the United States (Mathur, 2011).

The purpose of this quantitative study was to examine the attitudes and perceptions of registered dietitians with bachelor's degrees regarding the transition to an entry-level master's degree as the requirement for certification as a registered dietitian (RD). Due to the lack of literature available in the area of transition to the master's degree in the profession of dietetics, much of the information used to study the research gap was derived from other allied health care fields such as physical therapy (PT), occupational therapy (OT), and nursing. The research questions identified examined the BS, RD's attitudes and perceptions regarding impacting factors such as their years of work experience including salary levels and increments, professional stature including promotions and positions, and scope and type of practice.

The results and findings from this study indicate support for some aspects of the transition to an entry-level master's degree. Participants expressed greater support for a one-year 
transitional master's degree rather than the traditional master's degree. Data also indicated lack of support for the universal degree requirement of the master's degree for practice in the dietetics profession. Only $35.5 \%(\mathrm{n}=38)$ of the participant pool of $107 \mathrm{BS}$, RDs indicated that there should be a universal entry-level master's degree requirement for the profession of dietetics and to practice as a registered dietitian. These results were consistent with $36 \%(n=34)$ of participants' working in California stating that the universal degree requirement of a master's degree was needed for practice.

Participants felt that the master's degree improved the registered dietitian's ability to apply research in clinical practice, and improved clinical reasoning skills echoing similar findings in physical therapy studies (Mathur, 2011) and occupational therapy studies (Ellis, 2007) which stated that master's students were expected to demonstrate greater involvement in continuing research and application of research to clinical settings. Threkeld, Jensen, and Royeen (1999) examined the major considerations for the doctorate in physical therapy (DPT) and concluded that DPT was favored to meet societal needs, such as professional attitudes, competence, program influences, career enhancement, improved clinical skills and evidencebased practice for patient care and education. Mistry et al. (2014) however reported that clinical reasoning skills did not improve when transitioning to the master's degree in physical therapy, but improvement was seen when transitioning to the clinical doctorate in physical therapy (DPT).

The results from this study state that the transition to the traditional master's degree or transitional master's degree would not lead to improvement in leadership skills and enhancement in professionalism. These findings were very similar to studies done in physical therapy and other health care fields that reported that the participants did not agree that the transition to a master's degree level enhanced leadership, or professionalism (Brown-Benedict, 2008; Ellis, 
2007; Mathur, 2011; Mistry et al., 2014). This could be possible because leadership skills and professionalism were considered to be skills that were developed from practice and experience, and not just from attaining a higher degree.

In addition, $\mathrm{BS}, \mathrm{RDs}$ did not believe that the transition to a master's degree impacted the health care system positively with respect to a more defined type and scope of practice, or improved the quality of health care for the patients. They did not believe that the transition would alter the role of the registered dietitian, such as increase the consultant role or reduce the hands-on care etc. In other health care professions, such as physical therapy, occupational therapy, optometry and nursing, a primary reason for educational reform was to, increase autonomy of the profession and improve delivery of service to patients (Phelps \& Gerbasi, 2009). The results from this study did not show changes in these areas and it may be possible that the dietetics profession was already considered to provide good service delivery and autonomy, and therefore, the transition to a master's degree was not seen as bringing about such changes.

Registered dietitians (RDs) who had practiced for a few years were seen to be more inclined to be supportive of the transition and were willing to enroll in the master's degree however, the support decreased with increased years of practice. From the results, it can be concluded that the support for the transition to the master's degree as an entry-level requirement for the dietetics profession decreased as age progressed and with increased years of practice. Fifty-six percent of participants $(n=60)$ were predominantly between the ages of 30-39 years and $82 \%$ of the participant pool $(n=88)$ had practiced as registered dietitians' for $0-10$ years. Registered dietitians (RDs) who were between 30-39 years of age and had practiced for a few years ( $0-10$ years) were seen to be more inclined to be supportive of the transition and were 
willing to enroll in the master's degree. Participants older than 39 years of age $(n=32)$ were less supportive of the transition to the master's degree. As years of practice increased, participants were less supportive of the transition from bachelor's to the one -year transitional master's degree: those with $0-5$ or 6-10 years of practice were more supportive, while those with 11-15, 16-20, and $>20$ years of practice were more neutral. Similarly, participants working in the clinical setting such as the health care area were seen to be more willing to pursue a master's degree compared to those working in the non-clinical setting.

Fahlman (2012) investigated the need for educational leadership to enhance e-learning in health care settings and found that the younger workers entering the health care settings were technologically savvy and preferred to enhance their professional skills with innovative educational and technological practices. In this study, participants who believed that the transition to the master's degree was a positive change were found to favor the one-year transitional master's degree and stated that they were willing to enroll in the transitional master's degree. Approximately half of the participants stated that they preferred the "online" mode of instruction, and another half stated they preferred "mixed" mode of instruction including online and face-to-face interaction. These results are consistent with other studies done in the United States which report that the educational institutions have gone through revolutionary changes from a "supply-driven" to a "demand-driven" marketplace due to demographic, economic, technological, and sociocultural issues (Fahlman, 2012).

Participants believed that the transition to the master's degree would lead to greater recognition of the profession in the health care system and improve earning potential for the registered dietitians with enhanced professional opportunities such as promotions, hiring salaries, and salary raises. In addition to participants' attitudes and perception of the transition to the 
master's degree, results also showed that the master's degree was important in the workplace environment for several participants and they believed that it may lead to increased costs to the health care system.

Although this study did not examine the employer's perceptions and attitudes towards the registered dietitians' with bachelor's and master's degrees and whether the degree was a factor in hiring decisions of the employers, the questionnaire did ask the participants to identify themselves as employers of other RDs. Fourteen percent of the BS, RDs $(n=15)$ were employers of registered dietitians, of whom 8 indicated that they had hired BS, RDs, 6 indicated that they had hired MS, RDs and one participant indicated that they had hired a $\mathrm{PhD}, \mathrm{RD}$. A small percentage of the participants indicated that their workplace required a graduate degree for job promotions for registered dietitians, and there was a salary cap or salary limit for BS, RDs at their workplace. However, more than half the participants indicated that their workplace required a graduate degree such as Master of Arts, Master of Science, Master of Business Administration, and or a Doctorate degree for management level registered dietitian positions and that there was a system in place for promotions and level increases for BS, RDs at their work setting. These findings were similar to the study done on physical therapy employers prior to the transition to DPT as the entry-level requirement for the profession (Bank et al., 1998). Bank et al. (1998) revealed that employers did prefer to hire MPTs over therapists with a bachelor's degree or DPT for several reasons. Employers believed that MPTs applied research to clinical practice more frequently and were better prepared in areas of patient education, supervisory and management roles, and professional development. The results also indicated that MPTs earned higher salaries than professionals with lesser degrees. 


\section{Implications}

There is a lack of literature on studies examining the transition to the master's degree in the profession of dietetics, and studies done in other allied health care fields indicate that health care professionals such as physical therapists, occupational therapists, and nurse practitioners generally perform direct autonomous patient care and receive reimbursement from insurance companies, and do not require endorsement or prescriptions from another professionals such as physicians to perform care or to receive payment (Hasson, 2003). Currently in the United States, most states do not have laws and regulations that allow registered dietitians (RDs) to evaluate and treat patients without a physicians' referral although the scope of practice is changing gradually (CDR, 2015). A physician's referral and endorsement is required for a RD to receive insurance payment. It is strongly believed that once the transition to the master's degree takes place for the registered dietitian certification, insurance companies will recognize the RDs as autonomous practitioners and it will become easier to receive direct reimbursement.

Educators, researchers, consultants, and policy makers expect the health care

environment to revolutionize in the next decade as health care reform will emphasize preventive care, overall health and well-being of the patients. Health care service delivery will focus on individual clinical outcomes, patient satisfaction, and value delivered from treatment and care provided to patients. Health care decisions will be derived from scientific evidence-based practice and patients will have easy access to clinical knowledge and resources for their care (Nelson, 2013). To adapt to the new health care environment, the profession of dietetics and the registered dietitians will have to raise the importance and value of the profession and the RD certification to all stakeholders such as the patients, the employers, students, policy makers, and insurance agencies. The importance of collecting data on clinical and patient satisfaction 
outcomes will need to be emphasized and disseminated to insurance agencies and health care policy makers so that the value of the profession can be enhanced. It will also be important to study the costs in delivery of care to patients, establishing cost-effective and cost-efficient practices, and incorporating innovative practices in the profession.

Educators and researchers will play a vital role as the transition to the master's degree as an entry-level degree for the dietetics profession occurs and will result in curricular reforms and program reorganization in educational institutions. The arbitrary decision states that all students entering the nutrition and dietetics field will require a minimum of a master's degree by 2024 and all accredited Didactic Programs in Dietetics (DPD programs) will be required to have the curricular reforms in place for all freshmen entering Fall semester of 2017 (ACEND, 2015). With the decision handed down by CDR and the Future Education Model proposed by ACEND, the current undergraduate dietetics program at San Jose State University (SJSU) will be revised so that students graduating with the bachelor's degrees will be eligible for the new proposed Nutrition and Dietetic Technician Registered (NDTR) credential. Additionally, a new DPD curriculum for the graduate program will be developed so that students graduating with the master's degree will be eligible for the DI and the RD certification upon passage of the Registration exam (CDR, 2015).

Literature from studies conducted on curricular reforms in allied health care fields such as physical therapy, occupational therapy, and nursing have focused on the outcomes-based learning approach which is a student centered approach to learning and focuses on the student knowledge and the skills they gain during the course of the study or program. It focuses on what the students know and what they can do. The changes in technology, student needs, type of 
students, and progression in academic standards by governing agencies in the dietetics profession will require faculty and academic staff to continuously evaluate and revise the curricula.

Several studies from other health care professions such as physical therapy, occupational therapy, and nursing reported that the cost of the education to students, length of the program, potential for decreased diversity amongst professionals, lack of faculty to teach, lack of resources, and lack of demand and need in the community were major deterrents for the transition to the doctoral profession (Hummer et al.,1994; Detweiler et al., 1999; Beck and Doig, 2002; Domholdt et al., 2006; Graham et al., 2008).

The program changes in dietetics and the curricular reforms will affect the students it serves, and challenges and obstacles will be faced by all of the stakeholders such as the faculty, the students, the preceptors, and the employers during the transformation process. Students will be affected by the curricular reforms and face new course requirements as the old programs phase out. Implementation of new courses and programs may bring about increase in costs of education to students and the time needed to complete the additional requirements. Opponents argue that the added costs to students are unnecessary and will discourage individuals from entering these professions (Brown et al., 2015). There is also a concern that it may affect the diversity of practitioners in the profession which may ultimately lead to decreases in practitioner supply in fields already facing shortages (Beck \& Doig, 2002; Graham et al., 2008).

Faculty members often lack formal training in curriculum development or teaching and few take advantage of professional development programs offered or consider the professional development opportunities as helpful to improve their teaching skills or pedagogical knowledge (Stark et al., 1990). Most faculty are overburdened in terms of teaching load and lack the experience to work on curriculum revisions, hence educational developers and strategic planners 
have often been used to assist the academic staff (Lattuca et al., 2006). As the transition brings about curricular reforms and degree elevation, it is important to make sure that the faculty be at or above the level to teach the courses. This may have implications for universities who do not have faculty to teach graduate level courses and some faculty may have to carry an additional workload. Universities will also have to make employment arrangements for the hiring of new faculty as the program changes take effect which may incur additional costs and budget changes to the programs. In addition to increase in cost, time, and lack of resources that may occur with the transition to a higher degree, some researchers also argue that the transition may cause degree inflation. Therefore, it will be important to justify the transition by implementing the knowledge and skill content of the graduate degree in the new programs.

Contractual arrangements with clinical affiliations such as hospitals, skilled nursing facilities, school districts, and other community partners will be affected as the program changes occur as additional placements of students may be needed and time durations of rotations during dietetic internships may change. The transition will also affect self-supporting dietetic internships (DI) hosted by hospitals, medical centers, and other community based organizations such as the Women, Infants, and Children Program (WIC) as they will be compelled to partner with universities offering the graduate level programs.

\section{Recommendations}

As the transition to the master's program as an entry-level requirement for registered dietitians takes effect, it will be important to study the impact of the transition on the dietetics profession and all stakeholders such as students, faculty, policy makers, employers, preceptors, and the community. Although studies done in other allied health care fields such as physical therapy, occupational therapy, and nursing that have implemented the transition to a higher 
educational requirement have shown greater appreciation for research and application of research to clinical practice, improved clinical reasoning, and better preparedness for direct patient care, evaluation of the impact of the transition to the master's degree for entry-level registered dietitians will be important in answering some of the following questions in the future:

- Has the master's degree in dietetics improved delivery of service and patient care?

- Has the master's degree improved the employment prospects, salaries, work-force issues, and opportunities for growth in management level positions for the registered dietitians?

- Has the master's degree in dietetics resulted in registered dietitians' taking on leadership positions in professional organizations, advocacy groups, and administrative positions in the health care system?

- Has the master's degree in dietetics improved involvement of registered dietitians' in research, clinical teaching, and preceptor roles in dietetic internships?

- Has the master's degree in dietetics affected the registered dietitian licensure/certification, type of practice, and the scope of practice?

- Has the transition to the master's degree affected the applicant pool in terms of demographics, aptitudes, and number of applicants?

- Has the transition to the master's degree improved the public image of the profession of dietetics, and its acceptance by the community?

Although these are a few questions that can be explored to understand the impact of the transition, it will be important to know the effect of the transition on the dietetics profession and all of the stakeholders. 


\section{Summary}

The study indicated support for some aspects of the transition to an entry-level master's degree. Participants expressed greater support for a one-year transitional master's degree rather than the traditional master's degree, and findings also indicated lack of support for the universal degree requirement of the master's degree for practice in the dietetics profession. Participants felt that the master's degree improved the registered dietitian's ability to apply research in clinical practice, and improved clinical reasoning skills, however the transition would not lead to improvement in leadership skills and enhancement in professionalism. In addition, BS, RDs did not believe that the transition to a master's degree would impact the health care system positively with respect to a more defined type and scope of practice, or improve the quality of health care for the patients. They did not believe that the transition would alter the role of the registered dietitian, such as increase the consultant role or reduce the hands-on care etc.

Registered dietitians (RDs) who were younger in age and had practiced for a few years were seen to be more inclined to be supportive of the transition and were willing to enroll in the master's degree however, the support decreased with increased age and years of practice. In this study, participants who believed that the transition to the master's degree was a positive change were found to favor the one-year transitional master's degree and stated that they were willing to enroll in the transitional master's degree. Approximately half of the participants stated that they preferred the "online" mode of instruction, and another half stated that they preferred the "mixed" mode of instruction including online and face-to-face interaction. Participants believed that the transition to the master's degree would lead to greater recognition of the profession in the health care system and improve earning potential for the registered dietitians with enhanced professional opportunities such as promotions, hiring salaries, and salary raises. In addition to 
participants' attitudes and perception of the transition to the master's degree, results also showed that the master's degree was important in the workplace environment for several participants and they believed that it may lead to increased costs to the health care system.

While the results from the study must be interpreted with caution due to the small sample size and with majority of the participants working in California, this study highlights potential discrepancies between decisions implemented by the dietetics governing bodies, educational policies and professional reality within the dietetics community and identifies areas for future investigation. A large number chose the neutral category of "neither agreeing or disagreeing" for some areas; for example, $50 \%$ of the participants were neutral toward whether the transition to a master's degree increased the costs to the health care system, and $42 \%$ were neutral towards the belief that the transition would alter the role of the registered dietitian. It is difficult to understand why the RDs chose to remain neutral and it remains unclear whether these responses actually indicate neutrality or just a lack of opinion or acceptance of the impending decision.

This study provides insight into some attitudes of registered dietitians with bachelor's degrees toward both the educational changes that are taking place and those that may be implemented in the near future. While the transition to graduate level entry requirements in dietetics has been the topic of debate and discussion, it can be concluded that the time is right to investigate the educational needs of the profession to meet the demands of the society and all of the stakeholders. 


\section{REFERENCES}

Accreditation Council for Education in Nutrition and Dietetics (ACEND). (2015). Rationale for future education preparation of nutrition and dietetics practitioners. Retrieved on January 12, 2016 from http://www.eatrightacend.org/ACEND/content.aspx ?id=6442485290

American Association of Colleges of Nursing. (2006). The essentials of doctoral education for advanced nursing practice. Retrieved November 20, 2015 from http://www.aacn.nche.edu/DNP/pdf/Essentials.pdf

American Physical therapy Association (APTA). (2000). APTA Vision Sentence for Physical Therapy 2020 and APTA Vision Statement for Physical Therapy 2020 [House of Delegates 06-00-24-35]. Retrieved on November 18, 2015 from http://www.apta.org/governance/HOD/policies/HoDPolicies/Section_I/GOALS_AND_M ISSION/HOD_06002435.

Bank, J., Denton, M., \& Hannemann, C. (1998). Employers’ perceptions of new graduate physical therapists: baccalaureate versus post-baccalaureate education. Journal of Physical Therapy Education, 12, 30-40.

Beck, S.J., \& Doig, K. (2002). An entry-level MS degree in clinical laboratory science: is it time? Clinical Laboratory Science, 15, 167-176.

Berlin, L.E., \& Sechrist, K.R. (2002). The shortage of doctorally prepared nursing faculty: A dire situation. Nursing Outlook, 50, 50-56.

Bloomberg, L.D., \&Volpe, M. (2012). Completing your qualitative dissertation. (2 ${ }^{\text {nd }}$ ed.) Los Angeles, CA: Sage Publications. 
Brown, T., Crabtree, J.L., Mu, K., \& Wells, J. (2015). The next paradigm shift in occupational therapy education: The move to the entry-level clinical doctorate. American Journal of Occupational Therapy, 69(2), 240-251. doi: 10.5014/ajot.2015.016527.

Brown-Benedict, D. (2008). The doctor of nursing practice degree: Lessons from the history of the professional doctorate in other health disciplines. Journal of Nursing Education, 47(10), 448-457. doi: 10.3928/01484834-20081001-01

Brudvig, T., \& Colbeck, C. (2007). The doctorate of physical therapy: Clinical and academic physical therapists' perception of appropriate curricular changes. Journal of Physical Therapy Education, 21(1), 3-13.

Clement, D. G. (2005). Impact of the clinical doctorate from an allied health perspective. American Association of Nurse Anesthetists Journal, 73(1), 24-28.

Commission of Dietetics Registration. (2015). Graduate Degree Registration Eligibility Requirement. Retrieved on January 29, 2015 from www.cdrnet.org

Davis, B. W. (2011). A conceptual model to support curriculum review, revision, and design in an associate degree nursing program. Nursing Education Perspectives, 32(6), 389-394.

Desbrow, B., Leveritt, M., Palmer, M., \& Hughes, R. (2014). Evaluation of a curriculum initiative designed to enhance the research training of dietetics graduates. Nutrition \& Dietetics, 71(1), 57-63. doi:10.1111/1747-0080.12039

Detweiler, B.A., Baird, D.A., Jensen, G.M., \& Threlkeld, A.J. (1999). The post-professional doctorate of physical therapy: a survey of practicing physical therapists. Journal of Physical Therapy Education, 13, 44-52.

Dillman, D. (2009). Internet, mail and mixed-mode surveys: the tailored design method. (3rd ed.) Hoboken, NJ: Wiley. 
Domholdt, E., Kerr, L.O., \& Mount, K.A. (2006). Professional (entry level) doctoral degrees in physical therapy: status as of Spring 2003. Journal of Physical Therapy Education, 20, 68-76.

Ellis, L. (2007). Academics' perceptions of the professional or clinical doctorate: findings of a national survey. Journal of Clinical Nursing, 16, 2272-2279.

Elizondo-Montemayor, L., Hernández-Escobar, C., Ayala-Aguirre, F., \& Aguilar, G. M. (2008). Building a sense of ownership to facilitate change: the new curriculum. International Journal of Leadership in Education, 11(1), 83-102. doi:10.1080/13603120701663486

Ewell, P. (2008). Building academic cultures of evidence: a perspective on learning outcomes in higher education. Symposium of the Hong Kong University Grants Committee on Quality Education.

Fahlman, D. (2012). Educational leadership for E-Learning in the health care workplace. International Review of Research in Open and Distance Learning, 13(6), 236-246. Retrieved from http://libaccess.sjlibrary.org/login?url=http://search.ebscohost.com/login.aspx?direct=true $\& \mathrm{db}=\mathrm{eft} \& \mathrm{AN}=74422158 \&$ site $=$ ehost-live

Fraher, E.P., Summers, P., Gaul K., \& Rutledge, S. (2007). Allied Health Job Vacancy Tracking Report. Chapel Hill, NC: Cecil G. Sheps Center for Health Services Research, UNC Chapel Hill, the Council for Allied Health in North Carolina, and the North Carolina Area Health Education Centers.

Graham, C., Howell, M., Meyers, R., Schrantz, C., \& Wilder, N. (2008). Perspectives regarding doctoral degrees for practicing physical therapists. Nashville, TN: Combined Sections Meeting of the American Physical Therapy Association. 
Griffiths, Y., \& Padilla, R. (2006). National status of the entry-level doctorate in Occupational Therapy (OTD). American Journal of Occupational Therapy, 60(5), 540-550. doi: 10.5014/ajot.60.5.540.

Hasson, S. (2003). Doctorate in Physical Therapy (DPT): What is the DPT and why is it becoming the entry-level degree in the United States?. Physiotherapy Theory and Practice, 19(3), 121-122. doi: 10.1080/09593980307963

Horel, J. D., Ziegenfuss, D., \& Perry, K. D. (2013). Transforming an atmospheric sciene curriculum to meet students' needs. Bulletin of the American Meteorological Society, 94(4), 475-484. doi:10.1175/BAMS-D-12-00115.1

Hummer, L.A., Hunt, K.S., \& Figuers, C.C. (1994). Predominant thoughts regarding entry-level Doctor of Physical Therapy programs. Journal of Physical Therapy Education, 8, 60-66.

Johanson M.A. (2004). Factors influencing professional Master of Physical Therapy and Doctor of Physical Therapy students' program selection. Journal of Physical Therapy Education, 18: 9-21.

Johanson, M. A. (2005). Association of Importance of the doctoral degree with students' perceptions and anticipated activities reflecting professionalism. Physical Therapy, 85(8), 766-781.

King, J., Freburger, J. K., \& Slifkin, R. T. (2010). What does the clinical doctorate in physical therapy mean for rural communities?. Physiotherapy Research International, 15(1), 24-34. doi:10.1002/pri.455

Knowles, M. S. (1978). Andragogy: adult learning theory in perspective. Community College Review, 5(5), 59-20. 
Lambert, A., Terenzini, P., \& Lattuca, L. (2007). More than meets the eye: Curricular and Programmatic Effects on Student Learning. Research in Higher Education, 48(2), 141168. doi:10.1007/s11162-006-9040-5

Lattuca, L. R., \& Stark, J. S. (2009). Shaping the college curriculum: Academic plans in context (2nd ed.). San Francisco: Jossey-Bass.

Lattuca, L. R., Terenzini, P. T., \& Volkwein, J. F. (2006). Engineering change: A study of the impact of EC2000. Baltimore, MD: ABET.

Lenz, E. R. (2005). The practice doctorate in nursing: An idea whose time has come. Online Journal of Issues in Nursing, 10(3), 57-72.

Lieberman, S. A., Ainsworth, M. A., Asimakis, G. K., Thomas, L., Cain, L. D., Mancuso, M. G., \& ... Frye, A. W. (2010). Effects of comprehensive educational reforms on academic success in a diverse student body. Medical Education, 44(12), 1232-1240. doi:10.1111/j.1365-2923.2010.03770.x

Mathur, S. (2011). Doctorate in Physical Therapy: Is it time for a conversation? Physiotherapy Canada, 63(2),140-142. doi:10.3138/physio.63.2.140.

Mistry, Y., Francis, C., Haldane, J., Symonds, S., Uguccioni, E., Brooks, D., \& Berg, K. (2014). Attitudes toward Master's and Clinical Doctorate Degrees in Physical Therapy. Physiotherapy Canada, 66(4), 392-401. http://doi.org/10.3138/ptc.2013-40

Montoya, I.D., \& Kimball, O.M. (2007). Marketing clinical doctorate programs. Journal of Allied Health, 36, 107-112.

Naughton, C. A., \& Friesner, D. L. (2012). Comparison of pharmacy students' perceived and actual knowledge using the pharmacy curricular outcomes assessment. American Journal of Pharmaceutical Education, 76(4), 1-7. 
Nelson, R. M. (2013). The next evolution. Physical Therapy, 93(10), 1415-1425. doi:10.2522/ptj.2013.mcmillan.lecture

Novak, J. D. (1977). Theory of education. Ithaca, NY: Cornell University Press.

Novak, J. D. (1978). Theory of education. College \& University, 53(53), 344-346.

Plack, M.M., \&Wong, C.K. (2002). The evolution of the doctorate of physical therapy: moving beyond the controversy. Journal of Physical Therapy Education, 16(1), 48 -59.

Phelps, M. R., \& Gerbasi, F. (2009). Accreditation Requirements for Practice Doctorates in 14 Healthcare Professions. American Association of Nurse Anesthetists Journal, 77(1), 1926.

Stark, J., Lowther, M., Hagerty, B., Orczyk, C. (1986). A conceptual framework for the study of preservice professional programs in colleges and universities. Journal of Higher Education. 57, 231-258.

Stark, J. S., Lowther, M. A., Bentley, R. J., Ryan, M. P., Martens, G. G., Genthon, M. L., et al. (1990). Planning introductory college courses: Influences on faculty. Ann Arbor, MI: University of Michigan, National Center for Research to Improve Postsecondary Teaching and Learning.

Stark, J. S. (2000). Planning introductory college courses: content, context and form. Instructional Science, 28(5/6), 413-438.

Tam, M. (2014). Outcomes-based approach to quality assessment and curriculum improvement in higher education. Quality Assurance in Education: An International Perspective, 22(2), 158-168. doi:10.1108/QAE-09-2011-0059 
Terenzini, P. T., \& Reason, R. D. (2005, November 19). Parsing the first year of college: Rethinking the effects of college on students. Paper presented at the 2005 Association for the Study of Higher Education Conference, Philadelphia, PA.

ThrelThrelkeldkeld, A.J., Jensen, G.M., \& Royeen, C.B., (1999). The clinical doctorate: A framework for analysis in physical therapist education. Physical Therapy, 79(6), 567-581.

Tonni, I., \& Oliver, R. (2013). A Delphi approach to define learning outcomes and assessment. European Journal of Dental Education, 17(1), 173-180. doi:10.1111/eje.12000

Touger-Decker, R. (2005). Advanced practice doctorate in clinical nutrition: a new graduate degree option for registered dietitians. Topics in Clinical Nutrition, 20, 48-53.

University of New England (2016). Research Compliance. Retrieved on March 30, 2016 from http://www.une.edu/research/compliance/irb

Woods, E. (2001). The DPT: What it means for the profession. Magazine of Physical Therapy, 9(5), 36-43. 


\section{APPENDIX A}

\section{SURVEY INSTRUMENT}

Perceptions and Attitudes of BS, RDs

Registered Dietitians: Attitudes and Perceptions Regarding Bachelor's Degrees in Nutrition and Dietetics

Q1 After reading the consent information please indicate if you would like to participate. Please remember you can save the survey and complete it a later time.

I understand the above information and would like to participate in the survey (1)

I understand the above information, but I would like to WITHDRAW participation in the survey (2)

If I understand the above info... Is Selected, Then Skip To End of Survey

Q2 I am a:

Registered Dietitian (1)

Other (Please Specify) (2)

Q3 Please indicate whether you have completed the Bachelor's degree and DPD requirements from an U.S. accredited institution?

O Yes (1)

No (2)

Section A. Demographics

Q4 Gender:

Male (1)

Female (2)

Q5 Year of birth:

Q6 In what state did you complete the Didactic Program in Dietetics (DPD program)?

Q7 In which state did you complete the Bachelor's degree if different from the state you completed the DPD program?

Q8 In which state do you work? 
Q9 How long have you been practicing as a Registered Dietitian?

$0-5$ years $(1)$

O 6-10 years (2)

O $11-15$ years (3)

O $16-20$ years (4)

O > 20 Years (5)

Q10 What percent of time are you currently practicing in a clinical setting?

O None (1)

O $1-25 \%(2)$

O $26-50 \%$ (3)

O $51-75 \%(4)$

O $76-100 \%(5)$

Q11 How are you currently employed as a Registered Dietitian?

O Part-time (1)

O Full-time (2)

O Per diem (3)

Other (Please Specify) (4)

Q12 What is your primary place of employment?

Health care (Acute care hospital, sub-acute care facility long-term care, physician network) (1)

- Behavioral care clinics (Rehabilitation, mental illness, etc.) (2)

Educational setting (primary, secondary, university) (3)

Community non-profit (4)

Government (federal, city, state, or local) public health (5)

Wellness programs (workplace, health club, fitness center) (6)

Corporate/industry settings (R\&D, marketing, sales, etc.) (7)

C Communications and media (8)

- Self-employed consultant registered dietitian or private practice (9)

Not currently working (10)

Other (Please specify) (11) 
Q13 If applicable, what is your secondary place of employment?

O Health care (Acute care hospital, sub-acute care facility long-term care, physician network) (1)

O Behavioral care clinics (Rehabilitation, mental illness, etc.) (2)

O Educational setting (primary, secondary, university) (3)

O Community non-profit (4)

O Government (federal, city, state, or local) public health (5)

O Wellness programs (workplace, health club, fitness center) (6)

O Corporate/industry settings (R\&D, marketing, sales, etc.) (7)

O Communications and media (8)

O Self-employed consultant registered dietitian or private practice (9)

O Not applicable (10)

Other (Please specify) (11)

Q14 Which of the following describes your role(s)? (Select all that apply)

Research (basic science and medical) (1)

Research (product R\&D) (2)

Direct patient care (In-patient) (3)

$\square$ Direct patient care (Out-patient) (4)

Consultant RD (5)

Private Practice (Self-employed) (6)

Administration/Management (7)

Foodservice (8)

$\square$ Education (9)

口 Policy expert/advocate (10)

Community/population health (11)

Other (Please specify) (12)

Q15 Does your place of work have an academic affiliation (i.e. supervise dietetic interns)

Y Yes (1)

No (2) 
Q16 If you answered yes to the question above, how many students have you supervised in the last two years?

○ $1-2(1)$

O $3-4(2)$

5-6(3)

7-8 (4)

O $>8(5)$

Not applicable (6)

Q17 Have you completed any continuing education courses within the past 1-2 years?

$\bigcirc$ Yes (1)

No (Please Specify) (2)

Q18 Are you an employer of Registered Dietitians?

$\bigcirc$ Yes (1)

O No (2)

If No Is Selected, Then Skip To Do you currently require a graduate d...

If you answered yes to the question above, complete the following question.

Q19 Of the registered dietitians that you have employed, what is the highest level of education that they have achieved (check all that apply)

BS, RD (1)

$\square \mathrm{MS}, \mathrm{RD}(2)$

$\square \mathrm{PhD}, \mathrm{RD}(3)$

$\square$ Other (Please specify) (4)

Q20 Do you currently require a graduate degree for any nutrition and dietetics positions in your organization?

Y Yes (1)

No (2) 
Q21 At your facility, is there a degree requirement for management positions?

Yes (1)

No (2)

Q22 If you answered yes to the question above, what degrees qualify for management positions at your facility?

$\square$ Bachelor's (BA or BS) (1)

$\square$ Master of Arts (MA) (2)

Master of Science (MS) (3)

Master in Business Administration (MBA) (4)

口 $\mathrm{PhD}$ (Academic) or Doctorate (5)

Q23 The average starting annual salary of a new Registered Dietitian (RD) with a bachelor's degree at your facility would be?

$0<\$ 30,000(1)$

O $\$ 30,001-\$ 40,000$ (2)

O $\$ 40,001-\$ 50,000$ (3)

○ $\$ 50,001-\$ 60,000$ (4)

O $\$ 60,001-\$ 70,000(5)$

O $\$ 70,001-\$ 80,000$ (6)

O $\$ 80,001-\$ 90,000(7)$

O $\$ 90,001-\$ 100,000(8)$

O > $\$ 100,001$ (9)

Not sure (10)

Q24 The average starting annual salary of a new Registered Dietitian (RD) with a master's degree at your facility would be?

O $<\$ 30,000$ (1)

○ $\$ 30,001-\$ 40,000(2)$

O $\$ 40,001-\$ 50,000(3)$

O $\$ 50,001-\$ 60,000$ (4)

○ $\$ 60,001-\$ 70,000(5)$

○ $\$ 70,001-\$ 80,000$ (6)

O $\$ 80,001-\$ 90,000(7)$

O $\$ 90,001-\$ 100,000(8)$

O > $\$ 100,001(9)$

O Not sure (10) 
Q25 Does your facility have a salary cap for increments for bachelor's RDs?

Yes (1)

No (2)

Q26 Does your facility have a system for promotions or level increases for bachelor's RDs based on number of years of employment at the facility?

Yes (1)

No (2)

Q27 If educational institutions offer a one year transitional-master's program in nutrition and dietetics, would you be interested in applying and enrolling for the program?

Transitional Master's Degree is a one year program for registered dietitians with bachelor's degree focusing on research methodology and application of research to clinical setting.

Y Yes (1)

O No (2)

If No Is Selected, Then Skip To Do you think that there should be a u...

Q28 If you answered yes to the question above, what would be the preferred method for instruction for the program?

○ Face-to-face classes (1)

○ Online classes (2)

- Mixed-mode classes (combination of face-to face and online classes) (3)

Q29 Do you think that there should be a universal entry-level degree requirement (Master's degree requirement for all RDs) for the dietetics profession specifically for the Registered Dietitian certification?

$\circ$ Yes (1)

- No. Please specify the reason (2)

Section B. Attitudes Regarding a Transition from Bachelor's to Master's Degree The Accreditation Council for Education in Nutrition and Dietetics (ACEND) is recommending Master's degree preparation for entry level, generalist, registered dietitian nutritionists.

Q30 Overall, the transition from Bachelor's to Master's is a positive change for the profession of dietetics.Do you:

Strongly agree (1)

Somewhat agree (2)

Neither agree nor disagree (3)

Somewhat disagree (4)

Strongly disagree (5) 
Q31 When reading the following statements, please consider Registered Dietitians as a whole (including yourself). The change from Bachelor's to Master's..

\begin{tabular}{|c|c|c|c|c|c|}
\hline & $\begin{array}{l}\text { Strongly } \\
\text { disagree } \\
\text { (1) }\end{array}$ & $\begin{array}{c}\text { Somewhat } \\
\text { disagree (2) }\end{array}$ & $\begin{array}{c}\text { Neither agree } \\
\text { nor disagree } \\
\text { (3) }\end{array}$ & $\begin{array}{l}\text { Somewhat } \\
\text { agree (4) }\end{array}$ & $\begin{array}{l}\text { Strongly } \\
\text { agree (5) }\end{array}$ \\
\hline $\begin{array}{l}\text {...will result in } \\
\text { enhanced } \\
\text { clinical } \\
\text { reasoning } \\
(1)\end{array}$ & $\bigcirc$ & $\bigcirc$ & 0 & 0 & 0 \\
\hline $\begin{array}{l}\text {...will result in } \\
\text { improved } \\
\text { leadership } \\
\text { skills }(2)\end{array}$ & 0 & 0 & 0 & 0 & 0 \\
\hline $\begin{array}{c}\text {...will result in } \\
\text { improved } \\
\text { ability to } \\
\text { apply and } \\
\text { utilize } \\
\text { research } \\
\text { findings in a } \\
\text { clinical } \\
\text { setting (3) }\end{array}$ & 0 & 0 & 0 & 0 & 0 \\
\hline $\begin{array}{l}\text {...will result in } \\
\text { enhanced } \\
\text { professional } \\
\text { ism (4) }\end{array}$ & 0 & 0 & 0 & 0 & 0 \\
\hline $\begin{array}{l}\text {...will result in } \\
\text { enhanced } \\
\text { professional } \\
\text { opportunitie } \\
\text { s such as } \\
\text { promotions, } \\
\text { hiring } \\
\text { salaries and } \\
\text { salary } \\
\text { increases (5) }\end{array}$ & 0 & 0 & 0 & 0 & 0 \\
\hline
\end{tabular}


Q32 When reading the following statements, please consider the health care system. The change from Bachelor's to Master's...

\begin{tabular}{|c|c|c|c|c|c|}
\hline & $\begin{array}{c}\text { Strongly } \\
\text { disagree (1) }\end{array}$ & $\begin{array}{c}\text { Somewhat } \\
\text { disagree (2) }\end{array}$ & $\begin{array}{c}\text { Neither } \\
\text { agree nor } \\
\text { disagree (3) }\end{array}$ & $\begin{array}{l}\text { Somewhat } \\
\text { agree (4) }\end{array}$ & $\begin{array}{l}\text { Strongly } \\
\text { agree (5) }\end{array}$ \\
\hline $\begin{array}{c}\text {...will lead to a } \\
\text { more } \\
\text { defined } \\
\text { scope of } \\
\text { practice } \\
\text { within } \\
\text { your } \\
\text { health care } \\
\text { system }(1)\end{array}$ & 0 & 0 & 0 & 0 & 0 \\
\hline $\begin{array}{c}\text {...will lead to } \\
\text { greater } \\
\text { recognitio } \\
\text { n within } \\
\text { your } \\
\text { health care } \\
\text { system (2) }\end{array}$ & 0 & 0 & 0 & 0 & 0 \\
\hline $\begin{array}{c}\text {...will lead to } \\
\text { improved } \\
\text { quality of } \\
\text { care for } \\
\text { patients } \\
\text { (3) }\end{array}$ & 0 & 0 & 0 & 0 & 0 \\
\hline $\begin{array}{c}\text {...will increase } \\
\text { costs to } \\
\text { your } \\
\text { health care } \\
\text { system (4) }\end{array}$ & 0 & 0 & 0 & 0 & 0 \\
\hline
\end{tabular}


Q33 When reading the following statements, please consider the profession. The change from the Bachelor's to Master's...

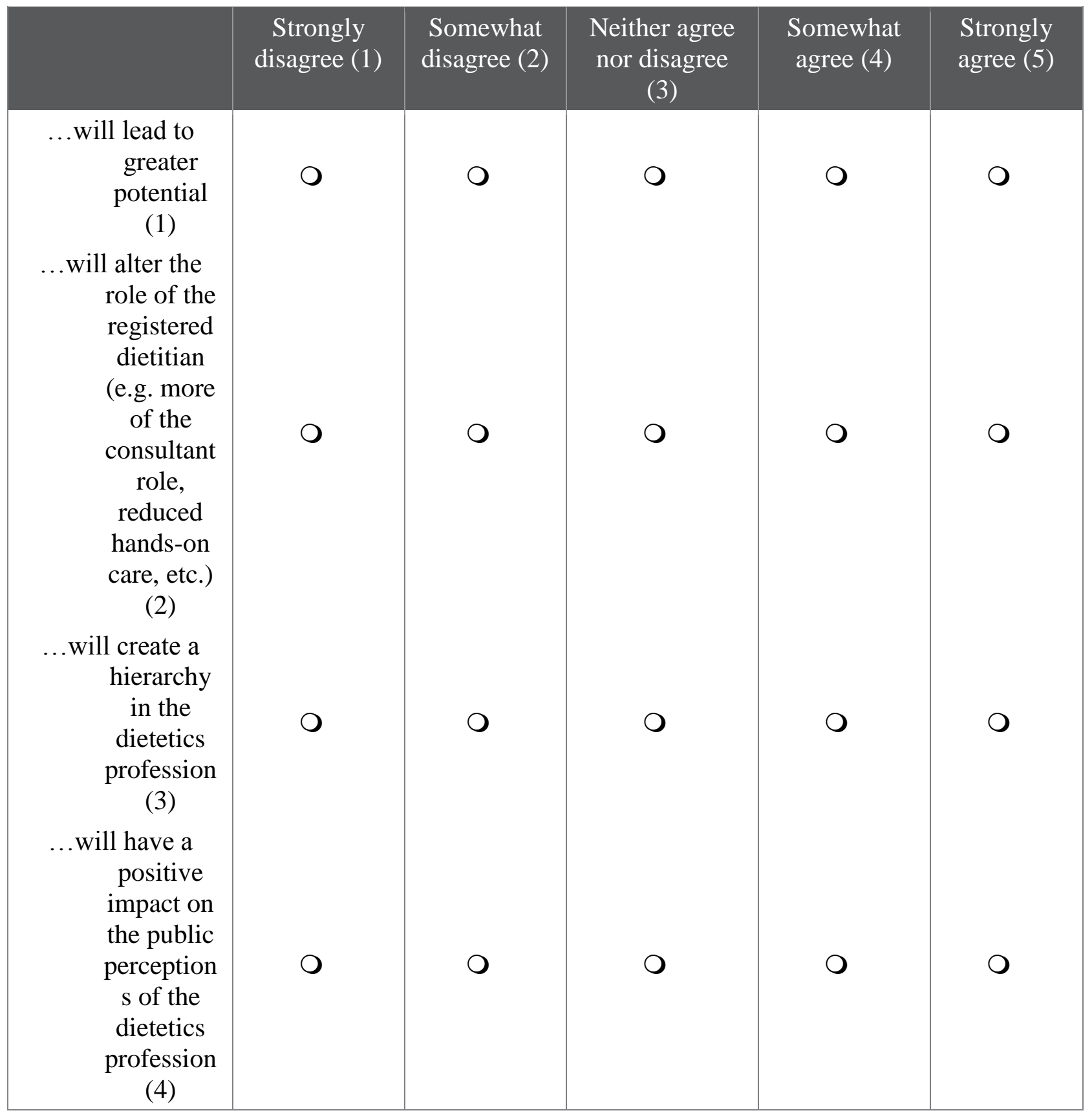


Section C. Attitudes Regarding a Transitional Master's Degree Post Entry-to-Practice Transitional Master's Degree is a one year program for registered dietitians with bachelor's degree focusing on research methodology and application of research to clinical setting.

Q34 Overall, you support the implementation of a transitional master's degree post entry-topractice. Do you:

O Strongly agree (1)

Somewhat agree (2)

Neither agree nor disagree (3)

Somewhat disagree (4)

Strongly disagree (5) 
Q35 When reading the following statements, please consider registered dietitians as a whole (including yourself). A transitional master's degree post entry-to-practice...

\begin{tabular}{|c|c|c|c|c|c|}
\hline & $\begin{array}{c}\text { Strongly } \\
\text { disagree (1) }\end{array}$ & $\begin{array}{l}\text { Somewhat } \\
\text { disagree } \\
\text { (2) }\end{array}$ & $\begin{array}{c}\text { Neither agree } \\
\text { nor disagree } \\
\text { (3) }\end{array}$ & $\begin{array}{c}\text { Somewhat agree } \\
\text { (4) }\end{array}$ & $\begin{array}{l}\text { Strongly } \\
\text { agree (5) }\end{array}$ \\
\hline $\begin{array}{l}\text {...will result in } \\
\text { enhanced } \\
\text { clinical } \\
\text { reasoning } \\
(1)\end{array}$ & 0 & 0 & 0 & 0 & 0 \\
\hline $\begin{array}{l}\text {...will result in } \\
\text { improved } \\
\text { leadership } \\
\text { skills (2) }\end{array}$ & 0 & 0 & 0 & 0 & 0 \\
\hline $\begin{array}{c}\text {...will lead to an } \\
\text { improved } \\
\text { ability to } \\
\text { apply } \\
\text { research in } \\
\text { a clinical } \\
\text { setting (3) }\end{array}$ & 0 & 0 & 0 & 0 & 0 \\
\hline $\begin{array}{c}\text {...will result in } \\
\text { enhanced } \\
\text { profession } \\
\text { alism (4) }\end{array}$ & 0 & 0 & 0 & 0 & 0 \\
\hline $\begin{array}{c}\text {...will result in } \\
\text { enhanced } \\
\text { profession } \\
\text { al } \\
\text { opportunit } \\
\text { ies such as } \\
\text { promotion } \\
\text { s, hiring } \\
\text { salaries } \\
\text { and salary } \\
\text { increases } \\
(5)\end{array}$ & 0 & 0 & 0 & 0 & 0 \\
\hline
\end{tabular}


Q36 When reading the following statements, please consider the health care system. A transitional master's degree post entry-to-practice...

\begin{tabular}{|c|c|c|c|c|c|}
\hline & $\begin{array}{c}\text { Strongly } \\
\text { disagree (1) }\end{array}$ & $\begin{array}{c}\text { Somewhat } \\
\text { disagree (2) }\end{array}$ & $\begin{array}{l}\text { Neither agree } \\
\text { nor disagree } \\
\text { (3) }\end{array}$ & $\begin{array}{c}\text { Somewhat } \\
\text { agree (4) }\end{array}$ & $\begin{array}{l}\text { Strongly } \\
\text { agree (5) }\end{array}$ \\
\hline $\begin{array}{c}\text {...will lead to a } \\
\text { more } \\
\text { defined } \\
\text { scope of } \\
\text { practice } \\
\text { within your } \\
\text { health care } \\
\text { system (1) }\end{array}$ & 0 & 0 & 0 & 0 & 0 \\
\hline $\begin{array}{l}\text {...will lead to } \\
\text { greater } \\
\text { recognition } \\
\text { within your } \\
\text { health care } \\
\text { system }(2)\end{array}$ & 0 & 0 & 0 & 0 & 0 \\
\hline $\begin{array}{c}\text {...will lead to } \\
\text { improved } \\
\text { quality of } \\
\text { care for } \\
\text { patients (3) }\end{array}$ & 0 & 0 & 0 & 0 & 0 \\
\hline $\begin{array}{l}\text {...will increase } \\
\text { costs to } \\
\text { your health } \\
\text { care system } \\
\text { (4) }\end{array}$ & 0 & 0 & 0 & 0 & 0 \\
\hline
\end{tabular}


Q37 When reading the following statements, please consider the profession. A transitional master's degree post entry-to-practice..

\begin{tabular}{|c|c|c|c|c|c|}
\hline & $\begin{array}{c}\text { Strongly } \\
\text { disagree (1) }\end{array}$ & $\begin{array}{c}\text { Somewhat } \\
\text { disagree (2) }\end{array}$ & $\begin{array}{c}\text { Neither agree } \\
\text { nor disagree } \\
(3)\end{array}$ & $\begin{array}{l}\text { Somewhat } \\
\text { agree (4) }\end{array}$ & $\begin{array}{l}\text { Strongly } \\
\text { agree (5) }\end{array}$ \\
\hline $\begin{array}{c}\text {...will lead to } \\
\text { greater } \\
\text { potential } \\
(1)\end{array}$ & 0 & 0 & 0 & 0 & 0 \\
\hline $\begin{array}{c}\text {...will alter the } \\
\text { role of the } \\
\text { registered } \\
\text { dietitian } \\
\text { (e.g. more } \\
\text { of the } \\
\text { consultant } \\
\text { role, } \\
\text { reduced } \\
\text { hands-on } \\
\text { care, etc.) } \\
(2)\end{array}$ & 0 & 0 & 0 & 0 & 0 \\
\hline $\begin{array}{c}\text {...will create a } \\
\text { hierarchy } \\
\text { in the } \\
\text { dietetics } \\
\text { profession } \\
(3)\end{array}$ & 0 & 0 & 0 & 0 & 0 \\
\hline $\begin{array}{c}\text {...will have a } \\
\text { positive } \\
\text { impact on } \\
\text { the public } \\
\text { perceptions } \\
\text { of the } \\
\text { dietetics } \\
\text { profession } \\
(4)\end{array}$ & 0 & 0 & 0 & 0 & 0 \\
\hline $\begin{array}{l}\text {...will help } \\
\text { registered } \\
\text { dietitians to } \\
\text { compete } \\
\text { against } \\
\text { other }\end{array}$ & 0 & 0 & 0 & 0 & 0 \\
\hline
\end{tabular}




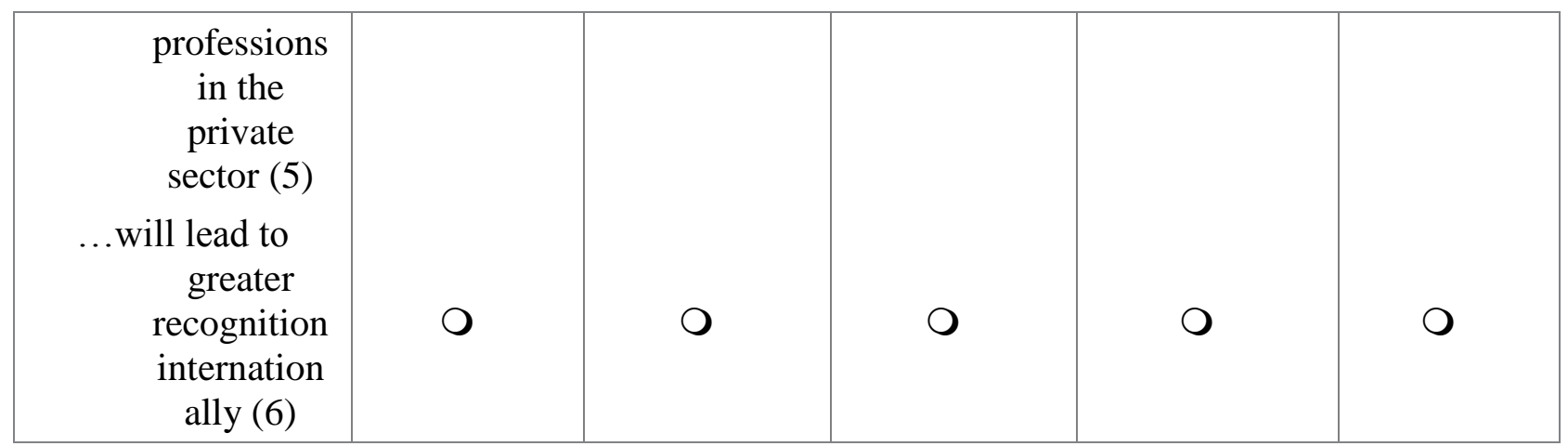




\section{Perception Regarding Importance Rank of Skill Sets Based on Degree Level}

Q38 Please RANK from 1 to 6 each, the importance of the following six skill sets for FUTURE nutrition and dietetic practitioners prepared at the BACHELOR or GRADUATE level by selecting a ranking from the pull down menu with 1 being the most important of the 6 skill sets, 2 being the second most important, etc. Within each degree level, each ranking number should only be used once.

Ranking of Importance of Skills Sets with Bachelor's Degree

Professional Research and Programmatic Skills including reading and evaluating academic and scientific research, designing, conducting, and applying translational and basic science research, and designing, implementing, and evaluating workplace programs and studies. (1)

Professional Teamwork and Communication Skills including working in collaborative teams and effective communication (written and oral). (2)

Client Care Skills including assessing nutritional status to diagnose problems; physical assessments; developing, monitoring and evaluating nutritional interventions; and counseling clients with behavior modification therapy. (3)

Population and Community Health Skills including planning, directing, and assessing community nutrition assessments; designing and implementing community nutrition interventions; effectively communicating across cultural boundaries; and mobilizing community partnerships. (4)

Management and Organizational Skills including leading staff development, project management, managing financial and human resources, and developing business plans. (5)

Food and Foodservice Skills including food and culinary preparation; monitoring and evaluating food production, service, distribution, safety, and sanitation systems; and designing menus for food systems. (6)

Q39 Please RANK from 1 to 6 each, the importance of the following six skill sets for FUTURE nutrition and dietetic practitioners prepared at the BACHELOR or GRADUATE level by selecting a ranking from the pull down menu with 1 being the most important of the 6 skill sets, 2 being the second most important, etc. Within each degree level, each ranking number should only be used once.

Ranking of Importance of Skills Sets with Master's Degree

Professional Research and Programmatic Skills including reading and evaluating academic and scientific research, designing, conducting, and applying translational and basic science research, and designing, implementing, and evaluating workplace programs and studies. 
Professional Teamwork and Communication Skills including working in collaborative teams and effective communication (written and oral). (2)

Client Care Skills including assessing nutritional status to diagnose problems; physical assessments; developing, monitoring and evaluating nutritional interventions; and counseling clients with behavior modification therapy. (3)

Population and Community Health Skills including planning, directing, and assessing community nutrition assessments; designing and implementing community nutrition interventions; effectively communicating across cultural boundaries; and mobilizing community partnerships. (4)

Management and Organizational Skills including leading staff development, project management, managing financial and human resources, and developing business plans. (5)

Food and Foodservice Skills including food and culinary preparation; monitoring and evaluating food production, service, distribution, safety, and sanitation systems; and designing menus for food systems. (6) 
Perceptions Regarding Skill Sets for Registered Dietitians Based on Bachelor's Degree Level

Q40 A. Professional Research and Practice Skills: When reading the following statements, please consider registered dietitians with bachelor's degrees as a whole (including yourself) and the importance of the following skills..

\begin{tabular}{|c|c|c|c|c|c|}
\hline & $\begin{array}{c}\text { Not } \\
\text { Essential } \\
\text { (1) }\end{array}$ & $\begin{array}{c}\text { Somewhat } \\
\text { Essential (2) }\end{array}$ & Essential (3) & $\begin{array}{c}\text { Very } \\
\text { Essential } \\
(4)\end{array}$ & $\begin{array}{l}\text { Unable to } \\
\text { Answer (5) }\end{array}$ \\
\hline $\begin{array}{l}\text { Perform data analysis } \\
\text { (1) }\end{array}$ & 0 & 0 & 0 & 0 & O \\
\hline $\begin{array}{c}\text { Analyze, evaluate, } \\
\text { and critique } \\
\text { scientific } \\
\text { studies (2) }\end{array}$ & 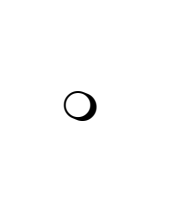 & O & 0 & O & 0 \\
\hline $\begin{array}{c}\text { Collect and interpret } \\
\text { data for use in } \\
\text { decision } \\
\text { making and } \\
\text { evaluation (3) }\end{array}$ & 0 & O & 0 & O & $\mathrm{O}$ \\
\hline $\begin{array}{c}\text { Engage in quality } \\
\text { assurance and } \\
\text { performance } \\
\text { improvement } \\
\text { activities (4) }\end{array}$ & O & $\mathrm{O}$ & $\mathrm{O}$ & O & O \\
\hline $\begin{array}{c}\text { Design, conduct, } \\
\text { analyze, and } \\
\text { disseminate } \\
\text { basic science, } \\
\text { clinical and/or } \\
\text { translational } \\
\text { research }(5)\end{array}$ & 0 & $\mathrm{O}$ & 0 & O & 0 \\
\hline $\begin{array}{l}\text { Lead efforts in health, } \\
\text { food and } \\
\text { nutrition } \\
\text { policy } \\
\text { development, } \\
\text { implementatio } \\
\text { n and } \\
\text { evaluation (6) }\end{array}$ & 0 & O & $\mathrm{O}$ & $\mathrm{O}$ & 0 \\
\hline $\begin{array}{c}\text { Use data collected to } \\
\text { make } \\
\text { operational } \\
\text { decisions }(7)\end{array}$ & 0 & 0 & 0 & 0 & 0 \\
\hline
\end{tabular}


Q41 B. Teamwork and Communication Skills: When reading the following statements, please consider registered dietitians with bachelor's degrees as a whole (including yourself) and the importance of the following skills..

\begin{tabular}{|c|c|c|c|c|c|}
\hline & $\begin{array}{c}\text { Not Essential } \\
\text { (1) }\end{array}$ & $\begin{array}{c}\text { Somewhat } \\
\text { Essential (2) }\end{array}$ & Essential (3) & $\begin{array}{c}\text { Very } \\
\text { Essential } \\
(4)\end{array}$ & $\begin{array}{l}\text { Unable to } \\
\text { Answer } \\
\text { (5) }\end{array}$ \\
\hline $\begin{array}{c}\text { Accurately } \\
\text { communicate } \\
\text { evidence } \\
\text { based } \\
\text { information } \\
(1)\end{array}$ & 0 & 0 & 0 & 0 & 0 \\
\hline $\begin{array}{c}\text { Use cross cultural } \\
\text { skills } \\
\text { effectively in } \\
\text { communicati } \\
\text { on }(2)\end{array}$ & 0 & 0 & 0 & 0 & 0 \\
\hline $\begin{array}{c}\text { Participate in team } \\
\text { decision } \\
\text { making (3) }\end{array}$ & 0 & 0 & 0 & 0 & 0 \\
\hline $\begin{array}{l}\text { Lead trans } \\
\text { disciplinary, } \\
\text { inter } \\
\text { professional, } \\
\text { and/or } \\
\text { interdisciplin } \\
\text { ary teams (4) }\end{array}$ & 0 & 0 & 0 & 0 & 0 \\
\hline $\begin{array}{c}\text { Employ strategies } \\
\text { and facilitate } \\
\text { team } \\
\text { building (5) }\end{array}$ & 0 & 0 & 0 & 0 & 0 \\
\hline $\begin{array}{c}\text { Translate research } \\
\text { into materials } \\
\text { for } \\
\text { consumers } \\
(6)\end{array}$ & 0 & 0 & 0 & 0 & 0 \\
\hline $\begin{array}{c}\text { Develops and uses a } \\
\text { variety of } \\
\text { media and } \\
\text { technologies } \\
\text { to } \\
\text { communicate } \\
\text { messages and } \\
\text { education (7) }\end{array}$ & O & O & $\mathrm{O}$ & 0 & O \\
\hline
\end{tabular}




\begin{tabular}{|c|c|c|c|c|c|}
\hline $\begin{array}{c}\text { Translate dietetics } \\
\text { vocabulary } \\
\text { across } \\
\text { disciplines } \\
\text { and in } \\
\text { laymen terms } \\
(8)\end{array}$ & 0 & 0 & 0 & 0 & 0 \\
\hline
\end{tabular}


Q42 C. Clinical Client Care Skills: When reading the following statements, please consider registered dietitians with bachelor's degrees as a whole (including yourself) and the importance of the following skills..

\begin{tabular}{|c|c|c|c|c|c|}
\hline & $\begin{array}{c}\text { Not } \\
\text { Essential } \\
\text { (1) }\end{array}$ & $\begin{array}{c}\text { Somewhat } \\
\text { Essential } \\
\text { (2) }\end{array}$ & Essential (3) & $\begin{array}{c}\text { Very } \\
\text { Essential (4) }\end{array}$ & $\begin{array}{l}\text { Unable to } \\
\text { Answer (5) }\end{array}$ \\
\hline $\begin{array}{l}\text { Analyze food intake in } \\
\text { clients with a } \\
\text { variety of } \\
\text { diseases and } \\
\text { medical } \\
\text { conditions (1) }\end{array}$ & O & ○ & O & O & $\mathrm{O}$ \\
\hline $\begin{array}{c}\text { Assess nutrition status } \\
\text { in clients with } \\
\text { a variety of } \\
\text { diseases and } \\
\text { medical } \\
\text { conditions (2) }\end{array}$ & O & O & O & O & 0 \\
\hline $\begin{array}{l}\text { Diagnose nutrition } \\
\text { problems in } \\
\text { clients with a } \\
\text { variety of } \\
\text { diseases and } \\
\text { medical } \\
\text { conditions (3) }\end{array}$ & O & O & 0 & O & $\mathrm{O}$ \\
\hline $\begin{array}{l}\text { Develop, monitor and } \\
\text { evaluate } \\
\text { nutrition } \\
\text { interventions in } \\
\text { clients with a } \\
\text { variety of } \\
\text { diseases and } \\
\text { medical } \\
\text { conditions (4) }\end{array}$ & O & $\mathrm{O}$ & $\mathrm{O}$ & 0 & $\mathrm{O}$ \\
\hline $\begin{array}{l}\text { Apply integrative } \\
\text { nutrition } \\
\text { principles to } \\
\text { nutrition care } \\
\text { and Medical } \\
\text { Nutrition } \\
\text { Therapy } \\
\text { (MNT), } \\
\text { including the } \\
\text { use of }\end{array}$ & 0 & O & O & O & $\mathrm{O}$ \\
\hline
\end{tabular}




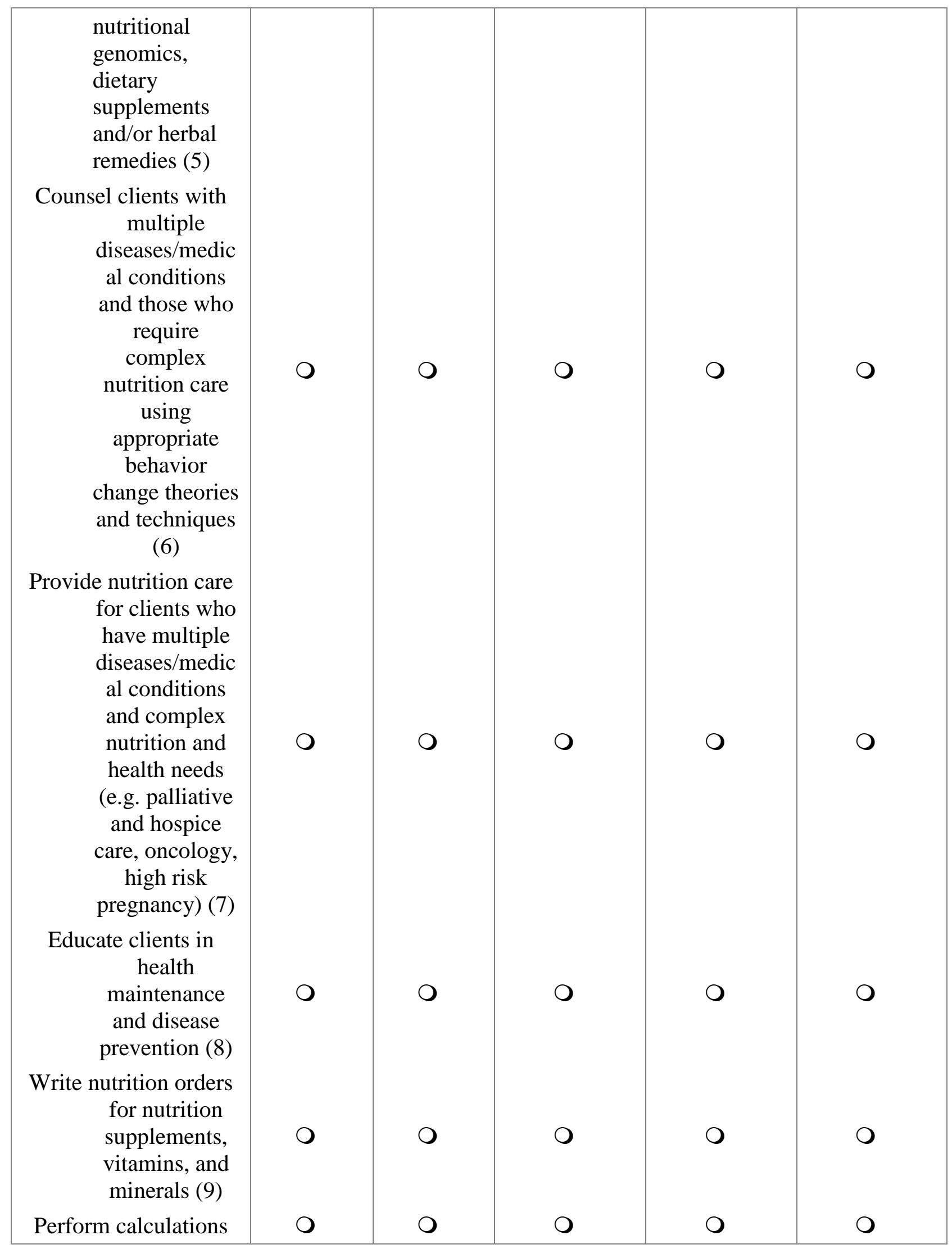




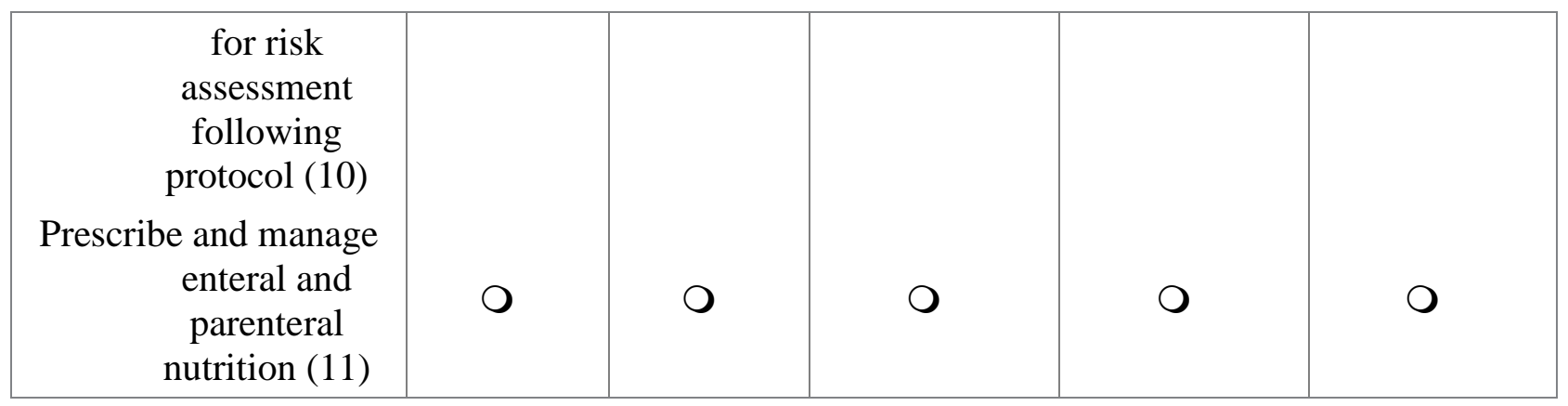


Q43 D. Community and Population Health Skills: When reading the following statements, please consider registered dietitians with bachelor's degrees as a whole (including yourself) and the importance of the following skills..

\begin{tabular}{|c|c|c|c|c|c|}
\hline & $\begin{array}{c}\text { Not } \\
\text { Essential (1) }\end{array}$ & $\begin{array}{l}\text { Somewhat } \\
\text { Essential (2) }\end{array}$ & Essential (3) & $\begin{array}{c}\text { Very } \\
\text { Essential (4) }\end{array}$ & $\begin{array}{l}\text { Unable to } \\
\text { Answer } \\
\text { (5) }\end{array}$ \\
\hline $\begin{array}{c}\text { Develop and } \\
\text { evaluate } \\
\text { policies, } \\
\text { laws, and } \\
\text { regulations } \\
\text { that address } \\
\text { and protect } \\
\text { health and } \\
\text { nutrition for } \\
\text { individuals } \\
\text { and } \\
\text { populations } \\
\text { (1) }\end{array}$ & 0 & 0 & $\mathrm{O}$ & 0 & 0 \\
\hline $\begin{array}{c}\text { Assess the need to } \\
\text { develop and } \\
\text { implement a } \\
\text { community } \\
\text { or } \\
\text { population } \\
\text { health } \\
\text { program } \\
\text { and/or } \\
\text { intervention } \\
\text { considering } \\
\text { biological, } \\
\text { behavioral, } \\
\text { psychologic } \\
\text { al, social, } \\
\text { economic, } \\
\text { policy } \\
\text { and/or } \\
\text { environment } \\
\text { al factors (2) }\end{array}$ & 0 & 0 & 0 & 0 & 0 \\
\hline $\begin{array}{r}\text { Interpret and use } \\
\text { national } \\
\text { nutrition }\end{array}$ & 0 & 0 & 0 & 0 & 0 \\
\hline
\end{tabular}




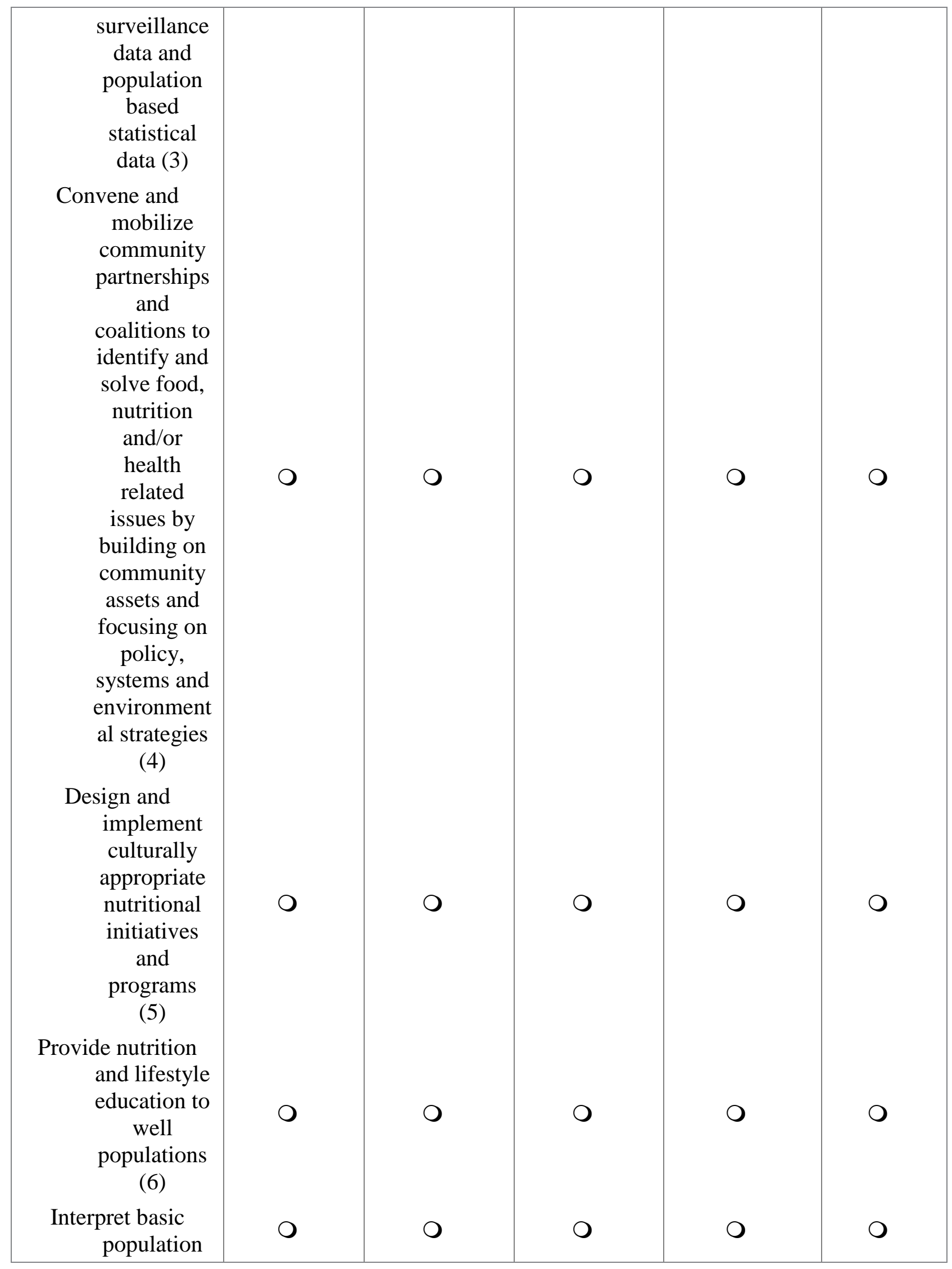




\begin{tabular}{|c|c|c|c|c|}
\hline $\begin{array}{c}\text { based } \\
\text { statistical } \\
\text { data (7) }\end{array}$ & & & \\
$\begin{array}{c}\text { Conduct culinary } \\
\text { demonstrati } \\
\text { ons to teach } \\
\text { cooking } \\
\text { skills, safe } \\
\text { food } \\
\text { handling } \\
\text { practices } \\
\text { and promote } \\
\text { consumptio } \\
\text { n of healthy } \\
\text { foods (8) }\end{array}$ & 0 & 0 & 0 & 0 \\
\hline
\end{tabular}


Q44 E. Leadership, Management, and Organizational SkillsWhen reading the following statements, please consider registered dietitians with bachelor's degrees as a whole (including yourself) and the importance of the following skills..

\begin{tabular}{|c|c|c|c|c|c|}
\hline & $\begin{array}{c}\text { Not } \\
\text { Essential } \\
\text { (1) }\end{array}$ & $\begin{array}{l}\text { Somewhat } \\
\text { Essential (2) }\end{array}$ & Essential (3) & $\begin{array}{l}\text { Very } \\
\text { Essential } \\
\text { (4) }\end{array}$ & $\begin{array}{l}\text { Unable to } \\
\text { Answer (5) }\end{array}$ \\
\hline $\begin{array}{c}\text { Develop operational } \\
\text { policies, } \\
\text { procedures, } \\
\text { job } \\
\text { descriptions, } \\
\text { work } \\
\text { schedules and } \\
\text { performance } \\
\text { standards }(1)\end{array}$ & 0 & 0 & 0 & 0 & O \\
\hline $\begin{array}{c}\text { Manage staffing } \\
\text { functions such } \\
\text { as } \\
\text { interviewing, } \\
\text { hiring, } \\
\text { motivating, } \\
\text { supervising, } \\
\text { evaluating and } \\
\text { terminating } \\
\text { employees (2) }\end{array}$ & 0 & 0 & 0 & 0 & O \\
\hline $\begin{array}{c}\text { Conduct employee } \\
\text { performance } \\
\text { evaluations } \\
\text { and counsel } \\
\text { employees for } \\
\text { performance } \\
\text { improvement } \\
\text { (3) }\end{array}$ & 0 & 0 & 0 & 0 & 0 \\
\hline $\begin{array}{c}\text { Lead process } \\
\text { improvement } \\
\text { activities to } \\
\text { improve } \\
\text { delivery of } \\
\text { food and } \\
\text { nutrition } \\
\text { services (4) }\end{array}$ & O & O & 0 & $\mathrm{O}$ & O \\
\hline
\end{tabular}




\begin{tabular}{|c|c|c|c|c|c|}
\hline $\begin{array}{r}\text { Develop operational } \\
\text { and capital } \\
\text { budgets }(5)\end{array}$ & 0 & $\bigcirc$ & 0 & $\bigcirc$ & 0 \\
\hline $\begin{array}{l}\text { Demonstrate conflict } \\
\text { resolution and } \\
\text { mediation } \\
\text { skills (6) }\end{array}$ & 0 & 0 & 0 & 0 & 0 \\
\hline $\begin{array}{c}\text { Adjust operations } \\
\text { based on } \\
\text { financial } \\
\text { performance } \\
(7)\end{array}$ & 0 & 0 & 0 & 0 & 0 \\
\hline $\begin{array}{l}\text { Direct strategic } \\
\text { planning (8) }\end{array}$ & 0 & 0 & 0 & 0 & 0 \\
\hline $\begin{array}{c}\text { Lead initiatives to } \\
\text { improve use } \\
\text { of sustainable } \\
\text { practices in } \\
\text { food and } \\
\text { nutrition } \\
\text { services (9) }\end{array}$ & 0 & 0 & 0 & 0 & 0 \\
\hline
\end{tabular}


Q45 F. Food and Foodservice Systems: When reading the following statements, please consider registered dietitians with bachelor's degrees as a whole (including yourself) and the importance of the following skills..

\begin{tabular}{|c|c|c|c|c|c|}
\hline & $\begin{array}{c}\text { Not } \\
\text { Essential } \\
\text { (1) }\end{array}$ & $\begin{array}{l}\text { Somewhat } \\
\text { Essential } \\
\text { (2) }\end{array}$ & Essential (3) & $\begin{array}{c}\text { Very } \\
\text { Essential (4) }\end{array}$ & $\begin{array}{l}\text { Unable to } \\
\text { Answer (5) }\end{array}$ \\
\hline $\begin{array}{c}\text { Develop menus and } \\
\text { standardized } \\
\text { recipes for } \\
\text { diverse } \\
\text { groups for } \\
\text { normal and } \\
\text { therapeutic } \\
\text { diets } \\
\text { applying } \\
\text { principles of } \\
\text { menu } \\
\text { planning and } \\
\text { knowledge of } \\
\text { medical } \\
\text { nutrition } \\
\text { therapy and } \\
\text { therapeutic } \\
\text { nutrition }(1)\end{array}$ & 0 & 0 & 0 & 0 & 0 \\
\hline $\begin{array}{c}\text { Conduct operational } \\
\text { analyses and } \\
\text { streamline } \\
\text { operations to } \\
\text { reduce costs } \\
\text { while } \\
\text { ensuring } \\
\text { health related } \\
\text { goals are not } \\
\text { compromised } \\
\text { (2) }\end{array}$ & 0 & $\mathrm{O}$ & 0 & 0 & O \\
\hline $\begin{array}{r}\text { Negotiate purchases } \\
\text { and contracts } \\
\text { for products } \\
\text { and services } \\
\text { (3) }\end{array}$ & 0 & 0 & 0 & 0 & 0 \\
\hline $\begin{array}{l}\text { Manage food } \\
\text { distribution }\end{array}$ & 0 & 0 & 0 & 0 & 0 \\
\hline
\end{tabular}




\begin{tabular}{|c|c|c|c|c|c|}
\hline $\begin{array}{c}\text { and service } \\
\text { ensuring } \\
\text { accuracy, } \\
\text { quality and } \\
\text { portion } \\
\text { control (4) } \\
\text { Manage production } \\
\text { and service } \\
\text { of food that } \\
\text { meets } \\
\text { nutrition } \\
\text { guidelines, } \\
\text { cost } \\
\text { parameters } \\
\text { and health } \\
\text { needs (5) } \\
\text { Plan and implement } \\
\text { food safety } \\
\text { and } \\
\text { sanitation } \\
\text { programs (6) } \\
\text { Teach others how to } \\
\text { prepare } \\
\text { healthy foods } \\
\text { using } \\
\text { knowledge of } \\
\text { food science } \\
\text { and culinary } \\
\text { techniques } \\
\text { (7) }\end{array}$ & 0 & 0 & $\mathrm{O}$ & 0 & 0 \\
\hline
\end{tabular}

Thank you for your participation and completing the questionnaire on registered dietitians' attitudes regarding the bachelor's degrees in nutrition and dietetics 


\section{APPENDIX B}

\section{CONSENT FORM}

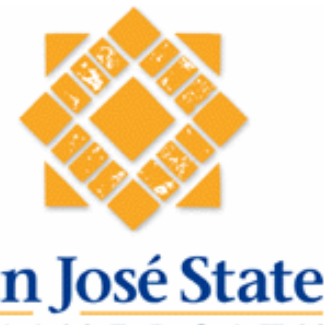

U N I VER S I T Y

\begin{abstract}
College of Applied Sciences and Arts Nutrition, Food Science, and Packaging
\end{abstract} Central Classroom BIdg. 200

One Washington Square San Jose, CA 95192-0058 Voice: 408-924-3100

Fax: 408-924-3114

The California State University:

Chancellor's Office

Bakersfield, Chico, Dominquez Hills, Fresno,

Fullerton, Hayward, Humboldt, Long Beach,

Los Angeles, Maritime Academy, Monterey

Bay, Northridge, Pomona, Sacramento, San

Bernardino, San Diego, San Francisco, San

Jose, San Luis Obispo, San Marcos,

Sonoma, Stanislaus

\section{REQUEST FOR YOUR PARTICPATION IN RESEARCH}

\section{TITLE OF THE STUDY}

Registered Dietitians: Attitudes and Perceptions Regarding Bachelor's Degrees in Nutrition and Dietetics

NAME OF THE RESEARCHER:

Ashwini Wagle, MS, RD, Doctoral Student in Educational Leadership Associate Professor and DPD Director Department of Nutrition, Food Science, and Packaging

San Jose State University, San Jose, CA 95192-0058

Lucy McProud, Ph.D, RD

Department Chairperson

Department of Nutrition, Food Science, and Packaging

San Jose State University, San Jose, CA 95192-0058

\section{PURPOSE}

The purpose of this quantitative study is to examine the attitudes and perceptions of a self-selected sample of registered dietitians with bachelor's degree regarding a transition to an entry-level master's degree as the requirement for certification as a Registered Dietitian (RD). This study will also examine these RDs attitudes and perceptions regarding impacting factors such as their years of work experience including salary levels and increments, professional stature including promotions and positions, and scope and type of practice.

\section{PROCEDURES}

Eligible participants will be emailed a link to complete a questionnaire via SurveyMonkey. Participants will be directed to complete the questionnaire in a sequence and directions will be provided. The questionnaire should take around 15 minutes to complete.

\section{POTENTIAL RISKS}

This study will be minimal risk for participants and 'Minimal Risk' means the probability and magnitude of harm or discomfort anticipated in the research are not greater in and of themselves than those ordinarily encountered in daily living.

\section{POTENTIAL BENEFITS}

It will be important to understand the effect of the transition on the future of practicing RDs with bachelor's degrees as the governing bodies of the 
Accreditation Council for Education in Nutrition and Dietetics (ACEND) and the Commission of Dietetics Registration (CDR) have not yet mentioned whether the transitional master's degree will be required for this population to bring them in compliance with the new mandate and make them educationally equivalent to the new graduate degree holders.

\section{COMPENSATION}

NA

\section{CONFIDENTIALITY}

Participants will be provided informed consent before completing and submitting the questionnaire. No personal identifiers will be included in the submitted questionnaires. Data will not be traced back to the participant in any way. Data will be accessed by primary researcher only.

\section{PARTICIPANT RIGHTS}

Your participation in this study is completely voluntary. You can refuse to participate in the entire study or any part of the study without any negative effect on your relations with San Jose State University. You also have the right to skip any question you do not wish to answer. This consent form is not a contract. It is a written explanation of what will happen during the study if you decide to participate. You will not waive any rights if you choose not to participate, and there is no penalty for stopping your participation in the study.

\section{QUESTIONS OR PROBLEMS}

You are encouraged to ask questions at any time during this study.

- For further information about the study, please contact Ashwini Wagle, MS, RD at email: Ashwini.wagle@ @jsu.edu or ph. 408924-3110

- Complaints about the research may be presented to Lucy McProud, Ph.D, RD at email Lucy.McProud@ sjsu.edu or ph. 408-924-3100

- For questions about participants' rights or if you feel you have been harmed in any way by your participation in this study, please contact Dr. Pamela Stacks, Associate Vice President of the Office of Research, San Jose State University, at 408-924-2479.

Please keep a copy of this form for your own records. By agreeing to participate in the study, it is implied that you have read and understand the above information. Please do not write any identifying information on the survey/questionnaire. 


\section{APPENDIX C}

\section{RECRUITMENT EMAIL}

Subject Line: Registered Dietitians (RDs) with Bachelor's Degree being sought for completion of a questionnaire.

Ashwini Wagle, MS, RD, Associate Professor and DPD Director in the Department of Nutrition, Food Science, and Packaging at San Jose State University (SJSU) and a doctoral student in Educational Leadership at University of New England is looking for participants for her research study. You are receiving this email because you are a member of the California Academy of Nutrition and Dietetics (CAND), San Jose Peninsula District of CAND, or part of SJSU Nutrition and Food Science Alumni Group.

The purpose of this quantitative study is to examine the attitudes and perceptions of a self-selected sample of registered dietitians with bachelor's degree regarding a transition to an entry-level master's degree as the requirement for certification as a Registered Dietitian (RD). If you decide to take part in this study, you would be required to complete the questionnaire (Qualtrics link provided). Participants will be directed to complete the questionnaire in a sequence and directions will be provided on the questionnaire. The questionnaire should take around 20 minutes to complete. You are not required to complete the questionnaire in one sitting and may complete the questionnaire in multiple sessions. To be able to take part in this study, you must be/have a Registered Dietitian license or certification with a bachelor's degree.

Qualtrics Anonymous Survey Link:

https://sjsu.qualtrics.com//SE/?SID=SV_cIx9t6eMEmTwqP3

Participants will be provided informed consent on Qualtrics and are required to read the information before completing and submitting the questionnaire. No personal identifiers will be included in the submitted questionnaires. Data will not be traced back to the participant in any way. Data will be accessed by primary researcher only. Your participation in this study is completely voluntary. You can refuse to participate in the entire study or any part of the study without any negative effect on your relations with San Jose State University.

If you are interested in participating or have any questions about the study, please contact Ashwini Wagle, MS, RD at email: Ashwini.wagle @ sjsu.edu or ph. 408-924-3110. You are encouraged to ask questions at any time during this study. Please keep a copy of this email for your own records. By agreeing to participate in the study, it is implied that you have read and understand the above information. Please do not enter any identifying information on the survey/questionnaire.

Thank you so much for taking the time to support dietetics research.

Sincerely,

Ashwini Wagle, MS, RD

Doctoral Student in Educational Leadership at University of New England

Associate Professor and DPD Director,

Department of Nutrition, Food Science, and Packaging

San Jose State University 


\section{APPENDIX D}

\section{LETTER OF PARTICIPATION- SAN JOSE STATE UNIVERSITY}

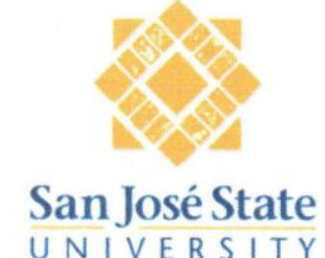

College of Applied Sciences and Arts Nutrition, Food Science, and Packaging Central Classroom Bidg. 200

One Washington Square San Jose, CA 95192-0058 Voice: 408-924-3100 Fax: 408-924-3114
The California State University: Chancellor's Office Bakersfield, Chico, Dominquez Hills, Fresno, Los Angeles, Marditime Academy Monterey, Bay. Northridge, Pomona, Sacramento, San Bernardino, San Diego, San Francisco, San Jose, San Luis Obispo, San Marcos, Sonoma,
Ashwini Wagle, MS, RD

Associate Professor and DPD Director,

Department of Nutrition, Food Science, Packaging

San Jose State University, San Jose, CA 95192-0058

Re: Approval for participation in study titled: Registered Dietitians: Attitudes and Perceptions Regarding Bachelors' Degrees in Nutrition and Dietetics

This letter of participation approves the use of members of the NUFS Alumni group for the purpose of the study "Registered Dietitians: Attitudes and Perceptions Regarding Bachelors' Degrees in Nutrition and Dietetics". The researcher plans study the impact of moving the dietetic internship and the registered dietitian (RD) certification to the masters' program on the RDs with bachelor's degrees currently working in the field. The survey questionnaire will be emailed via SurveyMonkey link to the department alumni and the primary researcher Ashwini Wagle's request to distribute the questionnaire to the group is approved between May 2016-August 2016.

Participants will be provided informed consent before completing and submitting the questionnaire. No personal identifiers will be included in the submitted questionnaires. This study will be minimal risk for participants and 'Minimal Risk' means the probability and magnitude of harm or discomfort anticipated in the research are not greater in and of themselves than those ordinarily encountered in daily living or during the performance of routine physical or psychological examinations or tests. The participant will have the right to leave the study at any point of time if they so wish and will not be coerced into completing the survey.

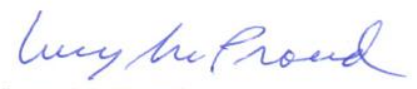

Lucy McProud,

Department Chairperson

Department of Nutrition, Food Science, Packaging

San Jose State University, San Jose, CA 95192-0058 


\section{APPENDIX E}

\section{LETTER OF PARTICIPATION CALIFORNIA ACADEMY OF NUTRITION AND DIETETICS}

STSUT Ashwini Wagle <ashwini.wagie@sjsu.edu>

\section{Doctoral Dissertation}

\section{4 messages}

Ashwini Wagle <ashwini.wagle@sjsu.edu>

Wed, Mar 30, 2016 at 4:28 PM

To: Pat Smith <patsmith@dietitian.org>

Cc: Kathryn Sucher <kathryn.sucher@sjsu.edu>

Dear Pat,

I am in the process of getting my IRB Human Subjects Review paperwork together for my doctoral

dissertation. The topic of my study is "Registered Dietitians: Attitudes and Perceptions Regarding

Bachelors' Degrees in Nutrition and Dietetics" and I plan to study the impact of moving the DI and RD to

the masters' program on the bachelors RDs currently working in the field. I am hoping to send the survey

questionnaire out to the CAND membership and need to know if that would be possible. The questionnaire

will look at the attitudes and perceptions of the bacheior RDs regarding the type and scope of practice,

years of work experience, professional stature, position, promotion, salaries etc.

I am also looking whether the RDs would be willing to pursue the transitional masters degree if required

Please let me know if that would be a possibility. I have attached a short proposal to the study. If it is ok to send the survey out, then I will need a letter of participation or an email approving the survey.

If I need to contact someone else to get the approval, I would appreciate if you let me know the name of the person. Please let me know when you can.

Thanks,

-Ashwini

$-$

Ashwini Wagle, MS.,RD, Doctoral Student in Educational Leadership (UNE)

Associate Professor and Director Didactic Program in Dietetics (DPD)

Department of Nutrition, Food Science and Packaging

San Jose State University

One Washington Square

San Jose, CA 95192-0058

Ph. (408)-924-3110

Fax. (408)-924-3114

ivi. Proposal Brief- Ashwini Wagle.docx

Prok

Pat Smith <patsmith@dietitian.org>

To: Ashwini Wagle<ashwini.wagle@sjsu.edu>, bridget@dietitian.org

Wed, Mar 30, 2016 at 4:34 PM

Cc: Kathryn Sucher <kathryn.sucher@sjsu.edu> 
Fax. (408)-924-3114

W] Proposal Brief- Ashwini Wagle.docx

$30 \mathrm{~K}$

Bridget Harvey-Elliott, MS, RD <bridget@dietitian.org>

Fri, Apr 1, 2016 at 1:56 PM Reply-To: bridget@dietitian.org

To: Ashwini Wagle <ashwini.wagle@sjsu.edu>

Hi Ashwini,

Yes, we can distribute your survey via our email newsletter, once we have reviewed the survey.

It you need only an approval email, then this email can serve as our approval to email out the survey, after reviewing.

Take Care!

\section{Bridget}

Bridget Harvey-Elliott, MS, RD

Administrator - CA Academy of Nutrition and Dietetics

(formerly California Dietetic Association)

bridget@dietitian.org

7740 Manchester Ave, Suite 102

Playa del Rey, CA 90293-8499

310.822 .0177

310.823 .0264 (fax)

www. dietitian.org

Return-Path: <ashwini.wagie@sisu.edu>

Fri, 1 Apr 2016 13:40:31 -0700

[Quoted text hidden]

Ashwini Wagle <ashwini.wagle@sjsu.edu>

To: bridget@dietitian.org

Sun, Apr 3, 2016 at 11:53 PM

Dear Bridget,

Thank you for your prompt email. I have attached the survey for you to review. Please let me know if you have any questions.

Thanks,

-Ashwini

IQuoted text hidden

[W] 160330 Questionnaire Ashwini Wagle.docx

$79 \mathrm{~K}$

Bridget Harvey-Elliott, MS, RD <bridget@dietitian.org>

Tue, Apr 5, 2016 at 12:24 PM

Reply-To: bridget@dietitian.org

To: Ashwini Wagle <ashwini.wagle@sjsu.edu>

Hi Ashwini, 
APPENDIX F

\section{INSTITUTIONAL REVIEW BOARD APPROVAL SAN JOSE STATE UNIVERSITY}

\section{SJSU

To: Ashwini Wagle

Department of Nutrition, Food Science, and Packaging

San Jose State University

One Washington Square

San Jose, CA 95192-0058

From: Pamela C. Stacks, Ph.D. Associate Vice President

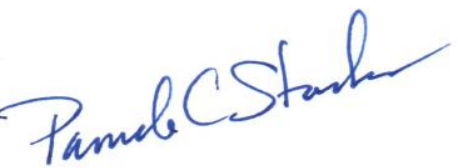

Office of Research

Date: April 19, 2016

The Human Subjects-Institutional Review Board has registered your study entitled:

"Registered Dietitians: Attitudes and Perceptions Regarding Bachelors' Degrees in Nutrition and Dietetics"

This registration, which provides exempt status under Exemption Category 2 of SJSU Policy S08-7, is contingent upon the subjects participating in your research project being appropriately protected from risk. This includes the protection of the confidentiality of the subjects' identity when they participate in your research project, and with regard to all data that may be collected from the subjects. The approval includes continued monitoring of your research by the Board to assure that the subjects are being adequately and properly protected from such risks. If at any time a subject becomes injured or complains of injury, you must notify Dr. Pamela Stacks, Ph.D. immediately. Injury includes but is not limited to bodily harm, psychological trauma, and release of potentially damaging personal information. This approval for the human subject's portion of your project is in effect for one year, and data collection beyond April 19, 2017 requires an extension request.

Please also be advised that all subjects need to be fully informed and aware that their participation in your research project is voluntary. Further, a subject's participation or refusal to participate, will not affect any services that the subject is receiving or will receive at the institution in which the research is being conducted. If you have any questions, please contact me at (408) 924-2479.

Protocol \#: F16062 


\section{APPENDIX G \\ INSTITUTIONAL REVIEW BOARD APPROVAL UNIVERSITY OF NEW ENGLAND

Institutional Review Board

Olgun Guvench, Chair

Biddeford Campus

11 Hills Beach Road

Biddeford, ME 04005

(207)602-2244 T

(207)602-5905 F

\section{Portland Campus}

716 Stevens Avenue

Portland, ME 04103

To: Ashwini R. Wagle

Cc: Carol Holmquist

From: Olgun Guvench

Date: May 16, 2016

Project \# \& Title: 050916-007, Registered Dieticians: Attitudes \& Perceptions Regarding Bachelor's Degrees in Nutrition \& Dietetics (Initial)

The Institutional Review Board (IRB) for the Protection of Human Subjects has reviewed the above captioned project, and has determined that the proposed work is exempt from IRB review and oversight as defined by 45 CFR 46.101(b)(2).

Additional IRB review and approval is not required for this protocol as submitted. If you wish to change your protocol at any time, you must first submit the changes for review.

Please contact Olgun Guvench at (207) 221-4171 or oguvench@une.edu with any questions.

Sincerely,

Olgun Guvench, M.D., Ph.D.

IRB Chair

IRB\#: 050916-007

Submission Date: 5/5/16

Status: Exempt, 45 CFR 46.101(b)(2)

Status Date: 5/16/16 